INSTITUTO DE PESQUISAS ENERGÉTICAS E NUCLEARES

Autarquia associada à Universidade de São Paulo

\title{
AVALIAÇÃO DO TEOR DE CARBONO ORGÂNICO TOTAL NA QUALIDADE DA ÁGUA: APLICAÇÃO NA RADIOFARMÁCIA.
}

\author{
STELLA BENEDETTI
}

Dissertação apresentada como parte dos requisitos para obtenção do Grau de Mestre em Ciências na Área de Tecnologia Nuclear - Aplicações.

Orientadora:

Prof. Dra. Margareth Mie Nakamura Matsuda

Versão Corrigida

A versão original se encontra no IPEN

SÃO PAULO

2012 


\section{DEDICATÓRIA}

À Deus pela minha vida, minha saúde e pelas pessoas maravilhosas que sempre colocou em meu caminho. Guiando-me pelo caminho do bem e da virtude.

Aos meus pais Rosa e Ronaldo que durante toda a vida incentivaramme e batalharam para que eu chegasse até aqui. Seus preciosos ensinamentos mostraram-me desde cedo o valor da educação e do aprimoramento.

Aos meus avós Nícea e Antônio (in memorian), que sempre me ensinaram o valor do trabalho e que cuidaram de mim com todo o carinho e dedicação enquanto meus pais trabalhavam, sendo para mim como meus segundos pais.

Ao meu primo Rafael pelo companheirismo e incentivo. Sempre foi para mim o irmão que nunca tive.

Às minhas grandes amigas Nariene Silva e Beatriz F. Carunchio, nossos quinze anos de amizade nos permitiram que uma sempre estivesse em auxílio e animando a outra mesmo que nossos caminhos acadêmicos tenham tomado rumos diferentes.

À minha amiga e colega Elisiane que tanto contribuiu e me deu forças para que eu conseguisse conquistar este sonho que eu por vezes considerei impossível para mim. 


\section{AGRADECIMENTOS}

À Universidade de São Paulo pelo oferecimento do curso de pósgraduação e ao Instituto de Pesquisas Energéticas e Nucleares pela infraestrutura fornecida e oportunidade concedida para a execução deste estudo.

Ao MSc. Jair Mengatti pela colaboração no que foi necessário para a realização deste trabalho.

Ao Natanael Gomes da Silva, que foi o facilitador em meu primeiro contato no IPEN e à MSc. Neuza Taeko Okasaki Fukumori, uma pessoa maravilhosa que me abriu as portas da Diretoria de Radiofarmácia (DIRF) me oferecendo a oportunidade de estágio e iniciação científica, sempre contribuindo com muito conhecimento e sugestões valiosas.

À Dra. Margareth Mie Nakamura Matsuda pela orientação, incentivo e conselhos, partilhando comigo seus conhecimentos, com insistência e perseverança em tudo o que faz. Sendo a responsável juntamente com a Msc. Neuza Taeko Okasaki Fukumori pelo meu amadurecimento profissional e científico.

À Dra. Tatiana Lavinas (in memorian) pela grande contribuição para este trabalho, auxiliando-me durante todo o início do projeto e à Dra. Maria Tereza Colturato, pela continuidade do trabalho da Dra. Tatiana, amizade e sugestões.

Ao Dr. João Alberto Osso Jr., pela valiosa contribuição e sugestões de grande importância para a conclusão deste trabalho.

À Dra. Elaine Bortoleti de Araújo e ao Dr. Rodrigo Leandro Bonifácio pelas sugestões e observações de grande importância para a finalização do trabalho. 
A todos os servidores, bolsistas e terceirizados da DIRF, em especial agradeço à equipe do controle e da garantia de qualidade pela colaboração, amizade e convivência no dia-a-dia do Instituto.

À MSc. Érika Vieira de Almeida, ao Laércio da Silva e ao José Luiz da Silva que sempre contribuíram na realização deste trabalho. Muito obrigada pelo aprendizado e por permitir que muitas vezes eu abusasse de vocês.

À Msc. Elisiane de Godoy Monteiro pelo auxílio e companhia todos os dias, incentivando-me.

À Angélica Tamião Zaffalon pela força e companhia nestes momentos finais da minha dissertação.

À Coordenação de Aperfeiçoamento de Pessoal de Nível Superior (CAPES), pelo auxílio financeiro. 
"Por vezes sentimos que aquilo que fazemos não é senão uma gota de água no mar.

Mas o mar seria menor se the faltasse uma gota."

(Madre Tereza de Calcutá) 


\title{
AVALIAÇÃO DO TEOR DE CARBONO ORGÂNICO TOTAL NA QUALIDADE DA ÁGUA: APLICAÇÃO NA RADIOFARMÁCIA
}

\author{
Stella Benedetti
}

RESUMO

Radiofármacos são preparações farmacêuticas que possuem um radionuclídeo em sua composição. Cerca de $95 \%$ deles são utilizados com finalidade diagnóstica e em sua maioria são administrados por via parenteral, requerendo o uso de água purificada (AP) e para injeção (API) nos processos de produção, controle de qualidade e pesquisa de novos radiofármacos. A produção de radiofármacos no Brasil deve atender às Boas Práticas de Fabricação (BPF), RDC n. 17/2010 e RDC n. 63/2009 da ANVISA e requisitos de qualidade definidos pelas farmacopeias vigentes. Considerando que os volumes dos lotes de fabricação de radiofármacos são reduzidos, de algumas dezenas a centenas de mililitros, e a sua validade é de algumas horas a alguns dias, frequentemente tem sido utilizados sistemas purificadores de uso laboratorial para a produção de AP e API nas radiofarmácias. A determinação de carbono orgânico total (COT) é um dos requisitos a serem atendidos na avaliação da qualidade de AP e API e o seu limite é de $500 \mu \mathrm{g} \mathrm{L}^{-1}$. O objetivo deste estudo foi validar o método analítico de COT que combina reações de acidificação e de oxidação química do carbono para análise de carbono inorgânico $(\mathrm{Cl})$ e carbono total $(\mathrm{CT})$, na análise de AP e API, avaliar o desempenho de sistemas de purificação de uso laboratorial para a produção de AP e API e comparar com a API adquirida de fornecedores externos. Utilizou-se um analisador de carbono modelo TOC-Vwp acoplado a um amostrador automático modelo ASI-V, ambos da marca Shimadzu ${ }^{\circledR}$ e controlados por software TOC Control-V e frascos de $40 \mathrm{~mL}$ lavados com $\mathrm{HNO}_{3} 15 \%$, com soluções de reagente oxidante $\left(\mathrm{Na}_{2} \mathrm{~S}_{2} \mathrm{O}_{8} \quad 0,5 \quad \mathrm{~mol}^{-1}\right)$ e acidificante $\left(\mathrm{H}_{3} \mathrm{PO}_{4}\right.$ 3,0 mol L-1 $)$, soluções de COT/CT $\left(\mathrm{C}_{8} \mathrm{H}_{5} \mathrm{O}_{4} \mathrm{~K}\right)$ e $\mathrm{Cl}\left(\mathrm{Na}_{2} \mathrm{CO}_{3}\right.$ e $\left.\mathrm{NaHCO}_{3}\right)$ nas concentrações $100-1000 \mu \mathrm{g} \mathrm{L}^{-1}$. Foram avaliados os parâmetros de validação 
de método: conformidade do sistema, robustez, repetibilidade, precisão intermediária, exatidão, linearidade e limites de detecção e quantificação. O desempenho de 5 sistemas de purificação foram avaliados, com amostragem de AP e API de 6 pontos ( 3 de AP e 3 de API) e foram analisados COT, condutividade, $\mathrm{pH}$, contagem de aeróbios totais e endotoxina bacteriana (somente para API). As melhores condições de análise foram $2 \mathrm{~mL}$ de oxidante, $3 \%$ de acidificante, tempo de integração da curva de CT de 10 minutos e 3 minutos para $\mathrm{Cl}$. As curvas analíticas de CT e $\mathrm{Cl}$ foram lineares nas faixas de concentrações analisadas, com a soma residual dos mínimos quadrados $\left(r^{2}\right)$ maior que 0,997 . Os resultados de repetibilidade apresentaram valores entre $0,40-4,40 \%$, a precisão intermediária por sua vez apresentou a seguinte variação, 0,65 a 4,63\% e exatidão apresentou valores na faixa de $96,76-112,52 \%$. Os limites de detecção (LD) e quantificação (LQ) foram 31,83 e 106,11 $\mu \mathrm{g} \mathrm{L}^{-1}$ e 59,16 e 197,22 $\mu \mathrm{g} \mathrm{L}^{-1}$, para $\mathrm{CT}$ e $\mathrm{Cl}$, respectivamente. A avaliação de desempenho dos purificadores indicam que um procedimento adequado de limpeza do reservatório de água é importante para manter a concentração de COT em cerca de $100 \mu \mathrm{g} \mathrm{L}^{-1}$. A análise de $\mathrm{COT} / \mathrm{Cl}$ pode ser utilizada como indicador da necessidade de manutenção do sistema purificador. Algumas API embaladas apresentaram COT acima de $500 \mu \mathrm{g} \mathrm{L}^{-1}$. O monitoramento de COT durante a avaliação de desempenho dos sistemas de uso laboratorial acoplados a reservatórios indicou que eles são equipamentos adequados para obtenção de AP e API em radiofarmácia. 


\title{
EVALUATION OF TOTAL ORGANIC CARBON CONTENT IN THE QUALITY OF THE WATER: APPLICATION IN RADIOPHARMACY
}

\author{
Stella Benedetti
}

\begin{abstract}
Radiopharmaceuticals are pharmaceutical preparations that have one radionuclide in their composition. About $95 \%$ of them are used with diagnostic purposes and most of them are parenterally administered, requiring the use of purified water (PW) and water for injection (WFI) in the production process, quality control and research of new radiopharmaceuticals. The production of radiopharmaceuticals in Brazil must comply with Good Manufacturing Practices (GMP), RDC n. 17/2010 and RDC n. 63/2009 from ANVISA, and the requirements defined by current pharmacopoeias. Considering that the batch volumes of the radiopharmaceuticals are reduced, up to some milliliters, and the shelf lives are from hours to a few days, purification systems for laboratory use have often been used to produce PW and WFI in the radiopharmacies. The determination of Total Organic Carbon (TOC) is one of the requirements for the assessment of PW and WFI and its limit is $500 \mu \mathrm{g} \mathrm{L}^{-1}$. The aim of this study was to validate the analytical method for TOC analysis that combines acidification and chemical oxidation to quantify inorganic carbon (IC) and total carbon (TC) in the analysis of PW and WFI; to evaluate the performance of purification systems for laboratorial use to produce PW and WFI and to compare with WFI acquired from external suppliers. It was used a carbon analyzer model TOC-Vwp coupled to an autosampler model ASI-V, both from Shimadzu ${ }^{\circledR}$ controlled by TOC-V Control software and $40 \mathrm{~mL}$ vials washed with $15 \% \mathrm{HNO}_{3}$, an oxidizing reagent $\left(\mathrm{Na}_{2} \mathrm{~S}_{2} \mathrm{O}_{8} 0.5 \mathrm{~mol} \mathrm{~L}{ }^{-1}\right)$, an acid reagent $\left(\mathrm{H}_{3} \mathrm{PO}_{4}\right.$ $\left.3.0 \mathrm{~mol} \mathrm{~L}{ }^{-1}\right)$, TOC/TC $\left(\mathrm{C}_{8} \mathrm{H}_{5} \mathrm{O}_{4} \mathrm{~K}\right)$ and $\mathrm{IC}\left(\mathrm{Na}_{2} \mathrm{CO}_{3}\right.$ and $\left.\mathrm{NaHCO}_{3}\right)$ solutions in the range of 0 - $1000 \mu \mathrm{g} \mathrm{L}^{-1}$. The evaluated validation parameters were system suitability, robustness, repeatability, intermediate precision, accuracy, linearity and detection and quantification limits. The performance of 5 purification systems were
\end{abstract}


evaluated by sampling PW and WFI from 6 places (3 were PW and $3 \mathrm{WFI}$ ) and TOC, conductivity, $\mathrm{pH}$, total aerobic count and bacterial endotoxin (API only) were analyzed. The best conditions of analysis were $2.0 \mathrm{~mL}$ oxidizing reagent, $3 \%$ acid reagent, 10 minutes integration curve time for TC and 3 minutes for IC. The TC and IC analytical curves were linear in the evaluated range, with residual sum of minimum squares $\left(r^{2}\right)$ greater than 0.997 . The results of repeatability were from 0.40 to $4.40 \%$, intermediate precision were from 0.65 to $4.63 \%$, and accuracy were in the range of 96.76 to $112.52 \%$. The detection limit (DL) and quantification limit (QL) were 31.83 and $106.11 \mu \mathrm{g} \mathrm{L}^{-1}$ and 59.16 and $197.22 \mu \mathrm{g} \mathrm{L}^{-1}$ for IC and $\mathrm{TC}$, respectively. The evaluation of the performance of the water purification system indicated that an adequate procedure for cleaning of the storage tank is important to maintain TOC concentration about $100 \mu \mathrm{g} \mathrm{L}^{-1}$. TOC /IC analysis can be used as an indicator of the need for maintenance of the purification system. Some commercial packed WFI presented TOC above $500 \mu \mathrm{g} \mathrm{L}^{-1}$. The TOC monitoring during evaluation of the performance of purification systems for laboratory use coupled with storage tank indicated that they are suitable equipment for obtaining PW and WFI in radiopharmacies. 


\section{SUMÁRIO}

Página

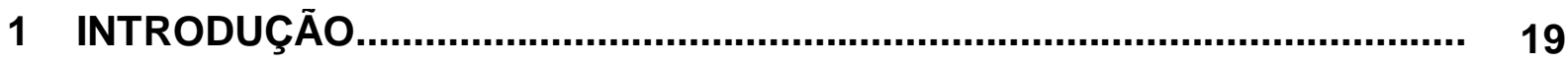

2 OBJETIVOS..................................................................................... 22

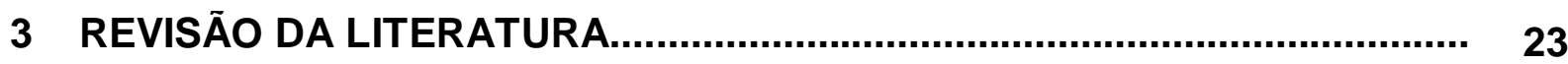

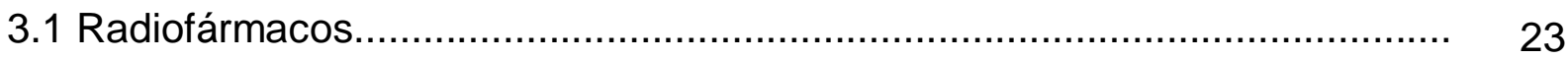

3.2 Água de uso farmacêutico................................................................. 25

3.2.1 Água potável................................................................................ 27

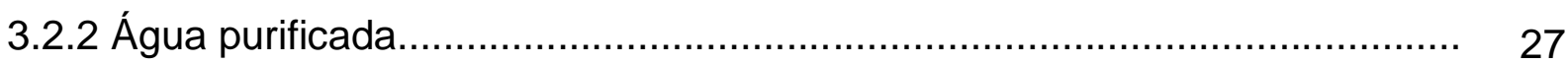

3.2.3 Água para Injeção........................................................................... 27

3.3 Análise de água de uso farmacêutico................................................... 28

3.4 Carbono Orgânico Total.................................................................... 29

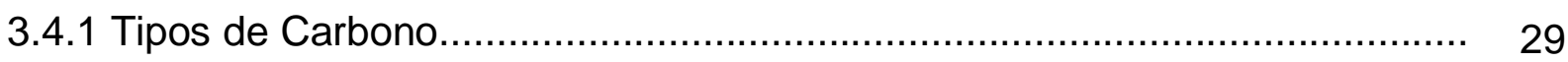

3.4.2 Frações de carbono orgânico total....................................................... 30

3.4.3 Métodos analíticos para determinação de carbono..................................... 30

3.5 Validação de métodos analíticos............................................................. 34

3.5.1 Conformidade do sistema............................................................... 36

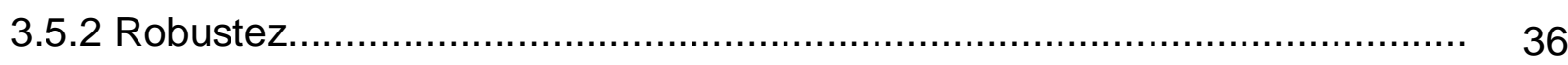

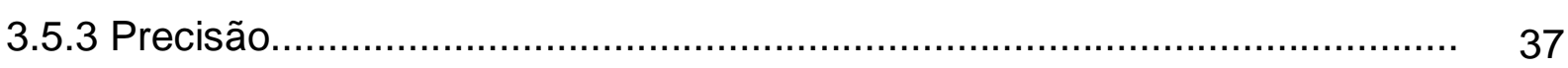

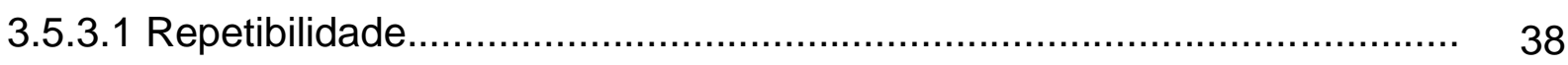

3.5.3.2 Precisão Intermediária................................................................... 38

3.5.3.3 Reprodutibilidade.................................................................... 39

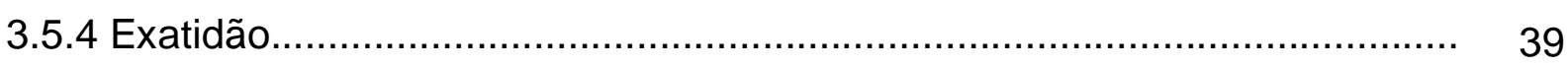

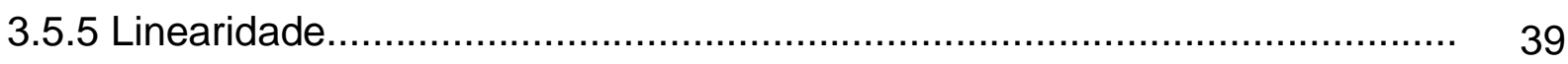

3.5.6 Limite de detecção......................................................................... 40

3.5.7 Limite de quantificação................................................................... 41

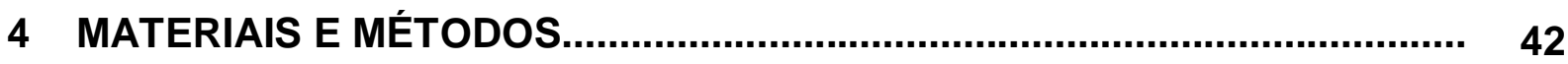

4.1 Equipamentos.......................................................................... 42

4.1.1 Características do analisador de carbono............................................. 42 
4.2 Materiais e Reagentes.................................................................. 44

4.2.1 Validação e coleta de amostras............................................................. 44

4.2.2 Conformidade do sistema..................................................................... 45

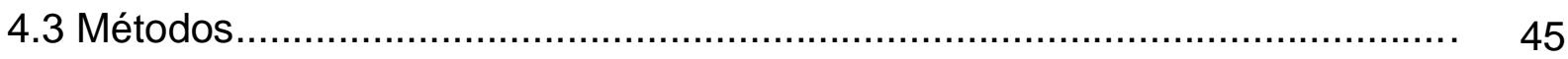

4.3.1 Método de amostragem de água...................................................... 45

4.3.2 Validação do método de determinação de COT........................................ 46

4.3.2.1 Conformidade do sistema (system suitability) ........................................ 46

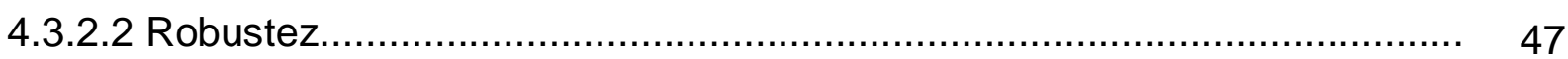

4.3.2.3 Repetibilidade, reprodutibilidade e exatidão........................................ 48

4.3.2.4 Linearidade

4.3.2.5 Limite de deteç̧ão e limite de quantificação......................................... 48

4.3.3 Avaliação de desempenho dos sistemas purificadores de água instalados na DIRF.

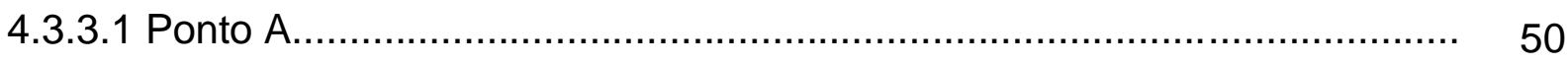

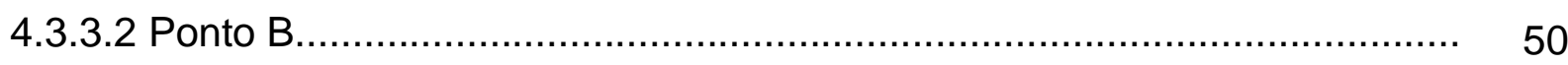

4.3.3.3 Ponto C.............................................................................. 51

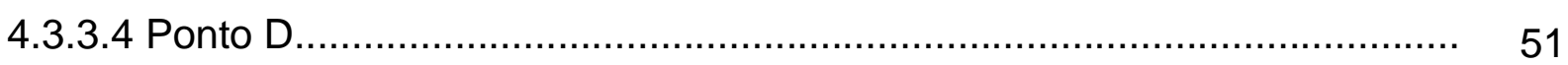

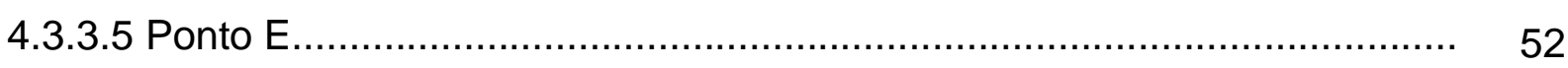

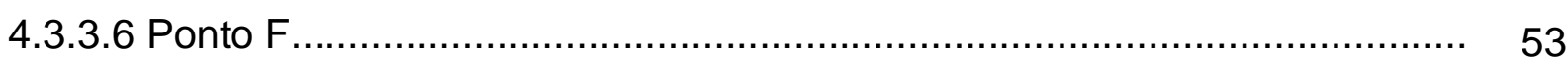

4.3.4 Análise de qualidade de API adquirida de fornecedores externos

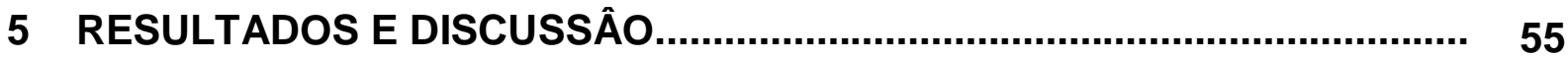

5.1 Validação do método de determinação de COT ............................................. 55

5.1.1 Conformidade do sistema (system suitability) ........................................ 55

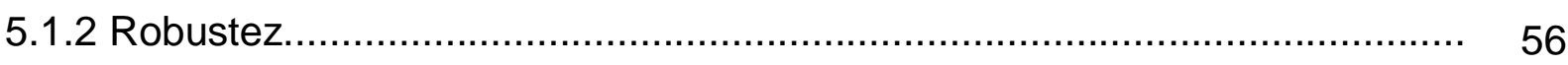

5.1.2.1 Volume de solução oxidante......................................................... 56

5.1.2.2 Volume de solução acidificante....................................................... 58

5.1.2.3 Tempo de integração da área da curva para o cálculo de CT.................. 59

5.1.2.4 Tempo de integração da área da curva para o cálculo de $\mathrm{Cl}$..................... 61

5.1.3 Repetibilidade, precisão intermediaria e exatidão...................................... 64

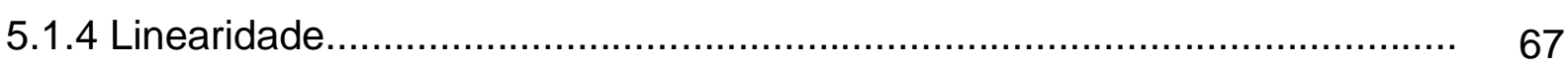

5.1.5 Limite de detecção e limite de quantificação........................................... 67 
5.2 Avaliação de desempenho dos sistemas purificadores de água instalados na DIRF

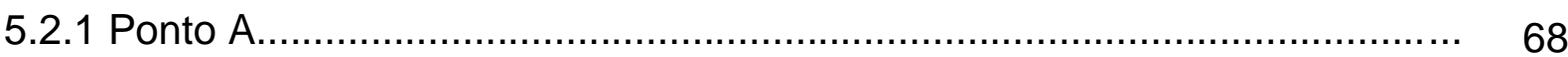

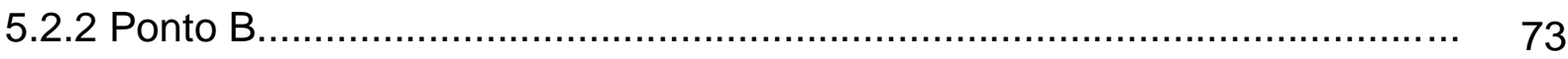

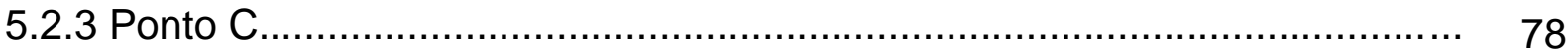

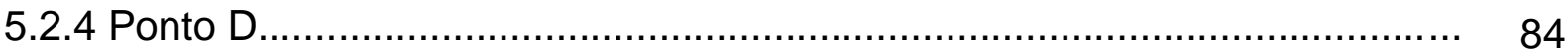

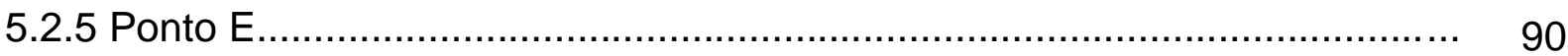

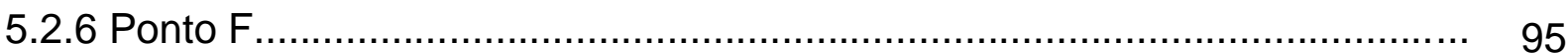

5.3 Análise de qualidade de água para injeção adquirida de fornecedores

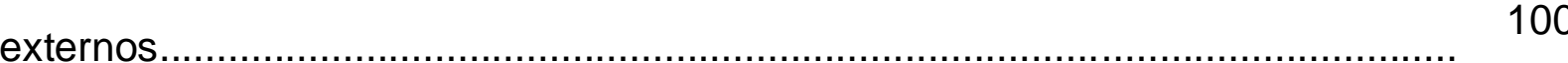

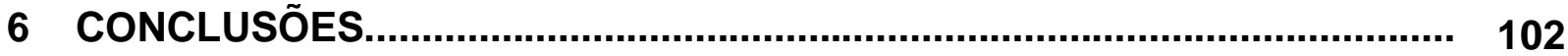

REFERÊNCIAS BIBLIOGRÁFICAS................................................................ 103 


\section{LISTA DE TABELAS}

Página

TABELA 1 - Especificações para água purificada e para injeção definidas pelas farmacopeias Americana, Europeia e Brasileira

TABELA 2 - Classificação de carbono orgânico conforme características físico-químicas.

TABELA 3 - Comparação da capacidade de detecção entre as técnicas analíticas.

TABELA 4 - Aplicação dos ácidos utilizados na determinação de COT.

TABELA 5 - Técnicas empregadas na determinação de COT.

TABELA 6 - Técnicas de detecção para quantificação de $\mathrm{CO}_{2}$.

TABELA 7 - Tipos de ensaios considerados pelos diferentes guias de validação de métodos analíticos.

TABELA 8 - Efeito da variação do volume de solução oxidante na obtenção da curva analítica de CT.

TABELA 9 - Efeito da variação do volume de solução acidificante na obtenção da curva analítica de $\mathrm{Cl}$

TABELA 10 - Efeito da variação do tempo de integração da área da curva para o cálculo de CT na obtenção da curva analítica de CT.

TABELA 11 - Efeito da variação do tempo de integração da área da curva para o cálculo de $\mathrm{Cl}$ na obtenção da curva analítica de $\mathrm{Cl}$

TABELA 12 - Repetibilidade e Exatidão intradia de CT no $1^{\circ}$ dia de análise......

TABELA 13 - Repetibilidade e Exatidão intradia de CT no $2^{\circ}$ dia de análise...... 65

TABELA 14 - Precisão intermediária de CT. 65

TABELA 15 - Repetibilidade e Exatidão intradia de $\mathrm{Cl}$ no 1ํ dia de análise....... 66

TABELA 16 - Repetibilidade e Exatidão intradia de $\mathrm{Cl}$ no $2^{\circ}$ dia de análise....... 66

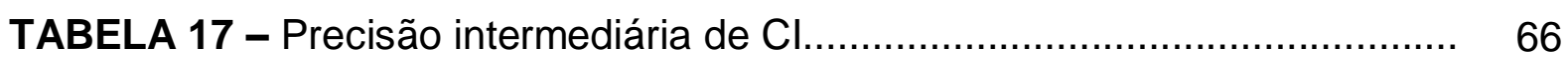

TABELA 18 - Curvas analíticas obtidas para CT e Cl................................. 67

TABELA 19 - Resultados das fases I e II do ponto A.................................... 69 
TABELA 20 - Resultados da fase III do ponto A …….................................... 70

TABELA 21 - Resultados da fase IV do ponto A.............................................. 71

TABELA 22 - Resultados das fases I e II do ponto B...................................... $\quad 74$

TABELA 23 - Resultados da fase III do ponto B............................................. 75

TABELA 24 - Resultados da fase IV do ponto B.......................................... 76

TABELA 25 - Resultados das fases I e II do ponto C...................................... 79

TABELA 26 - Resultados da fase III do ponto C.......................................... 80

TABELA 27 - Resultados da fase IV do ponto C........................................ 81

TABELA 28 - Resultados do esquema de coletas de 45 dias do ponto C......... 84

TABELA 29 - Resultados das fases I e II do ponto D...................................... 85

TABELA 30 - Resultados da fase III do ponto D........................................ 86

TABELA 31 - Resultados da fase IV do ponto D........................................ 87

TABELA 32 - Resultados do esquema de coletas de 45 dias do ponto D......... 90

TABELA 33 - Resultados das fases I e II do ponto E..................................... 91

TABELA 34 - Resultados da fase III do ponto E........................................... 92

TABELA 35 - Resultados da fase IV do ponto E.......................................... 93

TABELA 36 - Resultados das fases I e II do ponto F..................................... 96

TABELA 37 - Resultados da fase III do ponto F........................................... 97

TABELA 38 - Resultados da fase IV do ponto F.......................................... 98

TABELA 39 - Resultados das análises de qualidade de API de fornecedores externos e ponto $\mathrm{D}$. 


\section{LISTA DE FIGURAS}

Página

FIGURA 1 - Fluxograma de obtenção de água para uso farmacêutico............... 26

FIGURA 2 - Esquema do analisador de carbono............................................ 44

FIGURA 3 - Fluxograma de amostragem de água....................................... 46

FIGURA 4 - Esquema de coletas durante para avaliação de desempenho dos

sistemas purificadores de água durante 12 meses.

FIGURA 5 - Esquema de coletas durante para avaliação de desempenho dos sistemas purificadores de água durante 45 dias.

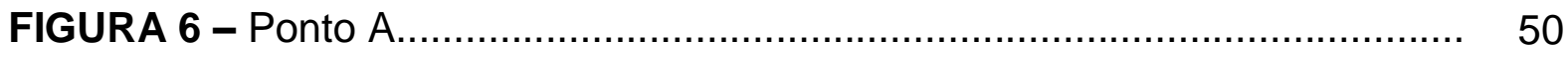

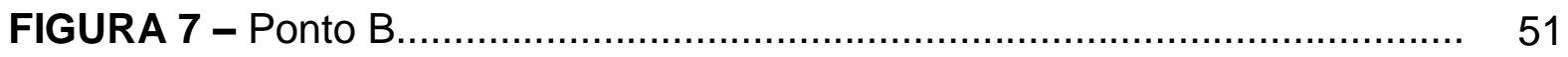

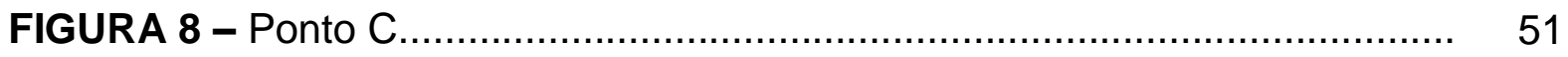

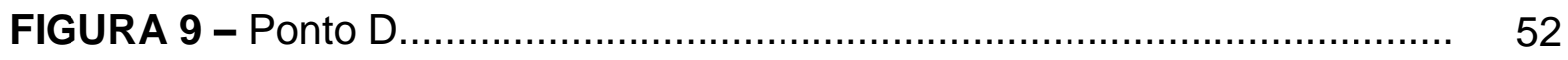

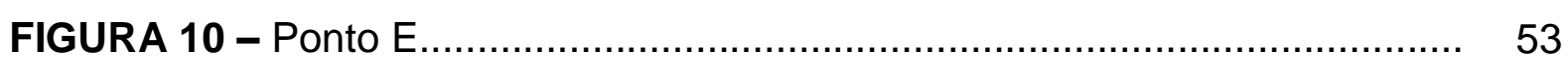

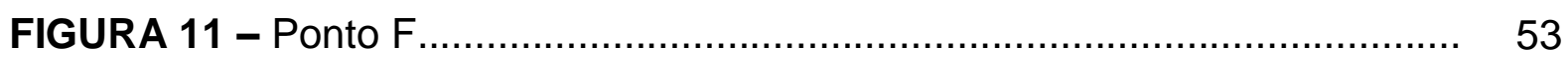

FIGURA 12 - Estrutura química da sacarose .............................................. 55

FIGURA 13 - Estrutura química da 1,4-benzoquinona.................................. 56

FIGURA 14 - Efeito da variação do volume de oxidante na análise de padrão de CT/COT de $250 \mu \mathrm{g} \mathrm{L}^{-1} \ldots \ldots \ldots \ldots \ldots \ldots \ldots \ldots \ldots \ldots \ldots \ldots \ldots \ldots \ldots \ldots$

FIGURA 15 - Efeito da variação do volume de solução acidificante na análise de padrão de COT de $250 \mu \mathrm{g} \mathrm{L}^{-1}$.

FIGURA 16 - Perfil da curva do sinal de $\mathrm{CO}_{2}$ para CT.

FIGURA 17 - Efeito da variação do tempo de integração da curva para o calculo de CT na análise de padrão de COT de $250 \mu \mathrm{g} \mathrm{L}^{-1}$.....

FIGURA 18 - Efeito da variação do tempo de integração da curva para o cálculo de $\mathrm{Cl}$ na análise de padrão de COT de $250 \mu \mathrm{g} \mathrm{L}^{-1}$.

FIGURA 19 - Perfil da curva do sinal de $\mathrm{CO}_{2}$ para $\mathrm{Cl}$

FIGURA 20 - Estrutura química do ftalato de potássio.

FIGURA 21 - Estrutura química do carbonato de sódio. 
FIGURA 22 - Estrutura química do bicarbonato de sódio.................................... 63

FIGURA 23 - Monitoramento de COT do ponto A ............................................. 72

FIGURA 24 - Resultados de $\mathrm{Cl}$ e condutividade do ponto A.............................. 72

FIGURA 25 - Monitoramento de COT do ponto B.......................................... 77

FIGURA 26 - Resultados de $\mathrm{Cl}$ e condutividade do ponto B.............................. 77

FIGURA 27 - Monitoramento de COT do ponto C......................................... 82

FIGURA 28 - Resultados de $\mathrm{Cl}$ e condutividade do ponto C.............................. 82

FIGURA 29 - Monitoramento de COT do ponto D....................................... 88

FIGURA 30 - Resultados de $\mathrm{Cl}$ e condutividade do ponto D............................. 88

FIGURA 31 - Monitoramento de COT do ponto E......................................... 94

FIGURA 32 - Resultados de Cl e condutividade do ponto E............................. 94

FIGURA 33 - Monitoramento de COT do ponto F....................................... 99

FIGURA 34 - Resultados de Cl e condutividade do ponto F............................. 99

FIGURA 35 - Tubulação do sistema de distribuição do ponto F........................ 100 


\section{LISTA DE ABREVIATURAS E/OU SIGLAS}

$\begin{array}{ll}{ }^{99 m} \mathrm{Tc}_{\mathrm{m}} & \text { Tecnécio meta estável } \\ { }^{99 \mathrm{TCO}_{4}-} & \text { Pertecnetato } \\ \mathrm{ANVISA} & \text { Agência Nacional de Vigilância Sanitária } \\ \mathrm{AP} & \text { Água Purificada } \\ \mathrm{API} & \text { Água Para Injeção } \\ \mathrm{BPF} & \text { Boas Práticas de Fabricação } \\ \mathrm{CCD} & \text { Cromatografia em Camada Delgada } \\ \mathrm{Cl} & \text { Carbono Inorgânico } \\ \mathrm{CLAE} & \text { Cromatografia Líquida de Alta Eficiência } \\ \mathrm{CMD} & \text { Concentração Média Determinada } \\ \mathrm{CNEN} & \text { Comissão Nacional de Energia Nuclear } \\ \mathrm{CO} & \text { Carbono Orgânico } \\ \mathrm{COAR} & \text { Carbono Orgânico Ácido Reagente } \\ \mathrm{COB} & \text { Carbono Orgânico Biológico } \\ \mathrm{COD} & \text { Carbono Orgânico Dissolvido } \\ \mathrm{CONP} & \text { Carbono Orgânico Não Purgável } \\ \mathrm{COPt} & \text { Carbono Orgânico Particulado } \\ \mathrm{COPu} & \text { Carbono Orgânico Purgável } \\ \mathrm{COT} & \text { Carbono Orgânico Total } \\ \mathrm{COV} & \text { Carbono Orgânico Volátil } \\ \mathrm{CT} & \text { Carbono Total } \\ \mathrm{CT}{ }_{1} & \text { Concentração Teórica } \\ \mathrm{CV} & \text { Coeficiente de Variação } \\ \text { DIRF } & \text { Diretoria de Radiofarmácia } \\ \mathrm{DP} & \text { Desvio Padrão } \\ \mathrm{DP} & \text { Desvio Padrão do coeficiente linear } \\ \mathrm{DPR} & \text { Desvio Padrão Relativo } \\ \mathrm{FA} & \text { Farmacopeia Americana } \\ & \end{array}$




\begin{tabular}{|c|c|}
\hline FB & Farmacopeia Brasileira \\
\hline FDA & Food and Drug Administration \\
\hline FE & Farmacopeia Europeia \\
\hline IC & Média de coeficiente angular \\
\hline $\mathrm{ICH}$ & International Conference on Harmonization \\
\hline INMETRO & Instituto Nacional de Metrologia, Qualidade e Tecnologia \\
\hline IPEN & Instituto de Pesquisas Energéticas e Nucleares \\
\hline IVND & Infra-vermelho Não Dispersível \\
\hline L & Litros \\
\hline LAL & Limulus Amebocyte Lysate \\
\hline LD & Limite de Detecção \\
\hline LQ & Limite de Quantificação \\
\hline $\mathrm{mg} \mathrm{L}^{-1}$ & Miligrama por litro \\
\hline $\min$ & Minutos \\
\hline $\mathrm{mL}$ & Mililitros \\
\hline $\mathrm{nm}$ & Nanômetros \\
\hline PTS & Portable Test System \\
\hline r & Coeficiente de correlação \\
\hline$r^{2}$ & Soma residual dos quadrados mínimos de regressão linear \\
\hline $\mathrm{R}_{\mathrm{B}}$ & Concentração do "branco" \\
\hline $\mathrm{R}_{\mathrm{BZ}}$ & Concentração de 1,4-benzoquinona \\
\hline $\mathrm{R}_{\mathrm{S}}$ & Concentração de sacarose \\
\hline $\mathrm{RDC}$ & Resolução da Diretoria Colegiada \\
\hline RE & Resolução Específica \\
\hline $\mathrm{RL}$ & Reagente Liofilizado \\
\hline SS\% & Conformidade do sistema \\
\hline UE $\mathrm{mL}^{-1}$ & Unidade de Endotoxina por mililitro \\
\hline UFC $\mathrm{mL}^{-1}$ & Unidade Formadora de Colônia por mililitro \\
\hline UFC $100 \mathrm{~mL}^{-1}$ & Unidade Formadora de Colônia por 100 mililitros \\
\hline UV & Ultra Violeta \\
\hline$\mu g \mathrm{~L}^{-1}$ & microgramas por litro \\
\hline$\mu \mathrm{m}$ & Micrômetros \\
\hline$\mu \mathrm{S} \mathrm{cm}{ }^{-1}$ & micro Siemens por centímetro \\
\hline
\end{tabular}




\section{INTRODUÇÃO}

A água é um dos itens mais importantes e mais amplamente utilizados na indústria farmacêutica, seja como produto de utilidade, insumo para a fabricação de diversas formas farmacêuticas, sendo o principal insumo de formas farmacêuticas líquidas, seja como base para a manipulação de soluções e reagentes utilizados na produção, controle de qualidade e em pesquisa de novos fármacos (1-6). A água empregada nos processos farmacêuticos deve atender aos parâmetros de qualidade definidos pelas farmacopeias e normas vigentes. Cada processo ou produto em uma indústria farmacêutica requer 0 atendimento aos requisitos de qualidade para a água: para a limpeza de laboratórios, por exemplo, a água pode ser potável, a produção de formas farmacêuticas sólidas, semi-sólidas e orais líquidas, bem como a produção de soluções e reagentes e limpeza de vidrarias requer o uso de água purificada - Purified Water ou AP; na fabricação de formas farmacêuticas de uso parenteral, na limpeza de equipamentos envolvidos, no processo de produção, e em processos de esterilização de produtos médicos invasivos, requer-se o uso de água para injeção - Water for Injection ou API. De um modo geral, as tecnologias de tratamento de água têm evoluído e AP e API podem ser obtidas por diferentes tecnologias de purificação. A produção de AP ou API requer a utilização de fonte de água que atenda no mínimo aos requisitos de qualidade de água potável. $\mathrm{O}$ armazenamento de AP deve ser adequado a fim de evitar contaminações que podem ser provenientes da fonte da água, de deficiência ou falta de manutenção na infraestrutura do sistema de purificação ou de distribuição da água $(3,7,8)$.

A maneira de se assegurar que o sistema de purificação é adequado ao seu objetivo consiste em validar o sistema de produção de água e monitorar a qualidade da água em amostras recolhidas de pontos críticos de sua produção, armazenamento e sistema de distribuição. Os ensaios de controle de qualidade da água são específicos ao tipo de água a ser monitorada e a aplicação desta água (9). As especificações básicas para qualidade de água estão definidas pelas Farmacopeias Brasileira (FB), Americana (FA) e Europeia (FE). A AP deve 
atender aos requisitos de pureza iônica e orgânica, além de especificações de controle de contaminação microbiológica. Por sua vez, a API deve atender às mesmas especificações químicas que a AP, bem como ao requisito de controle microbiológico mais restritivo e endotoxina bacteriana $(8,10,11)$.

Até 1994, as especificações AP e API envolviam basicamente os aspectos inorgânicos, através da determinação de sais dissolvidos, parâmetros qualitativos de substâncias oxidáveis e aspectos microbiológicos. A partir da 23a edição da FA (1995) uma nova análise foi introduzida, a determinação de carbono orgânico total (COT) tanto em AP como API, limitando a presença do material em $500 \mu \mathrm{g} \mathrm{L}^{-1}$ (3). O COT é uma expressão para designar vários tipos de carbono orgânicos que podem estar presentes na água, sendo, portanto não específica $(1,3,4,12)$.

A metodologia para a determinação de COT deve, como todo método analítico, ser validada segundo as diretrizes preconizadas pela resolução RE 899 de 2003 da Agência Nacional de Vigilância Sanitária (ANVISA). A validação de uma metodologia é um item das BPF e constitui-se na avaliação de parâmetros do método de análise empregado para que se comprove a sua segurança, aplicabilidade, precisão e a confiabilidade estatística (12-16).

Os radiofármacos têm como finalidade promover o diagnóstico e tratamento de diversas enfermidades, sobretudo na área oncológica. Na radiofarmácia, a água está presente em praticamente todas as etapas de produção. Além disto, a maioria dos radiofármacos é destinada ao uso parenteral, como é o caso dos radiofármacos prontos para o uso; componentes não radioativos para marcação com um componente radioativo; e radionuclídeos. Os geradores de ${ }^{99} \mathrm{Mo} /{ }^{99 \mathrm{~m}} \mathrm{Tc}$ utilizam solução de soro fisiológico ( $\mathrm{NaCl} 0,9 \%$ ), que é preparado com API, para a obtenção da solução injetável de pertecnetato de sódio ( $\left.{ }^{99 m} \mathrm{Tc}\right)(7,17-19)$.

A produção de radiofármacos deve cumprir às normas de Boas Práticas de Fabricação (BPF) vigentes, a saber: RDC n. 17 de 16 de abril de 2010, que dispõe sobre as boas práticas de fabricação de medicamentos e a RDC n. 63 de 18 de dezembro de 2009, que dispõe sobre BPF de radiofármacos, a fim de assegurar a qualidade, segurança e eficácia de seu uso em pacientes. 0 cumprimento das BPF é feito pelo monitoramento do processo de produção do radiofármaco, e inclui o ambiente no qual este é produzido, as matérias primas envolvidas e o produto acabado $(7,20,21)$. 
Para a maioria dos produtos radiofarmacêuticos, os lotes produzidos são pequenos e apresentam um curto prazo de validade (22). Este fato requer quantidades reduzidas de insumos no processo de fabricação de radiofármacos, incluindo a água. Para a indústria radiofarmacêutica a obtenção de água é feita na maioria das vezes por equipamentos de purificação laboratoriais, com sistemas de distribuição e armazenamento, com coleta para uso imediato, diferentemente dos utilizados na indústria farmacêutica convencional.

Os equipamentos de purificação devem ser qualificados e os sistemas para obtenção de AP e API devem ser validados e monitorados em uma radiofarmácia. Para tal, é necessária a utilização de metodologias analíticas validadas para a realização de ensaios de controle de qualidade, incluindo a metodologia para determinação de COT. 


\section{OBJETIVO}

O objetivo deste trabalho foi realizar a validação do método de análise de COT, que combina reações de acidificação e de oxidação química do carbono para análise de $\mathrm{Cl}$ e CT.

Além do objetivo principal, foram ainda parte do trabalho:

- Avaliar o desempenho de sistemas de purificação destinados ao uso laboratorial para a produção de água purificada e para injeção;

- Comparar a qualidade de água para injeção produzida por purificadores de uso laboratorial com a adquirida de fornecedores externos, e

- Verificar as potencialidades da análise de COT como indicador da qualidade do sistema purificador e do armazenamento de água. 


\section{REVISÃO DA LITERATURA}

\subsection{Radiofármacos}

O radiofármaco é um composto radioativo utilizado em procedimentos diagnósticos e terapêuticos, composto por um radionuclídeo ligado ou não a um fármaco. Aproximadamente $95 \%$ destes compostos são utilizados com finalidade diagnóstica por imagem e não possuem atividade farmacológica, enquanto que os radiofármacos aplicados em terapia podem causar danos teciduais por conta dos efeitos da radiação (17).

Por serem administrados em seres humanos, em sua grande maioria por via parenteral, devem-se cumprir as exigências de medicamentos injetáveis convencionais, atendendo aos requisitos de esterilidade, apirogenicidade, ausência de partículas estranhas, além de ensaios específicos: pureza radioquímica e radionuclídica $(17,18,23)$. A utilidade do radiofármaco é direcionada de acordo com a farmacodinâmica e farmacocinética da substância ligada ao radionuclídeo e ao tipo de radionuclídeo ligante, podendo este ser emissor de partícula alfa $(\alpha)$, de pósitron $\left(\beta^{+}\right)$, de négatron $\left(\beta{ }^{-}\right)$ou radiação gama $(\gamma)(17)$.

A produção de radiofármacos engloba três procedimentos, a saber: a obtenção do radionuclídeo, a síntese da substância ou molécula-alvo, e a marcação desta com o radionuclídeo (18).

O radionuclídeo pode ser obtido de três métodos diferentes: pelos reatores nucleares, onde núcleos de moléculas estáveis são bombardeados por nêutrons térmicos, instabilizando o átomo e por emissão de partícula, o átomo origina o radionuclídeo de interesse. Pode ser também produzido por aceleradores de partícula onde o átomo é bombardeado em aceleradores lineares ou cíclotrons por elétrons, prótons, dêuterons ou partículas $\alpha$, causando a instabilização do átomo originando o radionuclídeo de interesse. E o terceiro método de obtenção de radionuclídeos é por geradores, um sistema onde um radionuclídeo "pai" é enclausurado e cujo decaimento gera o radionuclídeo de interesse que pode ser facilmente separado por extração química, exemplos 
deste sistema são os geradores de ${ }^{99} \mathrm{Mo} /{ }^{99 m} \mathrm{Tc}$ e ${ }^{68} \mathrm{Ge} /{ }^{68} \mathrm{Ga}$. Desta forma os radiofármacos podem ser classificados em radiofármacos de reator, cíclotron ou gerador $(17,18)$.

De maneira geral, a classificação mais conhecida para radiofármacos é por sua apresentação: radiofármacos prontos para o uso; componentes não radioativos para marcação com um componente radioativo; e radionuclídeos (incluindo eluatos de geradores de radionuclídeos) (17).

A farmácia nuclear ou radiofarmácia é o lugar físico onde os radiofármacos são preparados, estocados e dispensados, cujos colaboradores são radiofarmacêuticos, químicos nucleares, físicos, entre outros profissionais, com treinamento em química radiofarmacêutica. A produção de radiofármacos deve observar as orientações da RDC n. 17 de 16 de abril de 2010, que dispõe sobre as Boas Práticas de Fabricação (BPF) de medicamentos e da RDC n. 63 de 18 de dezembro de 2009, que dispõe sobre BPF de radiofármacos, da ANVISA $(20,21)$.

A infraestrutura de uma radiofarmácia deve levar em conta a proteção radiológica e cuidados quanto à contaminação microbiológica e química do ambiente e do próprio radiofármaco. Para as preparações que envolvem manipulação de radiação em altas atividades, são utilizadas celas e salas conhecidas como "alas quentes", projetadas com 0 intuito de evitar contaminações radiológicas. Para garantir a manipulação sob condições assépticas, é utilizado fluxo laminar e filtros HEPA (high efficiency particulate air). Para o fracionamento de doses no preparo para aplicação em pacientes, devem ser utilizadas proteções de chumbo, e recipientes blindados com chumbo para o transporte das seringas. Outros cuidados na preparação de radiofármacos devem ser aplicados, como procedimentos de limpeza, prevendo a utilização de materiais estéreis durante o processo $(17,20,21,24)$.

Os rejeitos gerados por uma radiofarmácia podem ser classificados como rejeitos radioativos e rejeitos biológicos e devem ser tratados de acordo com as normas das agências de gerenciamento de radiação (Comissão Nacional de Energia Nuclear - CNEN) segundo a norma CNEN-NN-3.05: requisitos de radioproteção e segurança para serviços de medicina nuclear, e da ANVISA: resolução RDC № 306, de 7 de dezembro de 2004 que dispõe sobre o 
regulamento técnico para o gerenciamento de resíduos de serviços de saúde $(17,25,26)$.

\section{2 Água de uso farmacêutico}

Instalações farmacêuticas destinadas à elaboração e processamento de medicamentos e produtos para a saúde têm como principal insumo a água (27). É considerada água para uso farmacêutico aquela utilizada na síntese de fármacos, incorporados ao produto durante o processamento, em ensaios laboratoriais, em limpeza e higiene de equipamentos, em utensílios e sistemas, diagnósticos, em operações de esterilização e suas demais aplicações na área de saúde, necessárias ao cumprimento das $\operatorname{BPF}(2,3,28,29)$.

A água de uso farmacêutico pode ser dividida em dois grupos: Bulk Waters, água produzida no próprio local para utilização imediata, e a água embalada que é produzida, embalada e esterilizada para manutenção da qualidade, principalmente com relação a sua carga microbiana, para ser comercializada (8).

As propriedades químicas da água a tornam um meio de solubilização, adsorção, e suspensão de diversas substâncias, incluindo o carreamento de contaminantes que podem alterar a qualidade de um produto farmacêutico $(28,6)$.

A água de uso farmacêutico deve atender aos requisitos de qualidade físico-químicos e microbiológicos mínimos descritos nas farmacopeias, de acordo com a classificação desta água $(8,28)$.

A obtenção de água para uso farmacêutico envolve a associação de processos unitários de purificação, que podem ser por métodos de filtração, ultrafiltração, destilação, bidestilação, deionização, eletrodeionização, osmose reversa e osmose reversa de duplo passo que podem ainda estar associados a processos de pré-tratamento como cloração, descarbonatação, abrandamento e clarificação, tendo como produto de partida a água potável como mostra a FIG. 1 $(3,6-8,30)$. 


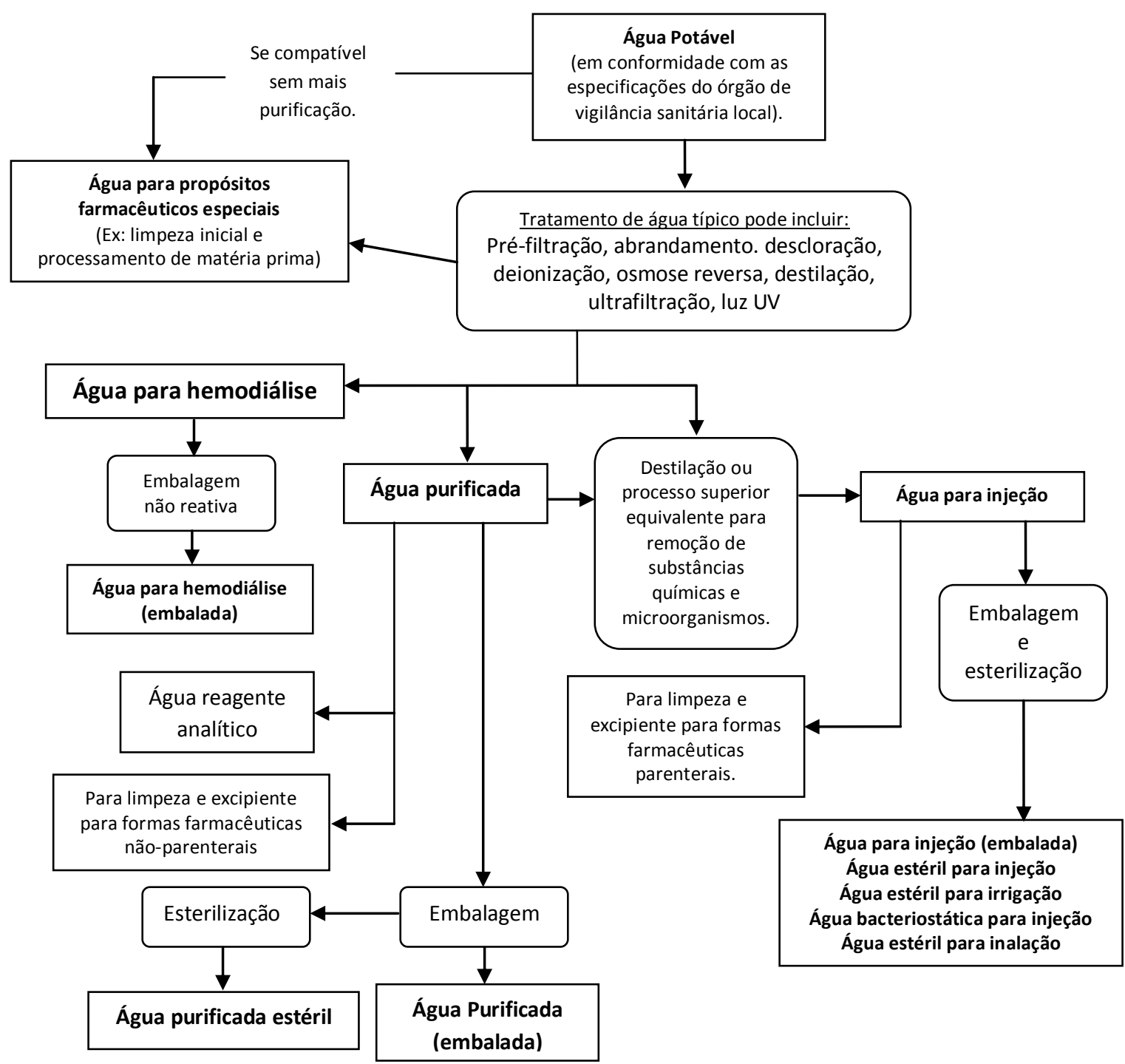

FIGURA 1 - Fluxograma de obtenção de água para uso farmacêutico (8).

Os sistemas de armazenamento e distribuição de água para uso farmacêutico devem ser adequados, para que as especificações das farmacopeias sejam atendidas, mantidas e controladas (28). Para tal, deve ser realizado nestes sistemas um processo de sanitização periódico realizado com a utilização de sanitizantes químicos, a saber: vapor de água ultrapura, ozônio $\left(\mathrm{O}_{3}\right)$, peróxido de hidrogênio $\left(\mathrm{H}_{2} \mathrm{O}_{2}\right)$, ácido peracético $\left(\mathrm{C}_{2} \mathrm{H}_{4} \mathrm{O}_{2}\right)$, cloro $\left(\mathrm{Cl}_{2}\right)$, hipoclorito ( $\left.\mathrm{ClO}^{-}\right)$, formaldeídos, glutaraldeído, detergentes catiônicos, hidróxido de sódio $(\mathrm{NaOH})$, brometos $\left(\mathrm{Br}^{-}\right)$e iodetos (l) (31). Estes sistemas devem ser validados para garantir a qualidade da água e evitar contaminações, que podem ser 
provenientes da fonte da água, de deficiências na infraestrutura do sistema ou na distribuição da água, ou falta de manutenção (28).

\subsection{1 Água Potável}

Segundo a portaria 2.914 de 12 de dezembro de 2011, que dispõe sobre os procedimentos de controle e de vigilância da qualidade da água para consumo humano e seu padrão de potabilidade, define-se como água potável aquela que atende aos padrões organolépticos, físico-químicos e microbiológicos por ela estabelecida (32).

\subsection{2 Água Purificada}

Utilizada como excipiente em preparações de medicamentos não parenterais e operações farmacêuticas como limpeza de equipamentos e utensílios que não entram em contato com soluções parenterais. Também é aplicável aos ensaios e testes em controle de qualidade e pesquisa e desenvolvimento onde este grau de pureza é indicado. A fonte de água recomendada para obtenção de $\mathrm{AP}$ é água potável $(8,33)$. O grau de pureza indicado para este tipo de água encontra-se na TAB. $1(8,28,34)$.

\subsection{3 Água para Injeção}

É empregada na produção de medicamentos de uso parenteral e na higienização dos utensílios e equipamentos que com eles entrem em contato, bem como em outras preparações onde o produto deve ter controle de endotoxina bacteriana $(8,33)$.

A água utilizada para a obtenção de API deve ser água potável submetida a um pré-tratamento, ou AP (8).

O equipamento e sistemas de estocagem e distribuição desta água devem evitar a contaminação microbiológica. Os requisitos de qualidade desta água estão relacionados na TAB. 1 (8,28,34). 
TABELA 1 - Especificações para água purificada e para injeção definidas pelas farmacopeias Americana, Europeia e Brasileira $(8,28,34)$.

\begin{tabular}{ccc}
\hline Tipo de água & Análises & Limites \\
\hline \multirow{2}{*}{ Água Purificada } & Condutividade & $1,3 \mu \mathrm{S} \mathrm{cm}^{-1}$ a $25^{\circ} \mathrm{C}$ \\
& $\mathrm{pH}$ & Entre 5 e 7 \\
& Cot & $<500 \mu \mathrm{g} \mathrm{L}^{-1}$ \\
Água para Injeção & Condutividade & $1,3 \mu \mathrm{Sm}^{-1}$ a $25^{\circ} \mathrm{C}$ \\
& $\mathrm{pH}$ & Entre 5 e 7 \\
& CoT & $<500 \mu \mathrm{g} \mathrm{L}^{-1}$ \\
& Endagem de aeróbios Totais & $<10 \mathrm{UFC} 100 \mathrm{~mL}^{-1}$ \\
& Endoxina bacteriana & $<0,25 \mathrm{UE} \mathrm{mL}^{-1}$ \\
\hline
\end{tabular}

UFC: Unidade formadora de colônia

UE: unidade de endotoxina

\subsection{Análise de água de uso farmacêutico}

O controle de qualidade da água é crucial, uma vez que a água tem grande capacidade de agregar compostos diversos e pode haver contaminações após o processo de purificação. Os contaminantes da água são representados por dois grandes grupos: químico e microbiológico (28).

Os tipos de ensaios relacionados ao controle de qualidade da água são específicos ao tipo de água a ser monitorada e à aplicação desta água. Os ensaios devem ser estabelecidos durante a validação do sistema de produção, armazenamento e distribuição e os pontos de amostragem de AP de acordo com o tipo de sistema de purificação, e devem ser mantidos com o monitoramento rotineiro da qualidade da água (9).

Até 1994, a água purificada era monitorada basicamente pelos seus aspectos inorgânicos, através da determinação de sais dissolvidos e parâmetros qualitativos de substâncias oxidáveis e microbiológicos. A partir da $23^{\underline{a}}$ edição da farmacopeia americana em 1995, um novo requisito foi estabelecido, a determinação de carbono orgânico total (COT) tanto na AP como na API, 
limitando a concentração do material em $500 \mu \mathrm{g} \mathrm{L}^{-1}$, como método não específico para determinação da presença de compostos orgânicos (4).

Os ensaios para AP e API estabelecidos pela farmacopeia americana e adotados pelas farmacopeias europeia e brasileira, envolvem (oito 28,34):

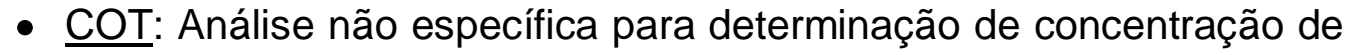
moléculas orgânicas na amostra. $(8,28,29,34)$.

- Contagem de aeróbios totais: ensaio microbiológico realizado com método de filtração por membrana em placa de meio R2A Agar ou meio (Nem Water Recear Instituto) NWRI ágar (8,34).

- $\underline{\mathrm{pH}}$ : o pH da água deve ser próximo ao neutro (5-7) para evitar interferências no preparo de soluções e em reações químicas, bem como evitar alteração do pH fisiológico quando administrado por via parenteral $(8,28,34,35)$.

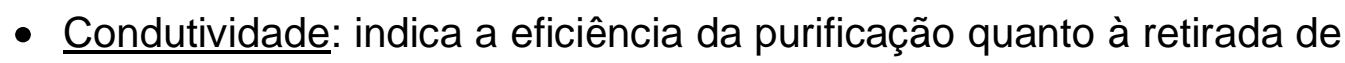
íons. Condutividade acima de $1,3 \mu \mathrm{S} \mathrm{cm}^{-1}$ em temperatura de $25{ }^{\circ} \mathrm{C}$, pode indicar contaminação severa por íons inorgânicos $(8,28,34)$.

- Endotoxina Bacteriana: Ensaio realizado somente em API, podendo ser semi-quantitativo por método de gel-clot ( $L A L)$ ou quantitativo por sistema de teste portátil (PTS), para a detecção da presença de lipossacarídeos provenientes da membrana e metabolismo de microorganismos pirogênicos $(8,28,34,36)$.

\subsection{Carbono Orgânico Total}

\subsubsection{Tipos de Carbono}

É possível encontrar três formas de expressão de carbono na natureza: carbono em sua forma elementar, tal qual carvão e grafite, carbono inorgânico (Cl), que é definido como toda espécie de sais de carbonatos $\left(\mathrm{CO}_{3}{ }^{-2} \mathrm{e}\right.$ bicarbonatos $\left.\mathrm{HCO}_{3}{ }^{-}\right)$, como dióxido de carbono $\left(\mathrm{CO}_{2}\right)$ dissolvido em água, e o carbono orgânico (CO), definido como todo átomo de carbono ligado covalentemente a uma molécula $(1,37)$.

Em amostras aquosas, a quantidade de carbono elementar é desprezível, e somente a quantidade de carbonos orgânicos e inorgânicos é considerada. Somados constituem a totalidade de carbono presente em meio aquoso ou carbono total (CT). Geralmente a denominação CT refere-se à soma 
das frações orgânica e inorgânica, uma vez que a quantidade de carbono elementar em amostras é insignificante $(1,27)$.

\subsubsection{Frações de carbono orgânico total}

O carbono orgânico total (COT) é uma expressão que denomina toda a matéria orgânica presente em uma amostra aquosa. As substâncias orgânicas podem ser classificadas com base nas características físico-químicas entre si. (TAB. 2) (27).

TABELA 2 - Classificação de carbono orgânico conforme características físicoquímicas (27).

\begin{tabular}{|c|c|c|}
\hline & Símbolo & Descrição \\
\hline Total & COT & $\begin{array}{l}\text { Toda forma de carbono de fonte orgânica ligado } \\
\qquad \text { covalentemente. } \\
\text { COT }=\text { COD }+ \text { COPu }\end{array}$ \\
\hline Dissolvido & COD & $\begin{array}{l}\text { Toda espécie de carbono solúvel, não filtrável por } \\
\text { membrana de } 0,45 \mu \mathrm{m} \text {. }\end{array}$ \\
\hline Particulado & COPt & $\begin{array}{l}\text { Possui partículas suspensas retidas por membranas } \\
\qquad \text { da ordem de } 0,2-10 \mu \mathrm{m} .\end{array}$ \\
\hline Volátil & COV & $\begin{array}{l}\text { Compostos de baixo peso molecular e pontos de } \\
\text { fusão abaixo de } 100^{\circ} \mathrm{C} .\end{array}$ \\
\hline Purgável & COPu & Matéria orgânica decomposta por pulverização. \\
\hline Não Purgável & CONP & Matéria orgânica não decomposta por pulverização. \\
\hline Ácido-reagente & COAR & $\begin{array}{l}\text { Matéria orgânica decomposta por tratamento com } \\
\text { ácido. }\end{array}$ \\
\hline Biológico & $\mathrm{COB}$ & Composto de origem biológica. \\
\hline
\end{tabular}

\subsubsection{Métodos analíticos para determinação de carbono}

A determinação de COT é realizada em diferentes áreas de pesquisa, tanto ambiental como industriais, com diferentes objetivos. A determinação de carbono orgânico em uma amostra líquida pode indicar: contaminação de água por compostos sintéticos, fluxo de carbono no sistema, presença de contaminantes biológicos pela formação de biofilmes, mau estado de conservação 
e ineficiência de um sistema de purificação $(8,27)$. Em indústria farmacêutica, a determinação de COT é um importante parâmetro para avaliação da qualidade da água, sendo utilizada com duas finalidades: na avaliação e validação de processos de limpeza de equipamentos envolvidos em produção de medicamentos, para indicar a ausência residual de princípios ativos e dos agentes sanitizantes empregados e contaminantes orgânicos, ou na avaliação da qualidade da água de uso farmacêutico nas diversas atividades industriais farmacêuticas (15,33,38-40). Entretanto a análise de COT constitui-se em uma ferramenta de análise inespecífica, representando todos os compostos orgânicos em uma amostra, em poucos minutos, uma característica vantajosa quando comparamos esta com algumas técnicas analíticas. A TAB. 3 compara a capacidade de detecção do COT com outras técnicas (33).

TABELA 3 - Comparação da capacidade de detecção entre as técnicas analíticas (33).

\begin{tabular}{c|ccc}
\hline \multirow{2}{*}{ Método Analítico } & \multicolumn{3}{|c}{ Capacidade de detecção } \\
\cline { 2 - 4 } & Fármacos residuais & Excipientes & Agentes de Limpeza \\
\hline COT & $\operatorname{Sim}$ & $\operatorname{Sim}$ & Sim \\
CLAE & $\operatorname{Sim}$ & $\operatorname{Sim}$ & Não \\
CCD & $\operatorname{Sim}$ & $\operatorname{Sim}$ & Não \\
Espectrometria & Sim/Não* & Sim/Não* & Não \\
Condutividade & Não & Não & Sim \\
\hline
\end{tabular}

\footnotetext{
${ }^{*}$ Dependente do analito em estudo.

CLAE: Cromatografia líquida de alta eficiência

CCD: Cromatografia em camada delgada
}

Análises de COT para validação de limpeza ou monitoramento de águas para uso farmacêutico são realizadas com o emprego de um analisador de carbono. Estas identificam o teor de carbono presente na amostra que pode ser expresso como COT ou CONP (33).

A determinação de COT pode ser realizada por dois métodos, o direto e o indireto.

No método direto, muitas vezes denominado de método de determinação de CONP, onde todo o carbono inorgânico deve ser removido da amostra anteriormente à determinação da fração orgânica por meio de 
acidificação ou calcinação. Na acidificação, toda a matriz inorgânica é decomposta e eliminada, e posteriormente um meio de decomposição da matriz orgânica é empregado para converter o carbono a $\mathrm{CO}_{2}$ para que este seja quantificado. O critério para a escolha do ácido para a composição do método está descrito na TAB. 4 (3,27).

TABELA 4 - Aplicação dos ácidos utilizados na determinação de COT (27).

\begin{tabular}{|c|c|}
\hline Ácido & Especificações \\
\hline $\mathrm{HCl}$ & $\begin{array}{c}\text { Reagente com } \mathrm{CO}_{3}{ }^{-2} \text { principalmente em amostras sólidas. } \\
\text { Pode induzir à reação de } \mathrm{CO} \text { quando aquecida. }\end{array}$ \\
\hline $\mathrm{H}_{3} \mathrm{PO}_{4}$ & $\begin{array}{c}\text { Ácido não oxidante. Amplamente aplicado em análises de } \\
\text { combustão a altas temperaturas em amostras de água. Deve- } \\
\text { se aplicar um método de remoção de gás clorídrico }\left(\mathrm{Cl}_{2}\right) \text { para } \\
\text { evitar interferência ou ineficácia da reação. }\end{array}$ \\
\hline $\mathrm{H}_{2} \mathrm{SO}_{3}$ & $\begin{array}{l}\text { Geralmente utilizado em tratamentos de solo. Promove perda } \\
\text { menor que } 2 \% \text { de } \mathrm{CO} \text {, mas pode constituir uma fonte de } \\
\text { contaminação de CO. }\end{array}$ \\
\hline Outros ácidos & $\begin{array}{c}\text { Com os ácidos } \mathrm{H}_{2} \mathrm{SO}_{4}, \mathrm{HNO}_{3} \text { e } \mathrm{HClO}_{4} \text {, a perda de } \mathrm{CO} \text { é maior } \\
\text { que } 80 \% . \mathrm{O} \mathrm{HClO}_{4} \text { sob aquecimento pode se converter em } \\
\text { espécies de percloratos tóxicos. }\end{array}$ \\
\hline
\end{tabular}

A oxidação do COT pode ser induzida por meio de combustão seca ou úmida, ou por oxidação química, e pode ser empregada em conjunto com outra técnica para obter limites de detecção menores, dependendo da matriz da amostra, características da amostra ou até mesmo do tipo de amostra (sólida ou líquida). A comparação entre as técnicas empregadas e suas limitações está relacionada na TAB. $5(27,33)$. 
TABELA 5 - Técnicas empregadas na determinação de COT (27).

\begin{tabular}{|c|c|c|}
\hline Método Químico & Técnica/Reagente & Limitações \\
\hline \multirow{3}{*}{ Oxidação Química } & Cromato & $\begin{array}{l}\text { Reagente somente com formas mais } \\
\text { facilmente oxidáveis de } \mathrm{CO} \text {, podendo } \\
\text { sofrer interferências por } \mathrm{Cl}^{-}, \mathrm{Fe}^{+2} \mathrm{e} \\
\qquad \mathrm{MnO}_{2} \text {. }\end{array}$ \\
\hline & Persulfato & $\begin{array}{l}\text { Necessidade da ativação por luz UV } \\
\text { e/ou aquecimento. Pode sofrer } \\
\text { interferências com } \mathrm{Cl}^{-}\end{array}$ \\
\hline & Luz UV & $\begin{array}{c}\text { Matérias particuladas e soluções } \\
\text { coloidais não são completamente } \\
\text { oxidadas. }\end{array}$ \\
\hline \multirow[t]{2}{*}{ Combustão } & Seca & $\begin{array}{l}\text { Requer temperaturas muito altas (1000- } \\
\left.\qquad 1100^{\circ} \mathrm{C}\right) .\end{array}$ \\
\hline & Úmida & Requer meio ácido para ativar a reação \\
\hline
\end{tabular}

Na combustão, a diferença de peso na amostra ao final da calcinação refere-se à concentração de COT, uma vez que neste caso a perda de peso em água é considerada insignificante (27).

O método mais utilizado para a determinação de COT em amostras líquidas é a indireta, onde é quantificado o teor de CT e $\mathrm{Cl}$ da amostra, e a concentração de COT é então obtida pela Eq. 1 (41).

$$
C O T=C T-C I
$$

Neste método são utilizadas duas alíquotas da amostra em duas determinações independentes. Uma para determinar o $\mathrm{CT}$ e outra para $\mathrm{Cl}$. O Cl é quantificado por meio de reação com ácido, como visto no método direto, e o $\mathrm{CO}_{2}$ liberado neste processo é quantificado. $\mathrm{O} \mathrm{CO}_{2}$ proveniente do $\mathrm{CT}$ é obtido através de reações químicas que fazem com que toda forma de carbono presente na amostra seja oxidada e decomposta, que são as mesmas reações de oxidação 
utilizadas em método direto, reações estas que conseguem decompor todo o carbono presente ( $\mathrm{Cl}$ e $\mathrm{CO})$ do analito $(3,27,41)$.

Para a detecção do $\mathrm{CO}_{2}$ gerado pela oxidação, a técnica mais utilizada é a espectrometria com infravermelho não dispersivo (IVND ou NDIR em inglês), por ser facilmente adaptável a equipamentos automatizados de análise e por oferecer alta sensibilidade e baixos limites de detecção em comparação com outras técnicas demonstradas na TAB. 6 (3,27,39,41,42).

TABELA 6 - Técnicas de detecção para quantificação de $\mathrm{CO}_{2}$ (27).

\begin{tabular}{cc}
\hline Técnica & Propriedades \\
\hline IVND & $\begin{array}{r}\text { Determina } \mathrm{CO}_{2} \text { diretamente e possui alta } \\
\text { sensibilidade. }\end{array}$ \\
Condutividade térmica & $\begin{array}{r}\text { Método indireto medindo a diferença de resistência } \\
\text { entre } \mathrm{CO}_{2} \text { e um gás referência. Pode sofrer } \\
\text { interferência por haletos. }\end{array}$ \\
Titulação & $\mathrm{CO}_{2}$ deve estar preso a uma base forte. \\
Gravimetria & Utilizando bulbos de adsorção. A concentração de \\
& $\mathrm{CO}_{2}$ é calculada pelo ganho de peso. \\
\hline
\end{tabular}

A titulação e a gravimetria não possuem sensibilidade suficiente para a detecção de baixas concentrações de COT, possibilitando detecções somente em faixas acima de $200 \mu \mathrm{g} \cdot \mathrm{L}^{-1}(27)$.

\subsection{Validação de métodos analíticos}

Em controle de qualidade de produtos farmacêuticos os métodos analíticos utilizados necessitam de validação para garantir a qualidade de dados obtidos por estas técnicas (43). A validação é essencial no cumprimento das BPF e uma ferramenta da garantia de qualidade (31).

A validação de um método ou processo é definida como a comprovação por meio de evidência experimental documentada de que os requisitos para a aplicação ou o uso específico são atendidos de forma consistente $(8,14,44,45)$. 
O objetivo da validação de um método analítico é demonstrar que ele é apropriado para a finalidade pretendida, atendendo às exigências necessárias $(14,32,46)$. Através da validação são coletados e analisados dados, que por meio de estudos estatísticos, evidenciam a eficiência de um método. Deve ser realizada quando se desenvolve ou se adapta um método, bem como na utilização de novas técnicas ou equipamentos (29,47-50). A realização de experimentos de validação e o registro documentado de todo o processo, fornece a segurança de que o método produzirá resultados que atendam às especificações de qualidade da medição de forma constante e sucessiva (51).

O desempenho de uma técnica analítica depende essencialmente de dois parâmetros: a qualidade instrumental e a confiabilidade estatística dos cálculos envolvidos no processamento de dados obtidos pelo método (13).

Para proceder a uma validação de metodologia deve-se ter total entendimento das aplicações, objetivo e escopo desta. Assim os parâmetros de validação e os critérios de aceitação devem seguir as normas vigentes $(43,52)$. Diferentes tipos de aplicação de um ensaio requerem conjuntos diferentes de parâmetros de validação. Os critérios de escolha destes são complexos e dependem do objetivo analítico do método. Os tipos de ensaio considerados pelas normas e guias vigentes estão dispostos na TAB. $7(8,11,14,40,48,52)$.

TABELA 7 - Tipos de ensaios considerados pelos diferentes guias de validação de métodos analíticos (40).

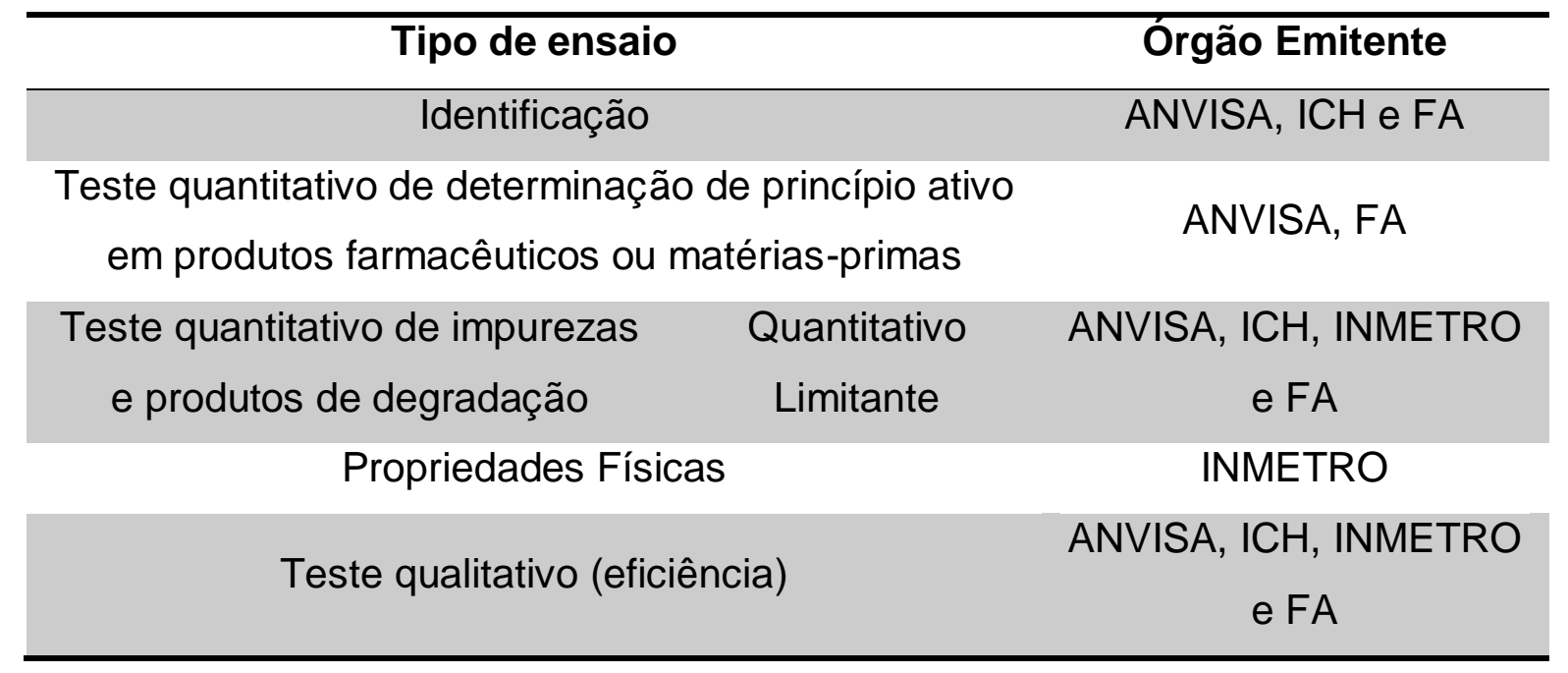


Procedimentos de validação têm sido propostos por diferentes grupos de trabalho, dentre eles: Food and Drug Administration (FDA), FA, International conference Harmonization (ICH), EURACHEM, ANVISA e o Instituto Nacional de Metrologia, Qualidade e Tecnologia (INMETRO) cujos guias apresentam algumas diferenças entre si (45).

Em testes quantitativos de determinação de impurezas os parâmetros de validação que necessitam ser investigados são: precisão, exatidão, limite de quantificação (LQ), limite de detecção (LD), linearidade e robustez (14,16,31).

O processo de validação de uma metodologia analítica é dinâmico. Durante o processo determinam-se os parâmetros do método, que são utilizados nas fases seguintes. Entretanto, se houver necessidade de alterações em fases anteriores, pode ocorrer uma revalidação. A validação pode ser um processo dispendioso e demorado, mas a confiabilidade dos dados gerados está ligada à qualidade deste $(31,51)$.

\subsubsection{Conformidade do sistema (System Suitability)}

O teste de conformidade de sistema é parte integral de diversas metodologias analíticas. Antes de realizar experimentos de validação deve-se avaliar se o sistema de análise é capaz de fornecer dados de qualidade aceitável. Testes de conformidade de sistema garantem que o sistema está apto a gerar resultados com exatidão e precisão $(44,46)$.

Os parâmetros para o teste de conformidade do sistema estabelecidos para um procedimento em particular depende do tipo de método a ser validado (TAB. 7) de acordo com um determinado compendio farmacopeico. Por exemplo, na avaliação da conformidade do sistema para a análise de COT deve ser realizada a recuperação de uma substância teste (1,4-benzoquinona), frente a uma substância referência (sacarose) (46).

\subsubsection{Robustez}

O estudo da robustez deve ser considerado durante a fase de desenvolvimento de um método (14).

Pode ser entendido como a susceptibilidade do método analítico em atender à determinação de um teor de uma substância quando submetido a variações nas condições de análise $(8,14,16,46,47,51)$. 
O método é considerado robusto quando não é afetado de forma significativa por alterações pequenas em suas condições analíticas. Com a constatação de susceptibilidade do método, as condições analíticas passam a ser controladas e cuidados nos procedimentos de preparo do ensaio e/ou amostra devem ser incluídos $(44,14)$.

Para a determinação da robustez, os parâmetros analíticos dos métodos devem ser alterados e os resultados obtidos devem ter a sua precisão comparada. A ANVISA e o ICH indicam uma lista de parâmetros a serem avaliados, mas pode-se também utilizar o teste de Youden, recomendado pelo INMETRO, que permite não somente avaliar, mas também ordenar a influência das variações. Quanto maior a robustez, maior será a confiança na precisão do método $(13,47,51,52)$.

\subsubsection{Precisão}

A precisão é definida como a avaliação do grau de concordância entre resultados obtidos em uma série de medidas em uma mesma amostra, sob uma determinada condição analítica $(8,15,43,46,51)$.

Ela é determinada em circunstâncias específicas de medição e os três níveis distintos mais comuns para expressá-la são: repetibilidade, precisão intermediária e reprodutibilidade, sendo a reprodutibilidade realizada nos casos em que um mesmo método é utilizado em diferentes laboratórios $(14,46,47,52)$.

Este parâmetro representa a dispersão de resultados entre ensaios independentes e repetidos em uma mesma amostra, amostras semelhantes ou um padrão (5). Estima-se então a dispersão entre os valores obtidos e o valor médio (13).

Os resultados da precisão de um método analítico devem ser calculados matematicamente pelo cálculo do coeficiente de variação (CV) também chamado de desvio padrão relativo (DPR), determinado pela Eq. 2 $(13,14,51,52)$.

$$
\operatorname{DPR}(\%)=\frac{(D P \times 100)}{C M D}
$$


Onde:

$\mathrm{DPR}=$ desvio padrão relativo

$\mathrm{DP}=$ Desvio padrão

$\mathrm{CMD}=$ Concentração média determinada

\subsubsection{Repetibilidade}

A repetibilidade, também chamada de repetitividade, pode ser expressa quantitativamente pela característica de dispersão de resultados por meio da análise de padrões conhecidos $(44,51,52)$.

As condições de análise para este parâmetro de validação devem permanecer inalteradas quanto a procedimentos de medição, observador, analista, local, instrumento e suas condições. As repetições de análise devem ocorrer no menor espaço de tempo possível $(16,47,52)$.

Para a avaliação deste parâmetro a ICH e a ANVISA recomendam um mínimo de nove determinações analíticas, sendo três replicatas de três padrões diferentes ou seis replicatas de uma mesma amostra $(14,44,46,51)$.

\subsubsection{Precisão Intermediária}

A precisão intermediária refere-se à concordância entre resultados avaliados de uma mesma amostra ou padrão utilizando-se um mesmo método, num mesmo laboratório, obtidos em dias diferentes ou com analistas diferentes $(14,44,46,51,52)$.

Ela é reconhecida como a variabilidade mais representativa de resultados em laboratório, e seu objetivo é avaliar se em um mesmo laboratório o método produz resultados precisos e confiáveis $(44,51)$.

Para a avaliação deste parâmetro a ANVISA recomenda um mínimo de análises em dois dias diferentes enquanto que a $\mathrm{ICH}$ sugere que esta precisão deve ser estabelecida dependendendo das circunstâncias para as quais o procedimento é proposto em um estudo mais complexo envolvendo análises em diferentes dias, em diferentes equipamentos e com diferentes analistas $(13,14,46,51)$. 


\subsubsection{Reprodutibilidade}

Expressa a precisão dos resultados em ensaios utilizando um mesmo método em diferentes laboratórios (46).

\subsubsection{Exatidão}

A exatidão reflete a proximidade entre o valor determinado e o valor de referência, e é relacionado com o erro absoluto de uma medida $(8,13,44,46,51)$.

Para esta avaliação, a ICH e a ANVISA recomendam a execução de no mínimo nove amostras, sendo três replicatas em três amostras de concentração conhecida. A determinação da exatidão do método é feita pela Eq. 3 $(13,14,16,51)$.

$$
\text { Exatidão }(\%)=\frac{(C M D \times 100)}{C T_{1}}
$$

Onde:

$\mathrm{CMD}=$ Concentração média determinada

$\mathrm{CT}_{1}=$ Concentração teórica

\subsubsection{Linearidade}

A linearidade refere-se à capacidade de um método em fornecer resultados diretamente proporcionais à concentração de uma amostra, dentro de uma faixa pré-estabelecida $(14,16,44,46,51)$.

Matematicamente define-se a linearidade de um método a partir da análise de uma curva analítica (geralmente resultante do sinal medido em função da concentração do analito), cuja faixa é definida pela aplicação do método. Obtém-se a equação da reta (Eq. 4) e os coeficientes de regressão, e a partir destes, o coeficiente de correlação linear $(r)$ e a soma residual dos quadrados mínimos da regressão linear $\left(r^{2}\right)$ são calculados $(44,47,51)$. O r e o ${ }^{2}$ podem ser obtidos pelas Eq. 5 e Eq. 6 (13,16). 


$$
\begin{gathered}
y=a x+b \\
r=\frac{\sum(x-\bar{x})(y-\bar{y})}{\sqrt{\left(\sum(x-\bar{x})^{2} \sum(y-\bar{y})^{2}\right)}} \\
r^{2}=\frac{\sum x \cdot y-\left(\sum x\right) \cdot\left(\sum y\right)}{\sqrt{\left[n \sum x^{2}-\left(\sum x\right)^{2}\right] \cdot\left[n \sum y^{2}-\left(\sum y\right)^{2}\right]}}
\end{gathered}
$$

Onde:

$\mathrm{X}=$ concentração do analito

$y=$ intensidade do sinal analítico

$\mathrm{a}=$ coeficiente angular

$\mathrm{b}=$ coeficiente linear

$\mathrm{n}$ = número de pontos da curva

O coeficiente de correlação $(r)$ e a soma residual dos quadrados mínimos de regressão linear $\left(r^{2}\right)$ permitem avaliar a qualidade da curva obtida. Quanto mais próximo de 1,0, menor é a dispersão dos resultados e menor a incerteza na medição em curvas ascendentes $(44,52)$.

A ANVISA recomenda que o coeficiente de correlação seja determinado pela análise de uma curva experimental analítica com, no mínimo, cinco concentrações diferentes e com resultado maior que 0,99 enquanto que 0 INMETRO sugere que este valor seja maior que $0,90(13,44,51,52)$.

\subsubsection{Limite de detecção (LD)}

O Limite de Detecção (LD) representa a menor concentração do analito que pode ser detectado por procedimento experimental, e pode ser determinado de três maneiras: método visual, relação sinal-ruído e baseado em parâmetros da curva analítica $(8,44,51)$.

Os primeiros métodos avaliam parâmetros qualitativos, enquanto que 0 último método é o de maior aplicação em análise instrumental, com a vantagem de avaliar parâmetros quantitativos e envolver cálculos simples, com dados 
obtidos a partir da determinação de curvas analíticas, como expresso pela Eq. 7 $(13,44,51,54)$.

$$
L D=\frac{\left(3 \cdot D P_{a}\right)}{I C}
$$

Onde:

LD = limite de detecção

$\mathrm{DP}_{\mathrm{a}}=$ desvio padrão do coeficiente de regressão linear

IC = média de coeficiente angular

O LD para um método pode variar em função do tipo de amostra. Para - INMETRO, o limite de detecção deve ser suficiente para fornecer indicação onde o nível de detecção do analito pode ser distinguido do sinal do branco (52).

\subsubsection{Limite de quantificação (LQ)}

O Limite de Quantificação (LQ) representa a menor concentração que pode ser medida considerando-se os limites de precisão e exatidão do método, em condições normais, com precisão e exatidão aceitáveis $(13,44,51)$.

Os mesmos métodos adotados para a determinação do LD podem ser adotados para o LQ: método visual, relação sinal-ruído e baseado em parâmetros da curva analítica (44). O LQ pode ser determinado pela Eq. 8 (14,51).

$$
L Q=\frac{\left(10 \cdot D P_{a}\right)}{I C}
$$

O LQ é parâmetro característico de métodos analíticos quantitativos para impurezas e produtos de degradação de princípios ativos de medicamentos. Ambos LD e LQ são expressos como concentração do analito na amostra $(8,14)$. 


\section{MATERIAIS E MÉTODOS}

\subsection{Equipamentos}

Todos os ensaios de determinação de COT foram realizados utilizandose um analisador de carbono modelo TOC-Vwp acoplado a um amostrador automático modelo ASI-V, ambos da marca Shimadzu ${ }^{\circledR}$ e controlados por software TOC Control-V Shimadzu ${ }^{\circledR}$. O gás de arraste utilizado foi o nitrogênio $\left(\mathrm{N}_{2}\right)$, grau 5.0 analítico (White Martins). Os dados foram analisados através dos softwares TOC Control-V Shimadzu ${ }^{\circledR}$, Origin $\left(\right.$ Microcal $^{\circledR}$ ) e Microsoft Excel.

pHmetro e condutivímetro modelo SevenEasy (Mettler Toledo ${ }^{\circledR}$ ) foram calibrados com padrões de $\mathrm{pH} 4,0 ; 7,0$ e 9,0 e padrão de condutividade de $84 \mu \mathrm{S} . \mathrm{cm}^{-1}$, respectivamente de acordo com requisitos para instrumentos de medição.

Bomba de filtração Milliflex (Millipore ${ }^{\circledR}$ ), funil de filtração estéril e descartável com filtro $0,45 \mu \mathrm{m}$ e meio de cultura R2A ágar (Millipore ${ }^{\circledR}$ ) foram utilizados para análise microbiana de contagem de aeróbios totais, conforme metodologia descrita na USP 35.

Os ensaios de $\mathrm{pH}$, condutividade e contagem de aeróbios totais foram realizados como parte dos requisitos compendiais de análise de AP e API e seus resultados foram utilizados apenas como indicadores de qualidade.

\subsubsection{Características do analisador de carbono}

O equipamento utilizado neste trabalho determinou a concentração de COT pelo método indireto, combinando reações de acidificação e de oxidação química para análise de $\mathrm{Cl}$ e $\mathrm{CT}$, respectivamente.

Por meio do amostrador automático de 8 portas as alíquotas da amostras são transferidas para os diferentes reatores onde ocorrem as reações.

Por exemplo, a reação de oxidação do ftalato de potássio $\left(\mathrm{C}_{8} \mathrm{H}_{5} \mathrm{O}_{4} \mathrm{~K}\right)$ por persulfato em meio ácido, catalisada por luz UV, em um reator úmido aquecido a 80,0 \pm 0,5 ${ }^{\circ} \mathrm{C}$ com produção de $\mathrm{CO}_{2}$ pode ser descrita pela Eq. 9: $\mathrm{O}$ $\mathrm{CO}_{2}$ produzido correspondeu ao carbono total (CT). 


$$
\mathrm{C}_{8} \mathrm{H}_{5} \mathrm{O}_{4} \mathrm{~K}+\mathrm{Na}_{2} \mathrm{~S}_{2} \mathrm{O}_{8} \stackrel{\Delta, \mathrm{UV}}{=} \mathrm{CO}_{2}+\text { Subprodutos }
$$

$\mathrm{O} \mathrm{CO}_{2}$ resultante foi transportado pelo gás de arraste, $\mathrm{N}_{2}$, passando por um desumidificador, um depurador de halógenos para retirar qualquer halógeno interferente na medição e por uma membrana filtrante chegando ao detector, uma célula de IVND, onde produziu um sinal. A área do pico foi calculada relacionando esta a uma determinada concentração de CT.

Para o cálculo da concentração de $\mathrm{Cl}$, a reação de acidificação para produção de $\mathrm{CO}_{2}$ ocorreu em outro reator, a frio e a alíquota da amostra foi transportada para este reator por meio do amostrador automático de 8 portas.

As reações de acidificação de $\mathrm{Na}_{2} \mathrm{CO}_{3}$ e $\mathrm{NaHCO}_{3}$ podem ser representadas pelas Eq. 10 e 11:

$$
\begin{gathered}
3 \mathrm{Na}_{2} \mathrm{CO}_{3}+3 \mathrm{H}_{3} \mathrm{PO}_{4} \longrightarrow 2 \mathrm{Na}_{3} \mathrm{PO}_{4}+3 \mathrm{CO}_{2}+2 \mathrm{H}_{2} \mathrm{O} \\
2 \mathrm{Na}_{2} \mathrm{HCO}_{3}+\mathrm{H}_{3} \mathrm{PO}_{4} \longrightarrow \mathrm{Na}_{2} \mathrm{HPO}_{4}+2 \mathrm{CO}_{2}+2 \mathrm{H}_{2} \mathrm{O}
\end{gathered}
$$

Semelhantemente ao que ocorreu em CT, $\quad \mathrm{CO}_{2}$ resultante foi transportado pelo gás de arraste até a célula de IVND. A área do pico foi calculada relacionando esta a uma determinada concentração de $\mathrm{Cl}$.

Uma vez determinadas as concentrações de CT e $\mathrm{Cl}$, O COT foi calculado utilizando-se a Eq. 1 (pag. 33).

O esquema do analisador de carbono está representado na FIG. 2. 


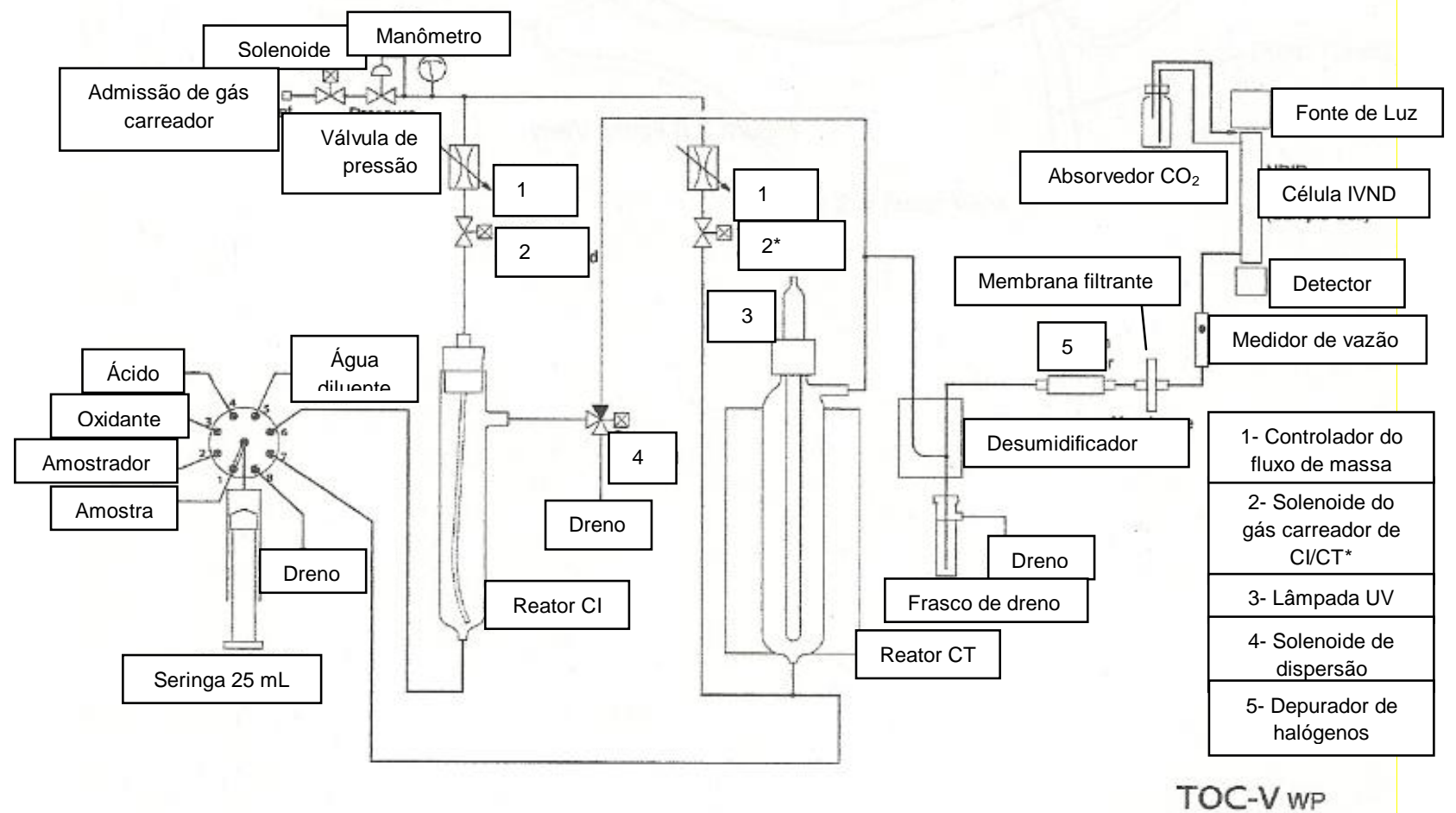

FIGURA 2 - Esquema do analisador de carbono.

\subsection{Materiais e reagentes}

\subsubsection{Validação e coleta de amostras}

A AP utilizada no preparo das soluções, como "branco" e como diluente, foi obtida de um sistema Elix-10 (Millipore ${ }^{\circledR}$ ) acoplado a um reservatório de $30 \mathrm{~L}$, com iluminação UV acionada durante 30 minutos a cada 24 horas.

As soluções de reagente oxidante (solução de $\mathrm{Na}_{2} \mathrm{~S}_{2} \mathrm{O}_{3} 0,5 \mathrm{~mol} \mathrm{~L}^{-1}$ ) e acidificante (solução de $\mathrm{H}_{3} \mathrm{PO}_{4} 3,0 \mathrm{~mol} \mathrm{~L}^{-1}$ ), de COT/CT (ftalato de potássio $\mathrm{C}_{8} \mathrm{H}_{5} \mathrm{O}_{4} \mathrm{~K}$ ), de $\mathrm{Cl}$ (mistura de carbonato de sódio $-\mathrm{Na}_{2} \mathrm{CO}_{3}$ e bicarbonato de sódio - $\mathrm{NaHCO}_{3}$ ) foram preparadas com reagentes PA (Merck). Separadamente, foram preparadas soluções estoque de COT/CT ou $\mathrm{Cl}$ na concentração de $50 \mathrm{mg} \mathrm{L}^{-1}$ para obtenção da curva analítica na faixa de 100-1000 $\mu \mathrm{g} \mathrm{L}^{-1}$.

Os frascos de $40 \mathrm{~mL}$ específicos para o amostrador do analisador de carbono foram utilizados para coleta de amostra para análise de COT. Estes frascos e os balões volumétricos utilizados no preparo dos reagentes foram lavados com AP e mantidos em solução $\mathrm{HNO}_{3} 15 \%$ por 24 horas. O material não volumétrico foi submetido à secagem e aquecimento em estufa a $60-80 \stackrel{\circ}{\circ}$ até 0 momento de sua utilização. A vidraria volumétrica calibrada foi seca em 
temperatura ambiente. Para coleta da amostra de água para a realização do ensaio microbiológico, e determinação de $\mathrm{pH}$ e condutividade, foi utilizado um frasco de vidro autoclavável de $500 \mathrm{~mL}$ e para a análise de endotoxina bacteriana foi utilizado um tubo apirogênico de $3 \mathrm{~mL}$.

Pinça, pano de limpeza Wipers Wypall X70 (Kimberly Clark $^{\circledR}$ ) e micropipeta foram autoclavados para utilização na análise microbiológica. Reagente LAL (Endosafe), tubos apirogênicos e endotoxina padrão e água apirogênica foram utilizados no ensaio de endotoxina bacteriana.

\subsubsection{Conformidade do sistema (System Suitability)}

As soluções de 1,4-benzoquinona $\left(\mathrm{C}_{6} \mathrm{H}_{4} \mathrm{O}_{2}\right)$ e sacarose $\left(\mathrm{C}_{12} \mathrm{H}_{22} \mathrm{O}_{11}\right)$ na concentração de $500 \mu \mathrm{gL}^{-1}$ foram preparadas a partir de padrões USP.

\subsection{Métodos}

\subsubsection{Método de amostragem de água}

A amostragem foi realizada após limpeza da saída de água (torneira) com álcool isopropílico $70 \% \mathrm{v} / \mathrm{v}$, seguida de drenagem da água do reservatório por três minutos para eliminar resíduos de álcool e obter amostra de água representativa daquela armazenada no reservatório, e enxágue por duas vezes de cada um dos frascos de coleta (ensaio microbiológico e dos frascos para análise de COT) com a água a ser analisada. O procedimento de amostragem de água produzida por alguns purificadores está representado no fluxograma na FIG.

3. 


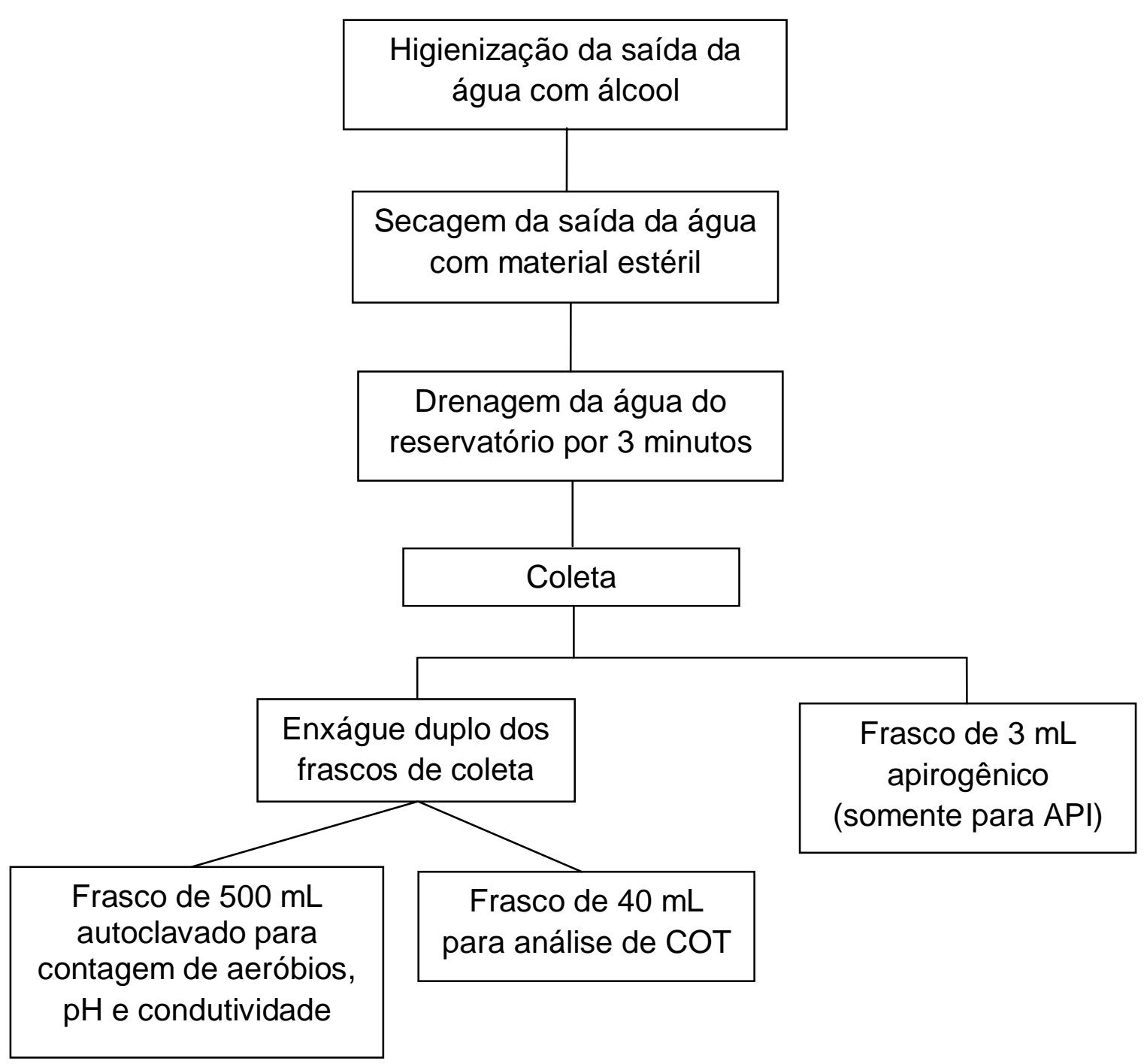

FIGURA 3 - Fluxograma de amostragem de água.

\subsubsection{Validação do método de determinação de COT}

Os parâmetros analisados estão descritos a seguir.

\subsubsection{Conformidade do sistema (System suitability)}

Para avaliação da conformidade de sistema, foram analisadas as soluções padrões de sacarose e 1,4-benzoquinona, preparados a partir de reagentes grau USP, nas concentrações de $500 \mu \mathrm{g} \mathrm{L}^{-1}$ e os resultados de COT foram aplicados na Eq. 12 para a obtenção da porcentagem SS\%. 


$$
S S_{\%}=100 \frac{\left(R_{B Z}-R_{B}\right)}{\left(R_{S}-R_{B}\right)}
$$

Onde:

$\mathrm{R}_{\mathrm{BZ}}=$ Concentração da solução de 1,4-benzoquinona

$\mathrm{R}_{\mathrm{B}}=$ Concentração da solução branco

$\mathrm{R}_{\mathrm{S}}=$ Concentração da solução de sacarose

\subsubsection{Robustez}

Quatro parâmetros do método de análise foram avaliados neste ensaio: Volume de solução oxidante (em $\mathrm{mL}$ ), volume de solução acidificante (em \%) e tempos de integração das áreas para o cálculo de CT e Cl (em minutos), considerando que estes são variáveis no software que controla o equipamento.

Os volumes de solução oxidante avaliados foram 0,$5 ; 1,0 ; 1,5 ; 2,0$ e $2,5 \mathrm{~mL}$ e de solução acidificante foram 1,0;1,5; 3,0; 4,0 e 5,0\%. Para a avaliação do efeito do volume de solução oxidante foram utilizadas soluções de CT (ftalato de potássio) e para avaliação do volume de solução acidificante, soluções de Cl (carbonato/bicarbonato de sódio).

Os tempos de integração das áreas para cálculo de CT e Cl foram avaliados separadamente, uma vez que a concentração de cada um dos tipos de carbono é calculada individualmente. Os tempos de integração foram 2, 3, 4, 5 e 10 minutos para CT e 2, 3, 5 e 10 minutos para Cl.

Foi feita a comparação entre o valor nominal de uma amostra de ftalato de potássio (COT/CT) de concentração $250 \mu \mathrm{g} \mathrm{L}^{-1}$ e o valor calculado. O valor calculado foi obtido após subtração do resultado da média de triplicata pelo "branco".

Para cada condição de análise (volume de solução oxidante, acidificante ou tempo de integração de área para o cálculo de CT ou CI) foram obtidas curvas analíticas. Para a avaliação dois primeiros parâmetros foram utilizadas soluções de CT ou Cl de 100, 250, 500 e $1000 \mu \mathrm{g} \mathrm{L}^{-1}$ enquanto para os dois últimos parâmetros foram utilizadas soluções de CT ou CI nas concentrações 250 e $1000 \mu \mathrm{g} \mathrm{L}^{-1}$. Cada solução foi analisada em triplicata e o CV foi calculado. As curvas analíticas foram avaliadas pela equação da reta e a soma residual dos 
quadrados mínimos de regressão linear $\left(r^{2}\right)$. As condições de análise que apresentaram menor CV entre o valor nominal e o obtido e o $r^{2}$ mais próximo de 1 foram escolhidas para serem utilizadas no método de análise de COT em água.

\subsubsection{Repetibilidade, precisão intermediária e exatidão}

Foram utilizados soluções de CT nas concentrações 100, 500 e $1000 \mu \mathrm{g} \mathrm{L}^{-1}$ e soluções de Cl nas concentrações 250, 500 e $1000 \mu \mathrm{g} \mathrm{L}^{-1}$, para avaliação de repetibilidade (intradia) e precisão intermediária (interdia). Cada solução foi analisada em triplicata por dois dias seguidos. A repetibilidade e a precisão intermediária foram obtidas calculando-se o desvio padrão relativo (DPR) entre as triplicatas e utilizando-se a Eq. 2 (pag. 37), enquanto a exatidão foi obtida utilizando a Eq. 3 (pag. 39).

\subsubsection{Linearidade}

Utilizando-se soluções padrão de CT e CI nas concentrações "branco", $100,250,500$ e $1000 \mu \mathrm{g} \mathrm{L}^{-1}(\mathrm{n}=5)$ foram obtidas as respectivas curvas analíticas. O $\mathrm{r}^{2}$ destas curvas foi obtido pelo software TOC Control-V. Para CT ou CI foram obtidas três curvas analíticas.

\subsubsection{Limite de detecção (LD) e limite de quantificação (LQ)}

Os LD e LQ foram calculados utilizando-se a média dos coeficientes angulares (IC) e o DP dos coeficientes lineares $\left(D^{a}\right)$ das curvas analíticas $(n=3)$ obtidas no ensaio de linearidade, conforme representado nas Eq. 6 (pag. 40 ) e Eq. 7 (pag. 41).

\subsubsection{Avaliação de desempenho dos sistemas purificadores de água instalados na DIRF}

Foi avaliado o teor de COT, condutividade, $\mathrm{pH}$ e aeróbios totais, na água produzida por sistemas purificadores de água instalados na DIRF no período de 12 meses para avaliação do desempenho, totalizando 92 análises (20092010). As coletas foram realizadas conforme diagrama representado na FIG. 4, extraído do protocolo de validação dos sistemas purificadores de água na parte de qualificação de desempenho. O protocolo foi elaborado por empresa contratada para este fim. 


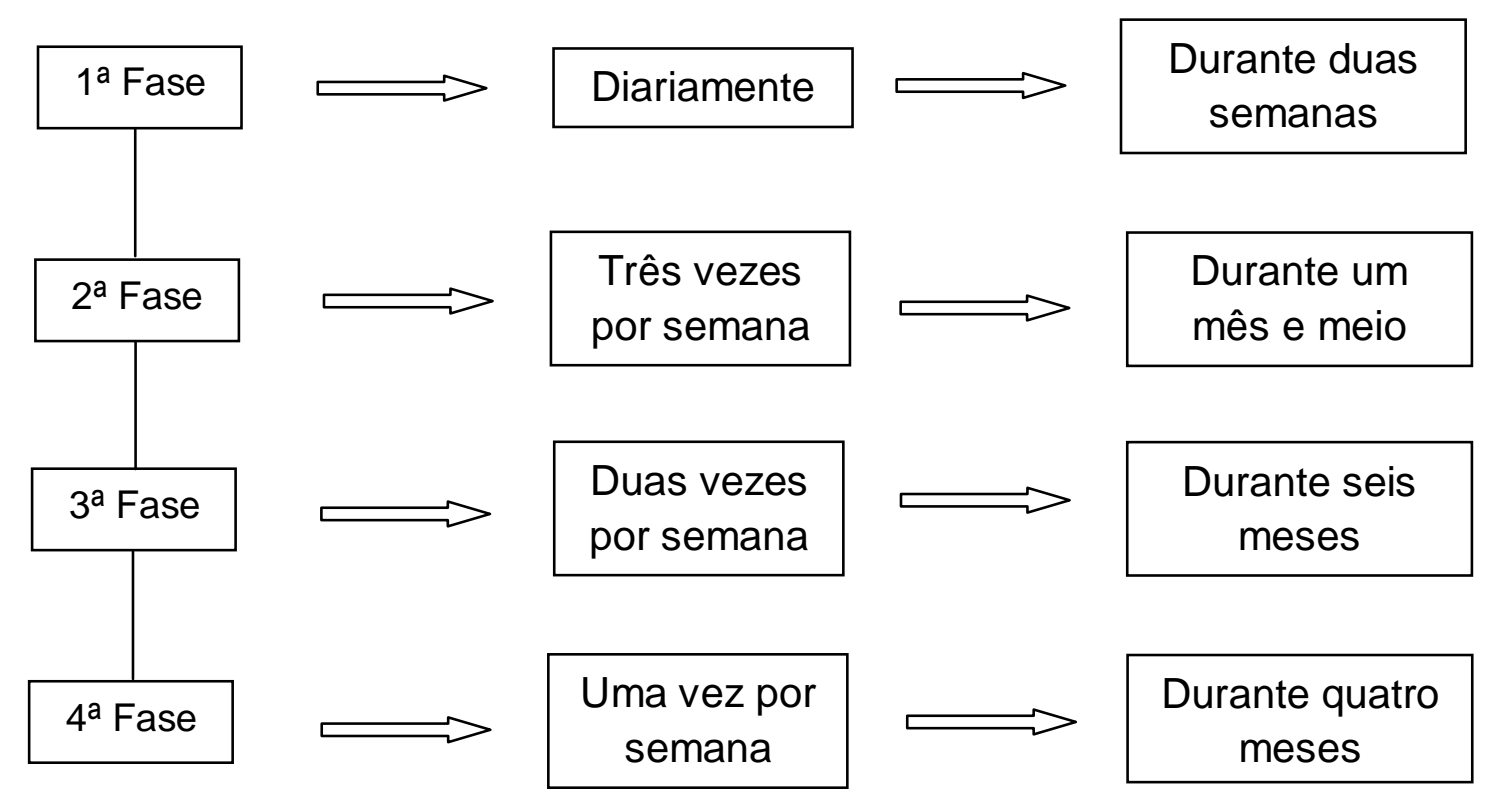

FIGURA 4 - Esquema de coletas para avaliação de desempenho dos sistemas purificadores de água durante 12 meses.

Para alguns pontos de coleta foi feita uma avaliação de desempenho durante 45 dias, seguindo-se o esquema da FIG. 5.

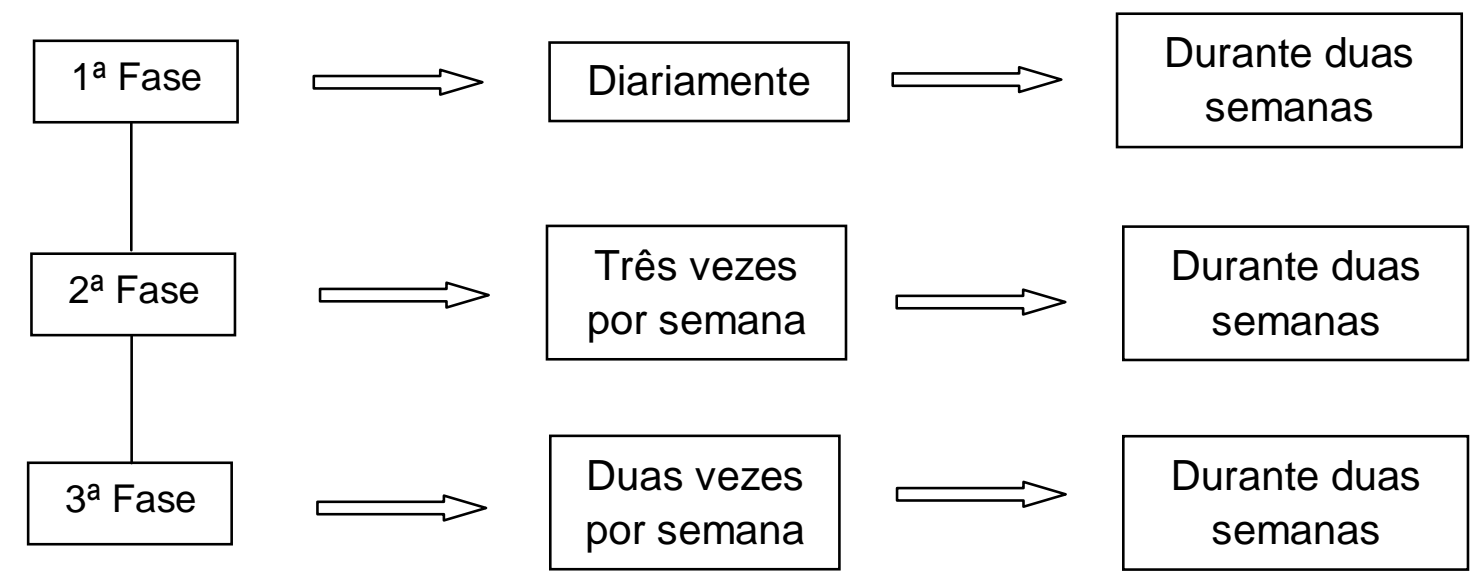

FIGURA 5 - Esquema de coletas para avaliação de desempenho dos sistemas purificadores de água durante 45 dias.

Os sistemas purificadores de água apresentaram os seguintes pontos principais: 


\subsubsection{Ponto A}

Ponto de coleta AP produzida por um equipamento de purificação por osmose reversa e eletrodeionização, com pré-filtração por filtro misto de pirofosfato de celulose e carvão ativo de $1 \mu \mathrm{m}$, e acoplado a um reservatório de $30 \mathrm{~L}$, com sistema de iluminação e sanitização por luz UV acionado por 30 minutos a cada 24 horas. A coleta de água foi feita na saída do reservatório. $O$ equipamento e seu ponto de coleta estão dispostos na FIG. 6.

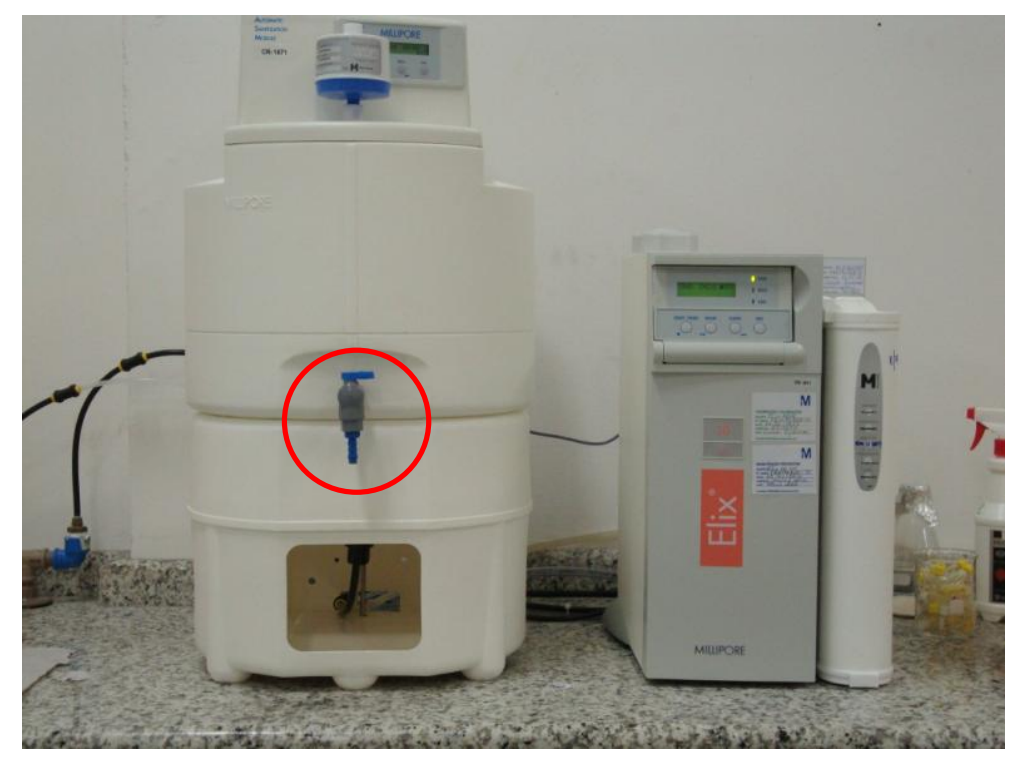

FIGURA 6 - Ponto A.

\subsubsection{Ponto B}

Ponto de coleta de AP produzida por um equipamento similar ao descrito no item (A), acoplado a um reservatório de $100 \mathrm{~L}$ com sistema de agitação e iluminação - sanitização por luz UV. A coleta de água foi feita na saída do reservatório. O equipamento e seu ponto de coleta estão dispostos na FIG. 7. 


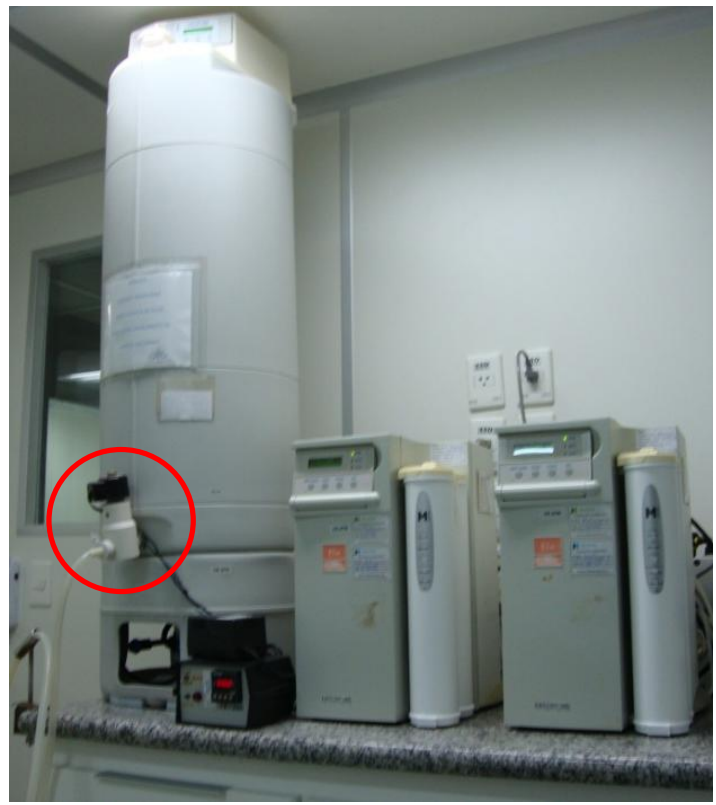

FIGURA 7 - Ponto B.

\subsubsection{Ponto C}

Ponto de coleta de AP produzida por um equipamento similar ao descrito no item (A). A coleta de água foi feita na saída do reservatório. O equipamento e seu ponto de coleta estão dispostos na FIG. 8.

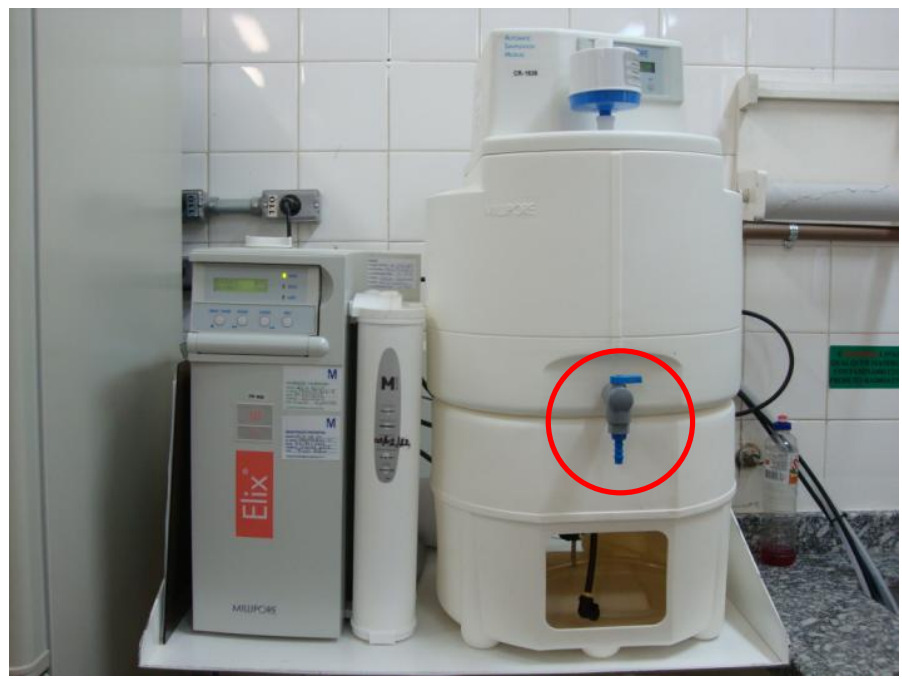

FIGURA 8 - Ponto C.

\subsubsection{Ponto D}

Ponto de coleta de API produzida por um equipamento com foto oxidação por luz UV (185-254 nm) e filtração por membrana de 0,22 $\mu \mathrm{m}$, 
alimentado pela água produzida no equipamento da FIG. 8. A coleta de água foi realizada na saída do sistema. O equipamento e seu ponto de coleta estão dispostos na FIG. 9.

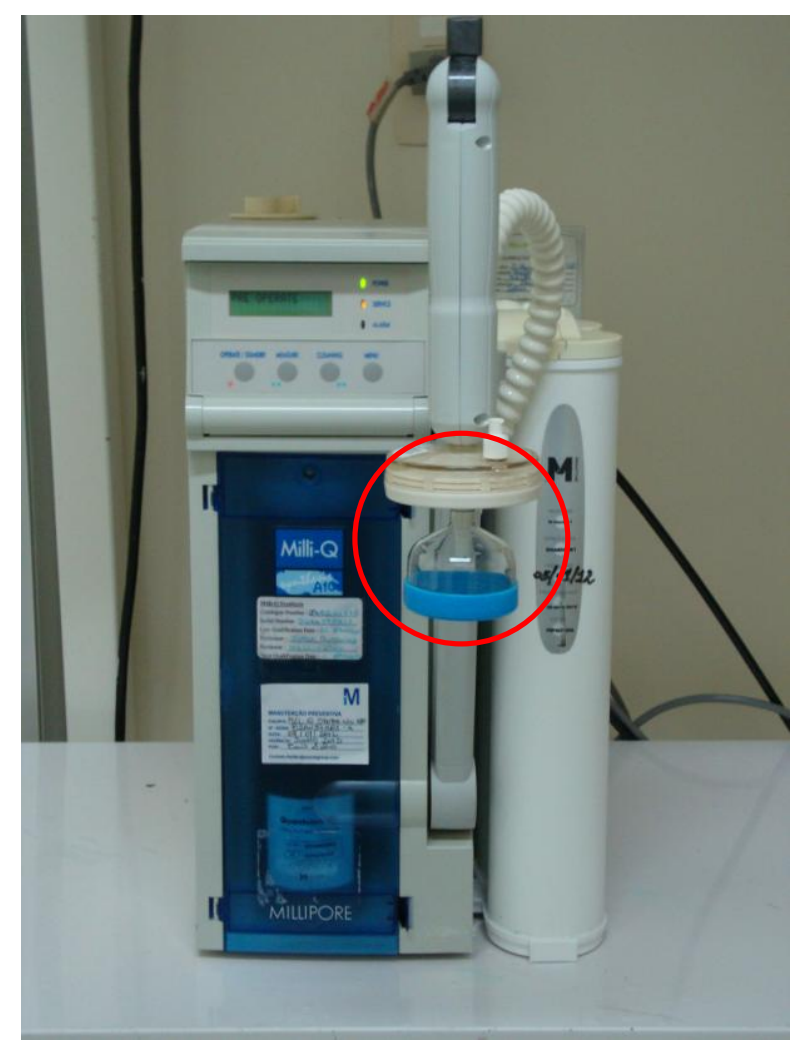

FIGURA 9 - Ponto D.

\subsubsection{Ponto E}

Ponto de coleta de API produzida por um purificador, com sistema de pré-filtração por filtros de celulose e carvão ativo de 5 e10 $\mu \mathrm{m}$ e purificação por osmose reversa duplo-passo com coluna deionizante. A coleta de água foi feita na saída do sistema de purificação, antes de ser armazenada em reservatório. $O$ equipamento e seu ponto de coleta estão dispostos na FIG. 10. 


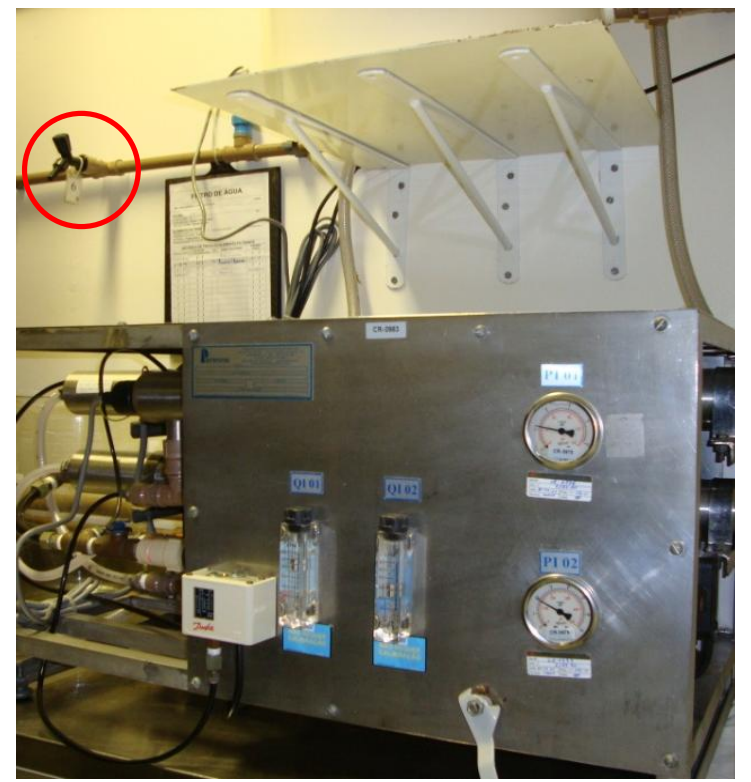

FIGURA 10 - Ponto E.

\subsubsection{Ponto F}

Ponto de coleta de API produzida pelo equipamento da FIG. 10 após o reservatório de $100 \mathrm{~L}$ sem sistema de iluminação por luz UV e agitação, no sistema de distribuição constituído com tubulação de policloreto de vinila (PVC). O equipamento e seu ponto de coleta estão dispostos na FIG. 11.

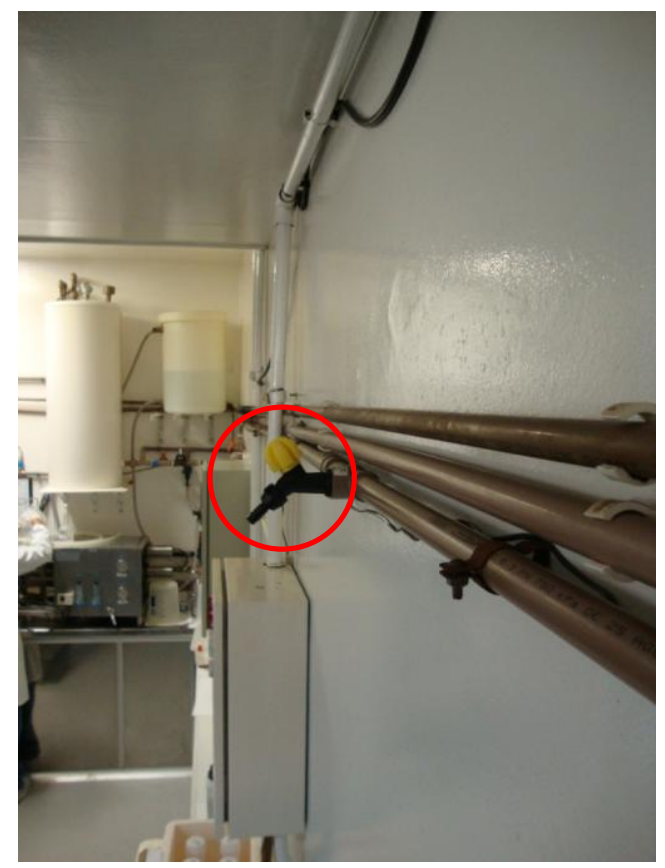

FIGURA 11 - Ponto F. 


\subsubsection{Análise de qualidade de API adquirida de fornecedores externos}

Algumas amostras de API embaladas em bolsas plásticas de volume de 250 a $1000 \mathrm{~mL}$ adquiridas de fornecedores externos foram analisadas contemplando COT, $\mathrm{pH}$, condutividade e análise microbiana para contagem de aeróbios totais. 


\section{RESULTADOS E DISCUSSÃO}

\subsection{Validação do método de determinação de COT}

O método para determinação de COT foi validado de acordo com as recomendações da norma RE no 899 de 29 de maio de 2003: Guia para validação de métodos analíticos e bioanalíticos, da ANVISA (7). Os parâmetros de validação seguiram as atribuições da categoria II da norma: Testes quantitativos ou ensaio limite para a determinação de impurezas e produtos de degradação em produtos farmacêuticos e matérias-primas, uma vez que COT é considerado uma impureza e o método analítico é quantitativo.

As soluções reagentes foram preparadas com AP com teor de COT menor que $100 \mu \mathrm{g} \mathrm{L}^{-1}$.

\subsubsection{Conformidade do sistema}

O objetivo do teste de conformidade do sistema foi averiguar a capacidade do método em quantificar a concentração de soluções de complexidade e estabilidades diferentes. A sacarose apresenta estabilidade em solução enquanto a 1,4-benzoquinona apresenta instabilidade em solução e fotossensibilidade (14). A estrutura molecular da sacarose e da 1,4-benzoquinona estão representadas na FIG. 12 e 13, respectivamente.

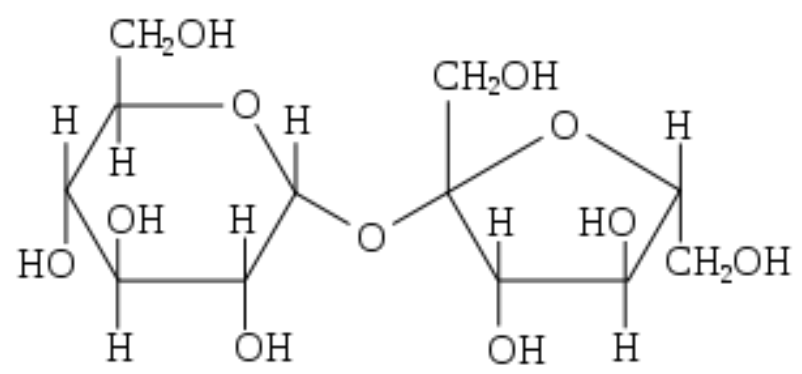

FIGURA 12 - Estrutura molecular da sacarose. 


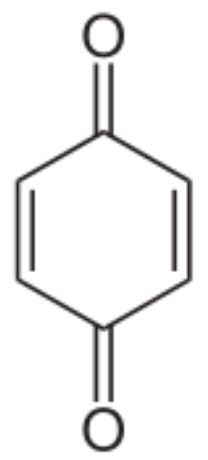

FIGURA 13 - Estrutura molecular da 1,4-benzoquinona.

O SS\% obtido foi de 106,21\% atendendo à faixa aceitável da farmacopeia americana (85-115\%) (10).

\subsubsection{Robustez}

Quatro parâmetros que necessitam ser definidos no analisador de carbono para a análise de COT foram alterados considerando-se os valores recomendados pelo fabricante. A influência da variação de cada um dos parâmetros no resultado de teor de carbono de soluções de concentração conhecida (CT, COT ou Cl) foi avaliada separadamente.

Os resultados obtidos foram expressos em tabelas e em gráficos. Cada condição de análise foi realizada em quintuplicata $(n=5)$ ou triplicata $(n=3)$. As condições experimentais dos parâmetros foram: volume de solução oxidante $1,5 \mathrm{~mL}$, volume de solução acidificante $3,0 \%$, tempo de integração da curva para o cálculo de TC 5,0 minutos e tempo de integração da curva para o cálculo de CI 3,5 minutos.

\subsubsection{Volume de solução oxidante}

O teor de COT resultante da análise de uma solução de CT de $250 \mu \mathrm{g} \mathrm{L}^{-1}$, variando-se $\mathrm{o}$ volume do oxidante $\mathrm{Na}_{2} \mathrm{~S}_{2} \mathrm{O}_{8} \quad 0,5 \mathrm{~mol} \mathrm{~L}^{-1}$ pode ser visualizado na FIG. 14. 


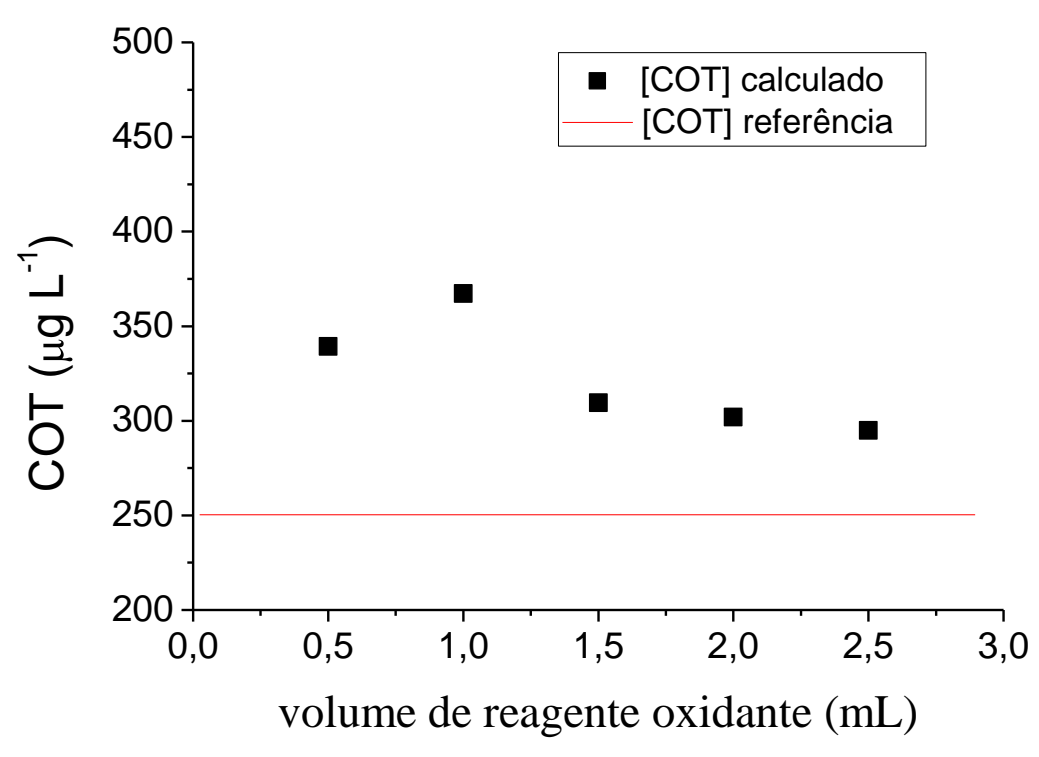

FIGURA 14 - Efeito da variação do volume de oxidante na análise de uma solução de COT/ CT de $250 \mu \mathrm{g} \mathrm{L}^{-1}(\mathrm{n}=5)$

Na FIG. 14 observou-se que os resultados de CT mais próximos do valor nominal de $250 \mu \mathrm{g} \mathrm{L}^{-1}$ foram obtidos com volume de oxidante na faixa de 1,5 a $2,5 \mathrm{~mL}$. Volumes de oxidante menores que $1,5 \mathrm{~mL}$ interferiram na análise de COT, com resultados maiores que o valor nominal.

A TAB. 8 relaciona os parâmetros das curvas analíticas (CV mínimo e máximo entre as triplicatas e $\mathrm{r}^{2}$ ) com a variação do volume de oxidante.

TABELA 8 - Efeito da variação do volume de solução oxidante na obtenção da curva analítica de CT.

\begin{tabular}{ccccc}
\hline $\begin{array}{c}\text { Volume de } \\
\text { Oxidante } \\
(\mathbf{m L})\end{array}$ & $\begin{array}{c}\text { CV Mínimo } \\
(\%)\end{array}$ & $\begin{array}{c}\text { CV Máximo } \\
(\%)\end{array}$ & $\begin{array}{c}\text { Equação da reta } \\
(\mathbf{y}=\mathbf{a x}+\mathbf{b})\end{array}$ & $\mathbf{r}^{\mathbf{2}}$ \\
\hline $\mathbf{0 , 5}$ & 2,0 & 17,1 & Área $=0,17[\mathrm{CT}]+45,76$ & 0,990 \\
$\mathbf{1 , 0}$ & 2,5 & 9,4 & Área $=0,16[\mathrm{CT}]+52,04$ & 0,994 \\
$\mathbf{1 , 5 ^ { * }}$ & 7,1 & 14,0 & Área $=0,16[\mathrm{CT}]+69,51$ & 0,853 \\
$\mathbf{2 , 0}$ & 0,5 & 4,6 & Área $=0,16[\mathrm{CT}]+47,73$ & 0,998 \\
$\mathbf{2 , 5}$ & 2,6 & 13,5 & Área $=0,16[\mathrm{CT}]+38,48$ & 0,996 \\
\hline
\end{tabular}


O volume de $1,5 \mathrm{~mL}$ recomendado pelo fabricante foi inadequado para compor o método, com $r^{2}$ menor que 0,9 . A menor faixa de variação de CV $(0,5-$ $4,6 \%$ ) foi obtida com volume de oxidante de $2,0 \mathrm{~mL}$, com boa correlação entre os pontos e $r^{2}$ de 0,998 . Outros volumes de oxidante resultaram em CV acima de $5,0 \%$.

A combinação dos resultados obtidos na FIG 14 e na TAB. 8 resultaram na escolha de volume de oxidante de 2,0 mL

\subsubsection{Volume de solução acidificante}

A variação de volume de solução acidificante $\left(\mathrm{H}_{3} \mathrm{PO}_{4}\right) 3,0 \mathrm{~mol} \mathrm{~L} \mathrm{~L}^{-1}$ na análise de uma solução de COT com concentração $250 \mu \mathrm{g} \mathrm{L}^{-1}$ resultou nos dados observados na FIG. 15.

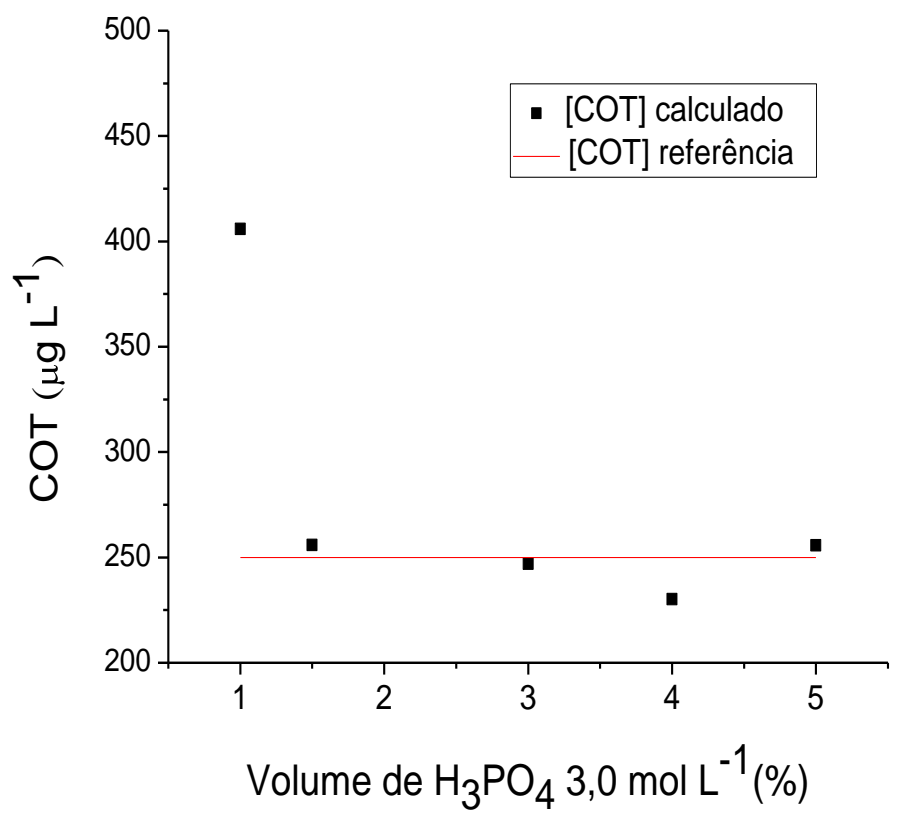

FIGURA 15 - Efeito da variação do volume de solução acidificante na análise de solução de COT de $250 \mu \mathrm{g} \mathrm{L}^{-1}(\mathrm{n}=5)$.

Na FIG. 15 observou-se que os resultados de COT mais próximos do valor nominal (250 $\mathrm{g} \mathrm{L} \mathrm{L}^{-1}$ ) foram obtidos com volumes de solução acidificante acima de $1,5 \%$.

Cerca de $1,0 \%$ de solução acidificante foram insuficientes para reagir com o $\mathrm{Cl}$ de uma solução de $250 \mu \mathrm{g} \mathrm{L}^{-1}$ e volumes maiores que $1,5 \%$ não apresentaram interferência no método analítico. 
A TAB. 9 relaciona os parâmetros das curvas analíticas (CV mínimo e máximo entre as triplicatas e $r^{2}$ ) com a variação do volume da solução acidificante.

TABELA 9 - Efeito da variação do volume de solução acidificante na obtenção da curva analítica de Cl.

\begin{tabular}{ccccc}
\hline $\begin{array}{c}\text { Volume de } \\
\text { Acidificante } \\
(\%)\end{array}$ & $\begin{array}{c}\text { CV Mínimo } \\
(\%)\end{array}$ & $\begin{array}{c}\text { CV Máximo } \\
(\%)\end{array}$ & $\begin{array}{c}\text { Equação da reta } \\
(\mathbf{y}=\mathbf{a x}+\mathbf{b})\end{array}$ & $\mathbf{r}^{2}$ \\
\hline $\mathbf{1 , 0}$ & 0,3 & 2,4 & Área $=0,17[\mathrm{Cl}]+30,08$ & 0,999 \\
$\mathbf{1 , 5}$ & 0,6 & 1,5 & Área $=0,22[\mathrm{Cl}]+27,73$ & 0,9995 \\
$\mathbf{3 , 0 *}$ & 0,2 & 0,7 & Área $=0,17[\mathrm{Cl}]+29,97$ & 0,998 \\
$\mathbf{4 , 0}$ & 0,3 & 1,3 & Área $=0,27[\mathrm{Cl}]+32,44$ & 0,9994 \\
$\mathbf{5 , 0}$ & 0,2 & 0,8 & Área $=0,16[\mathrm{Cl}]+24,47$ & 0,9995 \\
\hline
\end{tabular}

$(\mathrm{n}=5)$ para cada condição

${ }^{\star}$ Recomendado pelo fabricante

O menor CV foi obtido com a utilização de volume de acidificante igual a 3,0 e $5,0 \%$. A variação de volume de oxidante resultou em CV relativamente baixo e $r^{2}$ acima de 0,99 em todos os casos, indicando que a quantidade de acidificante, não interfere significativamente na obtenção de curva analítica de $\mathrm{Cl}$.

Considerando os resultados da FIG. 15 e TAB. 9, o volume de acidificante de 3,0 \% foi escolhido para compor o método de análise de COT.

\subsubsection{Tempo de integração da área da curva para o cálculo de CT}

A reação de oxidação de carbono orgânico produz $\mathrm{CO}_{2}$, que é então detectado pelo IVND. O parâmetro aqui avaliado foi o tempo considerado para a integração sob a curva de resposta do detector, no cálculo de CT. O perfil da curva do sinal de $\mathrm{CO}_{2}$ para CT está representado na FIG. 16. 


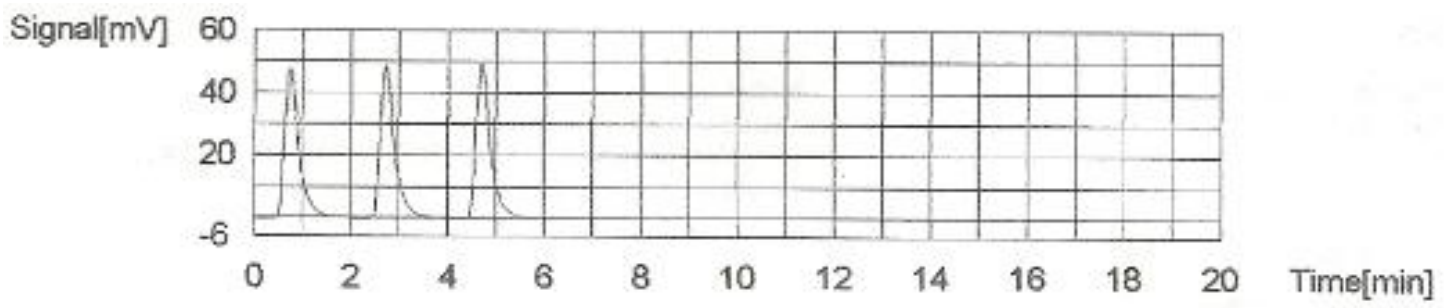

FIGURA 16 - Perfil da curva do sinal de $\mathrm{CO}_{2}$ para CT.

Os resultados de COT na análise de uma solução de concentração $250 \mu \mathrm{g} \mathrm{L}^{-1}$, modificando-se o tempo de integração da área sob a curva do sinal de CT podem ser observados na FIG. 17:

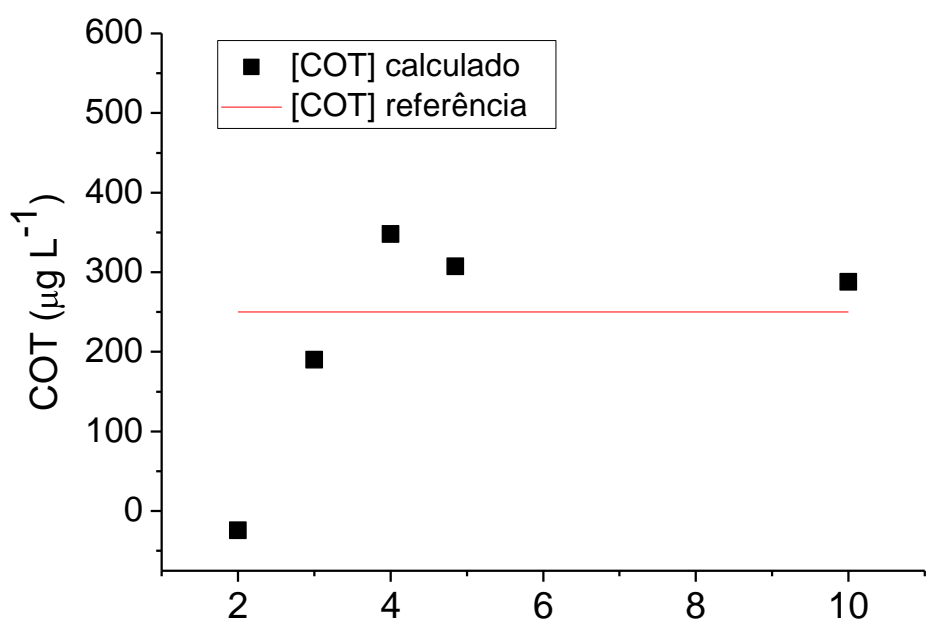

Tempo de integraçっo da curva de CT (min)

FIGURA 17 - Efeito da variação do tempo de integração da curva para o cálculo de CT, na análise de solução de COT de $250 \mu \mathrm{g} \mathrm{L}^{-1}(\mathrm{n}=3)$.

Tempos de integração menores que 4 minutos foram insuficientes para integrar a área do sinal de $\mathrm{CO}_{2}$ resultante da reação de oxidação do ftalato de potássio. Isto provavelmente ocorreu devido à cinética da reação de oxidação que é relativamente lenta (FIG. 16) quando comparada à reação de acidificação de $\mathrm{Cl}$ para produção de $\mathrm{CO}_{2}$. 
A TAB. 10 relaciona os parâmetros das curvas analíticas (CV mínimo e máximo entre as triplicatas $e^{2}$ ) com a variação do tempo de integração da área da curva para o cálculo de CT.

TABELA 10 - Efeito da variação do tempo de integração da área sob a curva no cálculo de CT, para a obtenção da curva analítica de CT.

\begin{tabular}{ccccc}
\hline $\begin{array}{c}\text { Tempo de } \\
\text { integração } \\
(\mathbf{m i n})\end{array}$ & $\begin{array}{c}\text { CV Mínimo } \\
(\%)\end{array}$ & $\begin{array}{c}\text { CV Máximo } \\
(\%)\end{array}$ & $\begin{array}{c}\text { Equação da reta } \\
(\mathbf{y}=\mathbf{a x}+\mathbf{b})\end{array}$ & $\mathbf{r}^{\mathbf{2}}$ \\
\hline $\mathbf{2}$ & 1,4 & 7,9 & Área $=0,18[\mathrm{CT}]+28,17$ & 1,000 \\
$\mathbf{3}$ & 1,0 & 7,0 & Área $=0,13[\mathrm{CT}]+42,70$ & 0,968 \\
$\mathbf{4}$ & 1,8 & 10,9 & Área $=0,11[\mathrm{CT}]+44,88$ & 0,988 \\
$\mathbf{5}^{*}$ & 5,5 & 19,3 & Área $=0,10[\mathrm{CT}]+36,81$ & 0,9992 \\
$\mathbf{1 0}$ & 0,9 & 6,0 & Área $=0,15[\mathrm{CT}]+38,78$ & 0,9993 \\
\hline
\end{tabular}

$(\mathrm{n}=3)$ para cada condição

${ }^{\star}$ Recomendado pelo fabricante

O tempo de integração de CT entre 4 e 9 minutos não foi suficiente para integrar a área na região da base do pico, influenciando no coeficiente linear, angular, $r^{2}$ e no CV que foi acima de $10 \%$. Para os tempos de integração de 3 e 4 minutos os $r^{2}$ das curvas analíticas foram menores que 0,99.

Os resultados mostraram que a menor faixa de CV $(0,9-6,0 \%)$ foi obtida com tempo de integração de 10 minutos. $O r^{2}$ obtido neste caso foi de 0,9993, indicando boa correlação entre os pontos da curva analítica e por isso foi escolhido como o tempo de integração de CT no método de análise.

\subsubsection{Tempo de integração da área da curva para o cálculo de $\mathrm{Cl}$}

O tempo de integração da curva de $\mathrm{Cl}$ é o tempo considerado para a integração sob a curva de resposta do detector para $\mathrm{CO}_{2}$, proveniente da reação de acidificação de substâncias inorgânicas ou $\mathrm{Cl}$. Uma solução de $\mathrm{Cl}$ de concentração $250 \mu \mathrm{g} \mathrm{L}^{-1}$ foi utilizada para avaliação do tempo de integração da área na curva do sinal de $\mathrm{Cl}$ e o resultado pode ser visualizado na FIG. 18. 


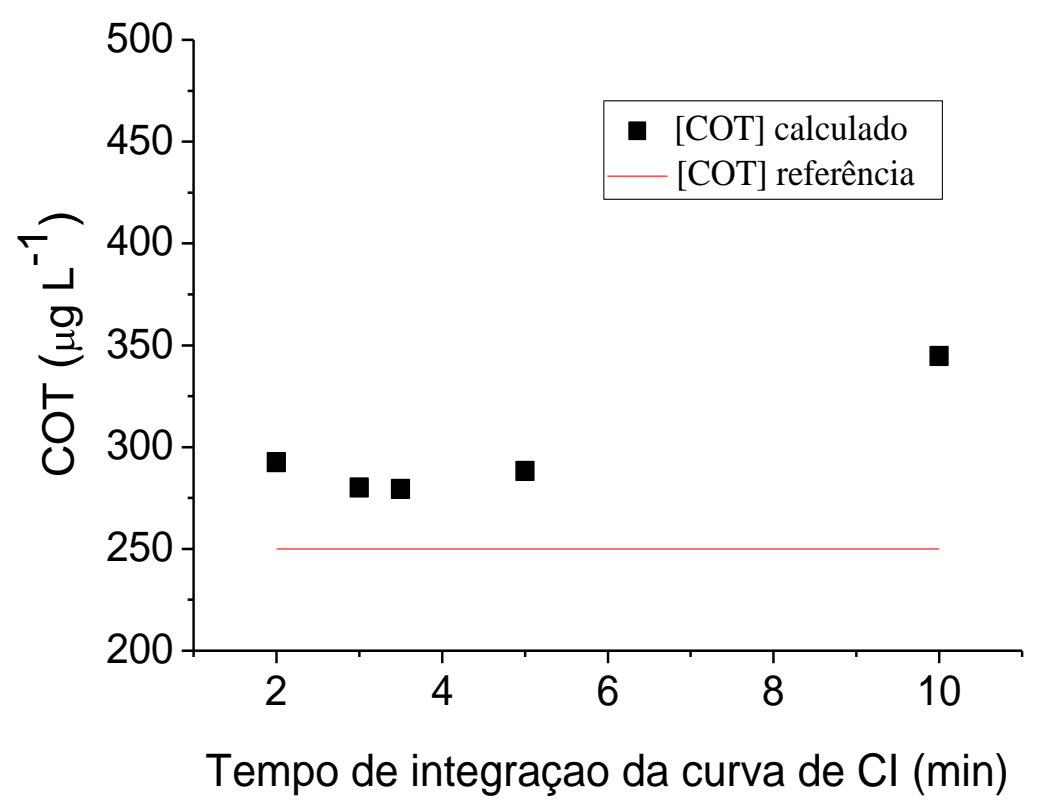

FIGURA 18 - Efeito da variação do tempo de integração da curva para o cálculo de $\mathrm{Cl}$ na análise de solução de COT de $250 \mu \mathrm{g} \mathrm{L}^{-1}(\mathrm{n}=3)$.

Na FIG. 18 observou-se que o tempo de integração de área da curva para cálculo de $\mathrm{Cl}$ entre 3 e 3,5 minutos resultou em valor de COT mais próximo ao valor nominal de $250 \mu \mathrm{g} \mathrm{L}^{-1}$. Isto ocorreu devido ao perfil do sinal de $\mathrm{CO}_{2}$ proveniente da reação de acidificação de substâncias inorgânicas, que pode ser visualizado na FIG. 19.

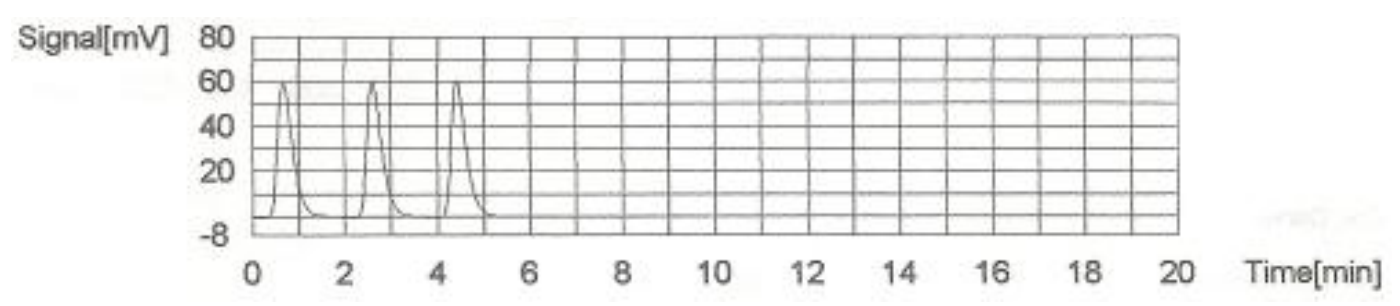

FIGURA 19 - Perfil da curva do sinal de $\mathrm{CO}_{2}$ para $\mathrm{Cl}$.

A integração sob a curva do sinal de $\mathrm{Cl}$ requer tempo menor que a integração de $\mathrm{CT}$, no cálculo de COT. A causa pode estar relacionada com a complexidade das estruturas químicas dos compostos envolvidos. O ftalato de potássio possui estrutura com anel cíclico e ligações covalente enquanto o 
carbonato e bicarbonato de sódio apresentam estruturas mais simples, conforme podemos observar nas FIG. 2021 e 22.

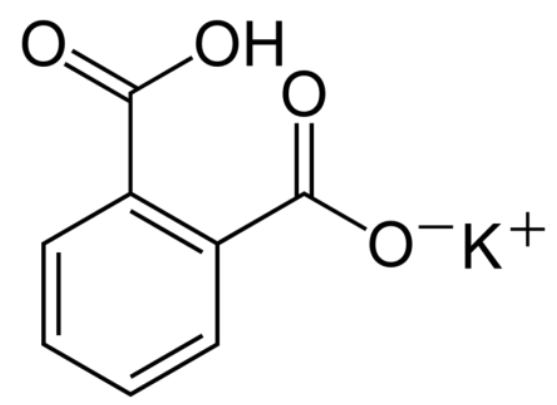

FIGURA 20 - Estrutura química do ftalato de potássio.

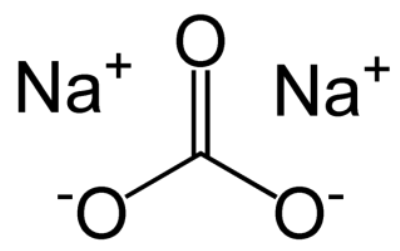

FIGURA 21 - Estrutura química do carbonato de sódio.

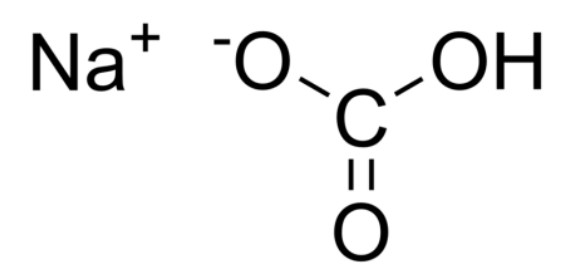

FIGURA 22 - Estrutura química do bicarbonato de sódio.

A TAB. 11 relaciona os parâmetros das curvas analíticas. (CV mínimo e máximo entre as triplicatas e $^{2}$ ) com a variação do tempo de integração da área da curva para o cálculo de $\mathrm{Cl}$. 
TABELA 11 - Efeito da variação do tempo de integração da área da curva para o cálculo de $\mathrm{Cl}$ na obtenção da curva analítica de $\mathrm{Cl}$.

\begin{tabular}{ccccc}
\hline $\begin{array}{c}\text { Tempo de } \\
\text { integração } \\
(\mathbf{m i n})\end{array}$ & $\begin{array}{c}\text { CV Mínimo } \\
(\%)\end{array}$ & $\begin{array}{c}\text { CV Máximo } \\
(\%)\end{array}$ & $\begin{array}{c}\text { Equação da reta } \\
(\mathbf{y}=\mathbf{a x}+\mathbf{b})\end{array}$ & $\mathbf{r}^{\mathbf{2}}$ \\
\hline $\mathbf{2}$ & 0,5 & 1,7 & Área $=0,17[\mathrm{Cl}]+25,30$ & 0,9994 \\
$\mathbf{3}$ & 0,0 & 0,5 & Área $=0,16[\mathrm{Cl}]+27,00$ & 0,9998 \\
$\mathbf{3 , 5 ^ { \star }}$ & 0,9 & 2,0 & Área $=0,18[\mathrm{Cl}]+27,69$ & 0,999 \\
$\mathbf{5}$ & 0,6 & 1,3 & Área $=0,18[\mathrm{Cl}]+31,63$ & 0,998 \\
$\mathbf{1 0}$ & 0,2 & 0,8 & Área $=0,18[\mathrm{Cl}]+29,01$ & 0,997 \\
\hline $\begin{array}{l}(\mathrm{n}=3) \text { para cada condição } \\
{ }^{*} \text { Recomendado pelo fabricante }\end{array}$ & & & & \\
\end{tabular}

Os CV foram abaixo dos $2,0 \%$ e os $r^{2}$ acima de 0,99 . Os parâmetros das curvas analíticas apresentaram pequena variação entre si, indicando que a alteração do tempo de integração apresenta pequena influência no cálculo de $\mathrm{Cl}$.

Considerando-se os resultados observados na FIG. 18 e na TAB. 11, foi escolhido o tempo de integração de 3 minutos para compor o método analítico para determinação de COT.

\subsubsection{Repetibilidade, precisão intermediária e exatidão}

Os resultados de DPR nos ensaios de repetibilidade para as três concentrações de CT foram obtidos utilizando-se a Eq. 2 (pag. 38) e os de exatidão foram obtidos com a Eq. 3 (pag. 39). Os resultados estão expressos nas TAB. 12 e 13.

TABELA 12 - Repetibilidade e Exatidão intradia de CT no $1^{\circ}$ dia de análise.

\begin{tabular}{cccc}
\hline $\begin{array}{c}\mathrm{CT} \\
\left(\mu \mathrm{g} \mathrm{L}^{-1}\right)\end{array}$ & $\begin{array}{c}\mathrm{CMD} \pm \mathrm{DP} \\
\left(\mu \mathrm{g} \mathrm{L}^{-1}\right)\end{array}$ & $\begin{array}{c}\text { DPR } \\
(\%)\end{array}$ & $\begin{array}{c}\text { Exatidão } \\
(\%)\end{array}$ \\
\hline 100 & $112,53 \pm 4,97$ & 4,40 & 112,52 \\
500 & $493,91 \pm 5,50$ & 1,11 & 98,78 \\
1000 & $1004,90 \pm 11,60$ & 1,15 & 100,49 \\
\hline$(\mathrm{n}=3)$ & & &
\end{tabular}


TABELA 13 - Repetibilidade e Exatidão intradia de CT no $2^{\circ}$ dia de análise.

\begin{tabular}{cccc}
\hline $\begin{array}{c}\mathbf{C T} \\
\left(\mu \mathrm{g} \mathrm{L}^{-1}\right)\end{array}$ & $\begin{array}{c}\mathbf{C M D} \pm \mathbf{D P} \\
\left(\mu \mathbf{g ~ L}^{-1}\right)\end{array}$ & $\begin{array}{c}\text { DPR } \\
(\%)\end{array}$ & $\begin{array}{c}\text { Exatidão } \\
(\%)\end{array}$ \\
\hline 100 & $104,50 \pm 3,02$ & 2,89 & 104,50 \\
500 & $483,84 \pm 4,75$ & 0,98 & 96,76 \\
1000 & $1012,91 \pm 12,71$ & 1,25 & 101,29 \\
\hline$(n=3)$ & & &
\end{tabular}

A repetibilidade (precisão intradia) e a exatidão do método, avaliados com solução de CT apresentaram resultados dentro dos limites aceitáveis pela RE no 899 de 2003 da ANVISA (DPR $\leq 5 \%$ e exatidão entre 80 - 120\%).

A precisão intermediária (precisão interdia) para CT apresentaram os resultados descritos na TAB. 14.

TABELA 14 - Precisão intermediária de CT.

\begin{tabular}{ccc}
\hline $\begin{array}{c}\mathbf{C T} \\
\left(\mu \mathrm{g} \mathrm{L}^{-1}\right)\end{array}$ & $\begin{array}{c}\mathbf{C M D} \pm \mathbf{D P} \\
\left(\mu \mathbf{g ~ L}^{-1}\right)\end{array}$ & $\begin{array}{c}\text { DPR } \\
(\%)\end{array}$ \\
\hline 100 & $109,06 \pm 4,89$ & 4,63 \\
500 & $488,97 \pm 7,13$ & 1,45 \\
1000 & $999,17 \pm 8,10$ & 0,81 \\
\hline$(n=3)$ & &
\end{tabular}

A precisão intermediária para CT apresentou-se dentro dos limites especificados (DPR $\leq 5 \%$ ).

Os resultados dos ensaios de repetibilidade (DPR) e exatidão para $\mathrm{Cl}$ calculados segundo a Eq. 3 (pag. 39) estão expressos nas TAB. 15 e 16. 
TABELA 15 - Repetibilidade e Exatidão intradia de $\mathrm{Cl}$ no 1ํ dia de análise.

\begin{tabular}{cccc}
\hline $\begin{array}{c}\mathbf{C l} \\
\left(\mu \mathrm{g} \mathrm{L}^{-1}\right)\end{array}$ & $\begin{array}{c}\text { CMD } \pm \text { DP } \\
\left(\mu \mathrm{g} \mathrm{L}^{-1}\right)\end{array}$ & $\begin{array}{c}\text { DPR } \\
(\%)\end{array}$ & $\begin{array}{c}\text { Exatidão } \\
(\%)\end{array}$ \\
\hline 250 & $265,76 \pm 1,21$ & 0,45 & 106,35 \\
500 & $516,32 \pm 2,97$ & 0,57 & 103,27 \\
1000 & $1006,61 \pm 6,85$ & 0,68 & 100,66 \\
\hline$(n=3)$ & & &
\end{tabular}

TABELA 16 - Repetibilidade e Exatidão intradia de $\mathrm{Cl}$ no $2^{\circ}$ dia de análise

\begin{tabular}{cccc}
\hline $\begin{array}{c}\mathbf{C l} \\
\left(\mu \mathbf{g ~ L}^{-1}\right)\end{array}$ & $\begin{array}{c}\text { CMD } \pm \text { DP } \\
\left(\mu \mathbf{g ~ L}^{-1}\right)\end{array}$ & $\begin{array}{c}\text { DPR } \\
(\%)\end{array}$ & $\begin{array}{c}\text { Exatidão } \\
(\%)\end{array}$ \\
\hline 250 & $258,23 \pm 1,97$ & 0,76 & 103,29 \\
500 & $501,97 \pm 3,37$ & 0,61 & 100,39 \\
1000 & $1016,00 \pm 4,14$ & 0,40 & 101,60 \\
\hline$(n=3)$ & & &
\end{tabular}

A repetibilidade (precisão intradia) e a exatidão do método, avaliados com solução de $\mathrm{Cl}$ apresentaram resultados dentro dos limites aceitáveis (DPR $\leq 5 \%$ e exatidão entre $80-120 \%$ ).

A precisão intermediária (precisão interdia) para $\mathrm{Cl}$ apresentou os resultados descritos na TAB. 17.

TABELA 17 - Precisão intermediária de Cl.

\begin{tabular}{ccc}
\hline $\begin{array}{c}\text { Cl } \\
\left(\mu \mathrm{g} \mathrm{L}^{-1}\right)\end{array}$ & $\begin{array}{c}\text { CMD } \pm \text { DP } \\
\left(\mu \mathrm{g} \mathrm{L}^{-1}\right)\end{array}$ & $\begin{array}{c}\text { DPR } \\
(\%)\end{array}$ \\
\hline 250 & $261,99 \pm 5,32$ & 2,03 \\
500 & $509,16 \pm 10,16$ & 1,99 \\
1000 & $1011,30 \pm 6,63$ & 0,65 \\
\hline$(\mathrm{n}=3)$ & &
\end{tabular}


A precisão intermediária para $\mathrm{Cl}$ apresentou-se dentro dos limites aceitáveis (DPR $\leq 5 \%)$.

\subsubsection{Linearidade}

As curvas analíticas obtidas na avaliação de linearidade para CT e Cl estão dispostas na TAB. 18 com seus respectivos $r^{2}$.

TABELA 18 - Curvas analíticas obtidas para CT e Cl.

\begin{tabular}{c|cc|cc}
\hline \multirow{2}{*}{$\mathbf{N}$} & CT & \multicolumn{2}{c}{$\mathbf{C l}$} \\
\cline { 2 - 5 } & $\begin{array}{c}\text { Eq. da reta } \\
\mathbf{y}=\mathbf{a x}+\mathbf{b}\end{array}$ & $\mathbf{r}^{2}$ & $\begin{array}{c}\text { Eq. da reta } \\
\mathbf{y =} \mathbf{a x}+\mathbf{b}\end{array}$ & $\mathbf{r}^{2}$ \\
\hline $\mathbf{1}$ & Área $=0,18[\mathrm{CT}]+28,74$ & 0,9994 & Área $=0,16[\mathrm{Cl}]+18,76$ & 0,998 \\
$\mathbf{2}$ & Área $=0,18[\mathrm{CT}]+49,05$ & 0,9991 & Área $=0,20[\mathrm{Cl}]+23,92$ & 0,997 \\
$\mathbf{3}$ & Área $=0,18[\mathrm{CT}]+41,68$ & 0,9992 & Área $=0,17[\mathrm{Cl}]+29,53$ & 0,998 \\
\hline
\end{tabular}

A faixa linear para determinação de $\mathrm{CT}$ e $\mathrm{Cl}$ foi de $0-1000 \mathrm{em}$ ambos os casos com $r^{2}>0,997$ acima do limite especificado $(0,99)$ atendendo às recomendações da ANVISA.

\subsubsection{Limite de detecção (LD) e limite de quantificação (LQ)}

Os LD e LQ calculados segundo as Eq 7 e Eq. 8 (pag. 41) para CT foram $31,83 \mu \mathrm{g} \mathrm{L}^{-1}$ e $106,11 \mu \mathrm{g} \mathrm{L}^{-1}$ respectivamente. Para $\mathrm{Cl}$, os valores calculados foram 59,16 $\mu \mathrm{g} \mathrm{L}^{-1}$ para LD e 197,22 $\mu \mathrm{g} \mathrm{L}^{-1}$ para LQ.

Os limites calculados não foram testados experimentalmente.

\subsection{Avaliação do desempenho de sistemas purificadores de água instalados na DIRF}

Com o tamanho reduzido dos lotes de produção em uma radiofarmácia, torna-se impraticável a aquisição e a utilização de grandes sistemas de purificação de água (AP e API) para atender à demanda do processo de fabricação de radiofármacos. Sistemas de purificação de água destinados ao uso laboratorial são utilizados para produção de água em uma radiofarmácia. No 
entanto, é necessário avaliar se a água atende aos padrões de qualidade exigidos nas normas para a indústria farmacêutica (TAB. 1, pag 28).

Os resultados da qualidade da água de cinco sistemas de purificação disponíveis na DIRF (3 pontos de coleta de AP e 3 pontos de coleta de API) para COT, condutividade, $\mathrm{pH}$, contagem de aeróbios totais e endotoxina estão relacionados a seguir. As especificações para AP e API estão descritas na TAB. 1, pag 28.

\subsubsection{Ponto A}

Os resultados das análises de desempenho do sistema de purificação identificado como ponto $A(A P)$ estão apresentados nas TAB. 19, 20 e 21. Na FIG. 23 está representado o perfil da variação do teor de COT durante as fases IIV, e na FIG. 24 estão relacionados os resultados de $\mathrm{Cl}$ e condutividade. 
TABELA 19 - Resultados das fases I e II do ponto A.

\begin{tabular}{|c|c|c|c|c|c|}
\hline & $\begin{array}{c}\text { COT } \\
\left(\mu \mathrm{g} \mathrm{L}^{-1}\right)\end{array}$ & $\begin{array}{c}C l \\
\left(\mu \mathrm{g} \mathrm{L}^{-1}\right)\end{array}$ & $\begin{array}{l}\text { Condutividade } \\
\qquad\left(\mu \mathrm{S} \mathrm{cm}^{-1}\right)\end{array}$ & pH & $\begin{array}{c}\text { Contagem de aeróbios } \\
\text { totais } \\
(\mathrm{UFC} \mathrm{mL})\end{array}$ \\
\hline \multirow{10}{*}{$\begin{array}{l}\bar{\Phi} \\
\stackrel{\mathscr{g}}{\tilde{L}} \\
\text { L }\end{array}$} & 64,94 & 350,8 & 0,82 & 6,65 & 50 \\
\hline & 73,63 & 142,3 & 0,67 & 6,86 & $<1$ \\
\hline & 110,0 & 146,9 & 0,63 & 6,30 & 10 \\
\hline & 91,35 & 175,4 & 0,79 & 6,53 & $<1$ \\
\hline & 143,3 & 168,3 & 0,97 & 6,25 & $<1$ \\
\hline & 20,57 & 131,7 & 0,82 & 6,03 & $<1$ \\
\hline & 4,02 & 187,8 & 0,83 & 5,97 & $<1$ \\
\hline & 92,18 & 207,3 & 0,90 & 6,76 & $<1$ \\
\hline & 10,29 & 200,7 & 0,80 & 6,69 & $<1$ \\
\hline & 60,86 & 128,6 & 0,70 & 6,87 & 19 \\
\hline \multirow{17}{*}{$\begin{array}{l}\overline{\overline{0}} \\
\bar{\phi} \\
\tilde{\Phi} \\
\tilde{\Phi}\end{array}$} & 140,4 & 124,6 & 0,46 & 6,95 & $>6.500$ \\
\hline & 39,67 & 182,0 & 0,93 & 6,72 & 10 \\
\hline & 123,4 & 134,8 & 0,43 & 5,75 & 10 \\
\hline & 146,4 & 116,0 & 0,65 & 5,82 & 10 \\
\hline & 52,86 & 175,9 & 0,81 & 5,93 & 10 \\
\hline & 69,57 & 179,2 & 0,81 & 6,09 & 10 \\
\hline & 116,4 & 212,4 & 1,10 & 6,03 & 30 \\
\hline & 37,66 & 156,5 & 0,65 & 6,02 & $<1$ \\
\hline & 56,33 & 201,6 & 0,68 & 6,43 & $<1$ \\
\hline & 35,16 & 126,1 & 0,79 & 6,00 & 65 \\
\hline & 43,81 & 135,8 & 0,85 & 6,41 & 32 \\
\hline & 170,3 & 140,6 & 0,74 & 6,23 & $<1$ \\
\hline & 71,38 & 119,6 & 0,75 & 6,95 & $<1$ \\
\hline & 20,62 & 184,1 & 0,70 & 6,76 & 12 \\
\hline & 92,94 & 221,8 & 0,76 & 6,73 & 20 \\
\hline & 41,45 & 167,2 & 1,04 & 5,87 & 25 \\
\hline & 20,20 & 183,5 & 1,20 & 5,93 & $<1$ \\
\hline
\end{tabular}


TABELA 20 - Resultados da fase III do ponto A.

\begin{tabular}{|c|c|c|c|c|c|}
\hline & $\begin{array}{c}\text { COT } \\
\left(\mu \mathrm{g} \mathrm{L}^{-1}\right)\end{array}$ & $\begin{array}{c}\text { Cl } \\
\left(\mu \mathrm{g} \mathrm{L}^{-1}\right)\end{array}$ & $\begin{array}{l}\text { Condutividade } \\
\qquad\left(\mu \mathrm{S} \mathrm{cm}^{-1}\right)\end{array}$ & $\mathrm{pH}$ & $\begin{array}{c}\text { Contagem de aeróbios } \\
\text { totais } \\
\left(\mathrm{UFC} \mathrm{mL} \mathrm{mL}^{-1}\right)\end{array}$ \\
\hline \multirow{33}{*}{ 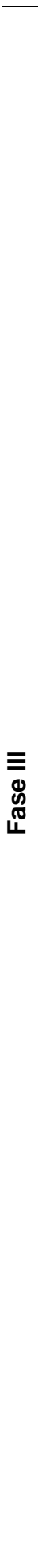 } & 4,16 & 209,4 & 0,76 & 6,24 & 20 \\
\hline & 82,48 & 130,4 & 0,91 & 5,88 & 7 \\
\hline & 87,68 & 158,2 & 0,90 & 6,57 & 15 \\
\hline & 72,67 & 168,1 & 0,98 & 6,73 & 2 \\
\hline & 79,63 & 129,3 & 0,97 & 6,65 & 110 \\
\hline & 73,43 & 174,7 & 0,97 & 5,82 & $<1$ \\
\hline & 85,38 & 133,0 & 1,03 & 6,69 & 45 \\
\hline & 108,0 & 165,2 & 1,15 & 6,64 & 10 \\
\hline & 78,88 & 129,4 & 0,98 & 6,35 & 44 \\
\hline & 83,43 & 133,5 & 0,67 & 6,05 & $<1$ \\
\hline & 86,4 & 185,0 & 0,83 & 6,73 & 35 \\
\hline & 58,48 & 144,7 & 0,74 & 6,65 & 2 \\
\hline & 38,41 & 142,9 & 0,78 & 6,62 & 82 \\
\hline & 99,44 & 153,0 & 0,73 & 5,97 & $<1$ \\
\hline & 70,17 & 125,1 & 0,64 & 6,28 & $<1$ \\
\hline & 97,53 & 139,1 & 0,72 & 6,20 & $<1$ \\
\hline & 36,02 & 149,7 & 0,86 & 6,02 & 9 \\
\hline & 35,56 & 166,6 & 0,85 & 6,25 & 29 \\
\hline & 61,08 & 176,6 & 0,99 & 6,34 & $<1$ \\
\hline & 45,38 & 166,6 & 0,85 & 5,85 & $<1$ \\
\hline & 67,63 & 148,8 & 0,90 & 5,97 & 11 \\
\hline & 52,91 & 184,4 & 0,95 & 6,56 & $<1$ \\
\hline & 52,66 & 191,4 & 1,02 & 6,22 & 51 \\
\hline & 48,34 & 143,3 & 0,78 & 5,74 & 18 \\
\hline & 9,68 & 150,3 & 3,74 & 6,42 & 22 \\
\hline & 51,54 & 216,7 & 0,91 & 6,35 & 14 \\
\hline & 31,30 & 165,3 & 0,90 & 6,66 & $<1$ \\
\hline & 26,29 & 179,4 & 1,09 & 5,95 & 30 \\
\hline & 305,6 & 156,6 & 2,60 & 6,42 & 1 \\
\hline & 26,12 & 154,9 & 0,81 & 5,68 & 31 \\
\hline & 159,4 & 177,9 & 0,95 & 5,79 & 7 \\
\hline & 99,01 & 170,6 & 0,86 & 5,93 & 9 \\
\hline & 205,9 & 114,1 & 0,91 & 6,04 & 18 \\
\hline
\end{tabular}


TABELA 20 - Continuação.

\begin{tabular}{|c|c|c|c|c|c|}
\hline & $\begin{array}{c}\text { СОT } \\
\left(\mu \mathrm{g} \mathrm{L}^{-1}\right)\end{array}$ & $\begin{array}{c}\text { Cl } \\
\left(\mu \mathrm{g} \mathrm{L}^{-1}\right)\end{array}$ & $\begin{array}{l}\text { Condutividade } \\
\qquad\left(\mu \mathrm{S} \mathrm{cm}^{-1}\right)\end{array}$ & $\mathrm{pH}$ & $\begin{array}{c}\text { Contagem de aeróbios } \\
\text { totais } \\
\text { (UFC mL }\end{array}$ \\
\hline \multirow{15}{*}{$\begin{array}{l}\equiv \\
\bar{\Phi} \\
\mathbb{W} \\
\mathscr{\leftarrow}\end{array}$} & 88,54 & 129,5 & 0,83 & 6,34 & 3 \\
\hline & 236,8 & 178,1 & 0,95 & 6,43 & 5 \\
\hline & 102,9 & 161,1 & 0,80 & 5,94 & 38 \\
\hline & 188,6 & 182,2 & 0,70 & 5,96 & 9 \\
\hline & 46,58 & 156,2 & 1,08 & 6,57 & $<1$ \\
\hline & 30,15 & 139,0 & 0,72 & 5,76 & $<1$ \\
\hline & 152,5 & 167,3 & 0,93 & 5,77 & 1 \\
\hline & 154,3 & 127,3 & 0,73 & 5,99 & $<1$ \\
\hline & 47,31 & 125,6 & 0,99 & 6,45 & 5 \\
\hline & 52,14 & 134,8 & 0,73 & 5,93 & $<1$ \\
\hline & 79,62 & 147,3 & 0,80 & 6,83 & $<1$ \\
\hline & 148,7 & 124,0 & 0,64 & 6,23 & 45 \\
\hline & 249,8 & 129,8 & 0,96 & 6,04 & $>6.500$ \\
\hline & $<\mathrm{LD}$ & $<L D$ & 0,80 & 5,93 & $<1$ \\
\hline & $<\mathrm{LD}$ & $<\mathrm{LD}$ & 0,79 & 5,68 & 15 \\
\hline
\end{tabular}

TABELA 21 - Resultados da fase IV do ponto A.

\begin{tabular}{|c|c|c|c|c|c|}
\hline & $\begin{array}{c}\text { СОT } \\
\left(\mu \mathrm{g} \mathrm{L}^{-1}\right)\end{array}$ & $\begin{array}{c}\text { Cl } \\
\left(\mu \mathrm{g} \mathrm{L}^{-1}\right)\end{array}$ & $\begin{array}{l}\text { Condutividade } \\
\qquad\left(\mu \mathrm{S} \mathrm{cm}^{-1}\right)\end{array}$ & $\mathrm{pH}$ & $\begin{array}{l}\text { Contagem de aeróbios totais } \\
\left.\text { (UFC mL } \mathrm{mL}^{-1}\right)\end{array}$ \\
\hline \multirow{16}{*}{ 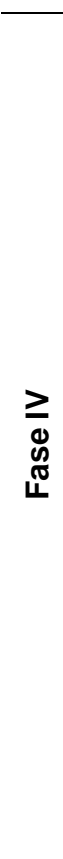 } & 142,0 & 135,2 & 0,81 & 5,23 & 43 \\
\hline & 173,2 & 127,4 & 0,80 & 6,76 & $<1$ \\
\hline & 159,1 & 153,1 & 1,03 & 5,5 & 15 \\
\hline & 311,3 & 131,2 & 0,90 & 5,5 & $<1$ \\
\hline & 69,16 & 159,9 & 0,86 & 5,5 & 10 \\
\hline & 0,18 & 181,9 & 0,74 & 6,32 & $<1$ \\
\hline & 51,43 & 117,3 & 0,69 & 5,87 & 24 \\
\hline & 380,7 & 130,1 & 0,87 & 7,38 & $<1$ \\
\hline & 24,47 & 162,1 & 0,75 & 6,64 & 12 \\
\hline & $<$ LD & 190,8 & 0,68 & 6,57 & $<1$ \\
\hline & 53,69 & 154,6 & 0,78 & 5,94 & 8 \\
\hline & 64,13 & 144,3 & 0,87 & 6,89 & $<1$ \\
\hline & 95,22 & 191,3 & 0,20 & 6,92 & $<1$ \\
\hline & 35,26 & 240,4 & 0,71 & 6,22 & 3 \\
\hline & 65,90 & 149,7 & 0,73 & 6,51 & $<1$ \\
\hline & 143,3 & 150,9 & 0,74 & 6,07 & 9 \\
\hline
\end{tabular}




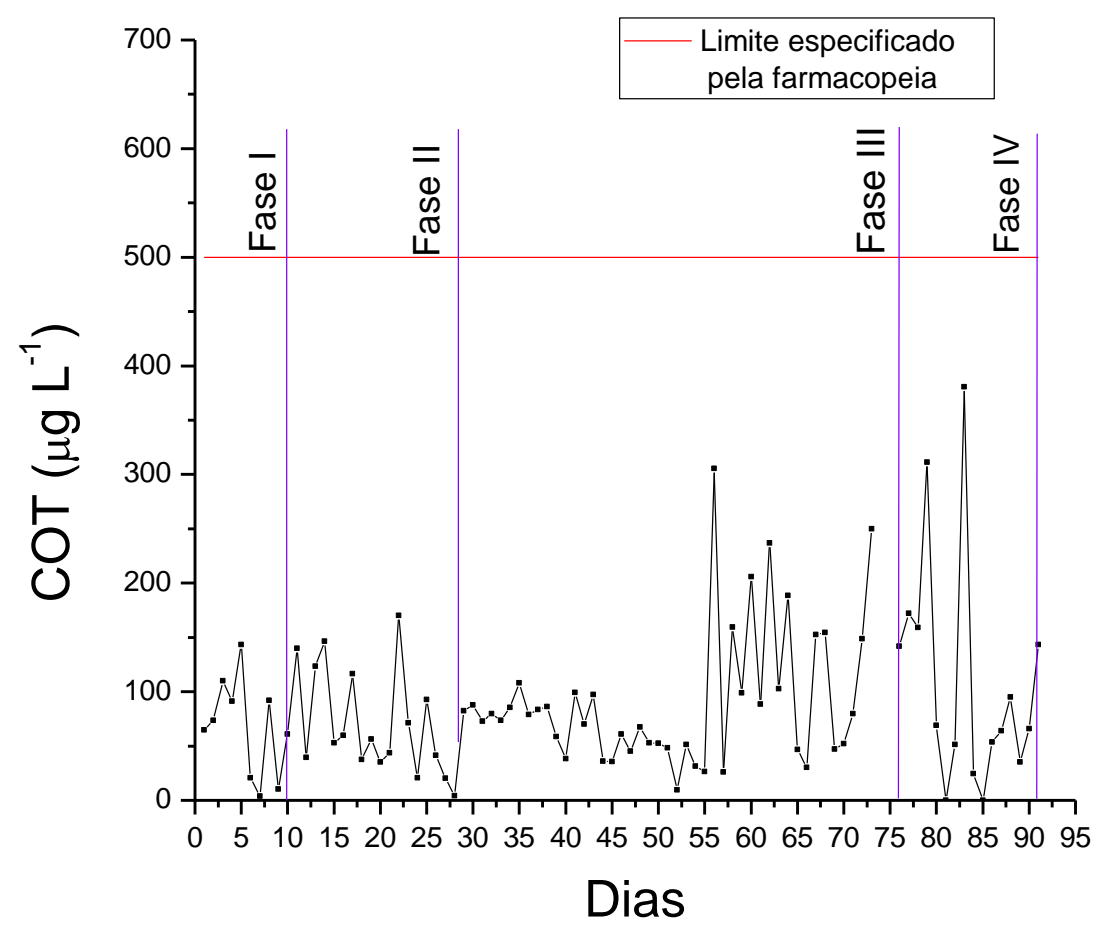

FIGURA 23 - Monitoramento de COT do ponto A.

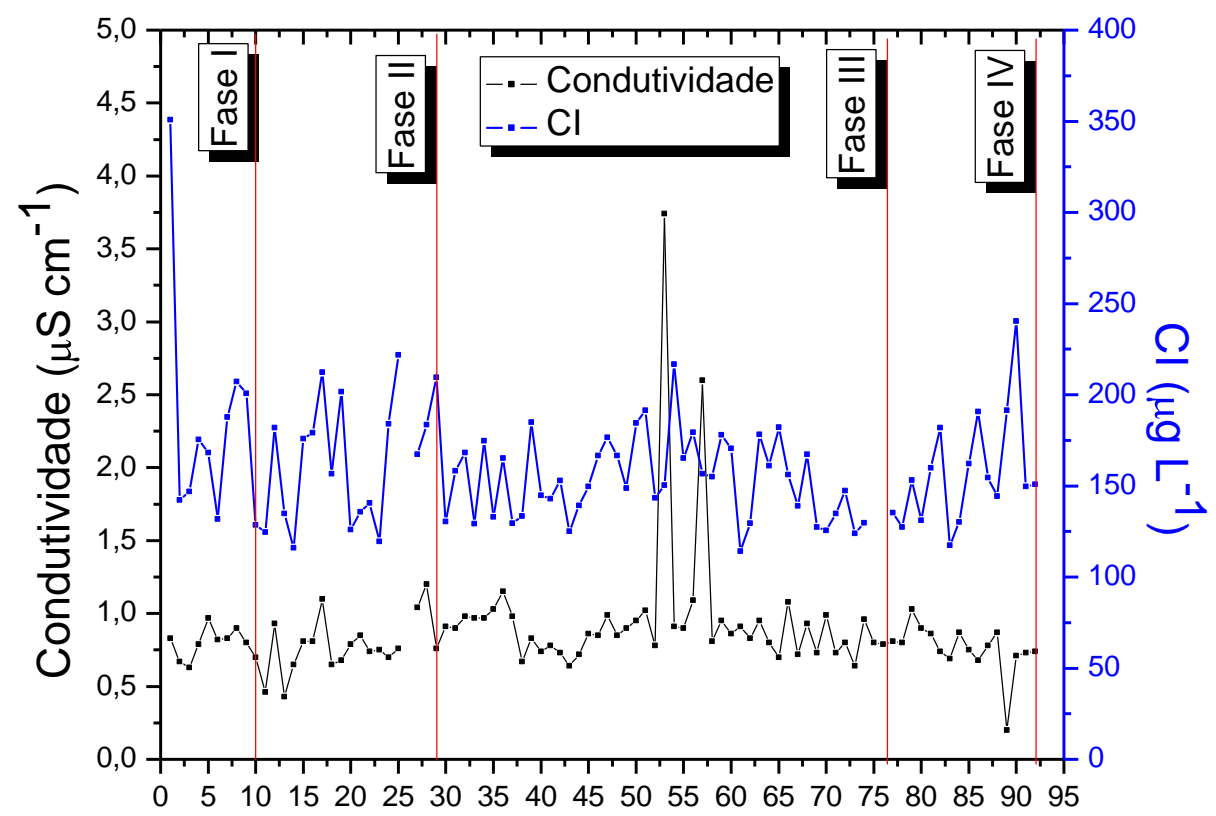

Dias

FIGURA 24 - Resultados de $\mathrm{Cl}$ e condutividade do ponto A. 
Durante o período de monitoramento do sistema de purificação identificado como ponto $A$, a concentração de COT manteve-se abaixo de $500 \mu \mathrm{g} \mathrm{L}^{-1}$ (FIG. 23), limite definido pelas farmacopeias. Durante os dois primeiros meses de monitoramento da qualidade da água, a concentração máxima de COT foi de cerca de $200 \mu \mathrm{g} \mathrm{L}^{-1}$. Após o estabelecimento da frequência de limpeza do reservatório de $30 \mathrm{~L}$ com $\mathrm{NaOH}$ a cada 15 dias, observou-se que o COT mantevese abaixo de $100 \mu \mathrm{g} \mathrm{L}^{-1}$ durante aproximadamente 3 meses. No período final da fase III observou-se uma elevação no COT, cuja causa foi atribuída à necessidade de manutenção do sistema de osmose reversa, que foi posteriormente substituído durante a fase IV, restabelecendo a concentração de COT para abaixo de $100 \mu \mathrm{g} \mathrm{L}^{-1}$.

A condutividade, $\mathrm{o} \mathrm{pH}$ e a contagem de aeróbios totais apresentaram alguns resultados fora das especificações. Observou-se durante o monitoramento que há uma relação entre o perfil da variação de Cl e condutividade (FIG. 24), sugerindo que a condutividade pode estar relacionada com a presença de carbonatos na água. Não foi observada relação entre a contaminação microbiológica e o COT, na faixa de concentração e contagem microbiana observadas no estudo.

\subsubsection{Ponto B}

Os resultados das análises de desempenho do sistema de purificação identificado como ponto $B(A P)$ estão apresentados nas TAB. 22, 23 e 24. Na FIG. 25 está representada a variação na concentração de COT durante as fases IIV, e na FIG. 26 estão relacionados os resultados de $\mathrm{Cl}$ e condutividade. 
TABELA 22 - Resultados das fases I e II do ponto B.

\begin{tabular}{|c|c|c|c|c|c|}
\hline & $\begin{array}{c}\text { COT } \\
\left(\mu \mathrm{g} \mathrm{L}^{-1}\right)\end{array}$ & $\begin{array}{c}C l \\
\left(\mu \mathrm{g} \mathrm{L}^{-1}\right)\end{array}$ & $\begin{array}{l}\text { Condutividade } \\
\qquad\left(\mu \mathrm{S} \mathrm{cm}^{-1}\right)\end{array}$ & pH & $\begin{array}{c}\text { Contagem de aeróbios } \\
\text { totais } \\
(\mathrm{UFC} \mathrm{mL})\end{array}$ \\
\hline \multirow{10}{*}{$\begin{array}{l}\bar{\Phi} \\
\stackrel{\mathscr{g}}{\tilde{L}} \\
\text { L }\end{array}$} & 112,3 & 205,0 & 0,61 & 6,96 & $<1$ \\
\hline & 94,61 & 111,4 & 0,55 & 6,76 & $<1$ \\
\hline & 152,6 & 127,9 & 0,60 & 6,64 & 2 \\
\hline & 85,59 & 117,7 & 0,68 & 6,45 & $<1$ \\
\hline & 109,2 & 153,6 & 0,76 & 6,33 & $<1$ \\
\hline & 146,1 & 154,1 & 0,28 & 5,96 & $<1$ \\
\hline & 165,4 & 147,2 & 0,67 & 6,40 & 5 \\
\hline & 37,28 & 163,5 & 0,65 & 7,24 & 4 \\
\hline & 124,9 & 130,4 & 0,62 & 6,99 & $<1$ \\
\hline & 109,9 & 115,9 & 0,64 & 6,91 & $<1$ \\
\hline \multirow{17}{*}{$\begin{array}{l}\overline{\overline{0}} \\
\bar{\phi} \\
\tilde{\Phi} \\
\tilde{\Phi}\end{array}$} & 101,7 & 128,0 & 0,74 & 6,92 & $>6.500$ \\
\hline & 76,93 & 152,5 & 0,83 & 5,96 & 15 \\
\hline & 160,8 & 122,4 & 0,83 & 5,80 & 21 \\
\hline & 157,3 & 125,3 & 0,70 & 6,02 & 9 \\
\hline & 314,0 & 137,5 & 0,73 & 6,15 & 19 \\
\hline & 89,18 & 149,5 & 0,73 & 5,91 & 9 \\
\hline & 50,09 & 148,7 & 0,65 & 6,57 & $<1$ \\
\hline & 30,18 & 149,0 & 0,63 & 6,00 & $<1$ \\
\hline & 96,52 & 111,4 & 0,58 & 6,51 & $<1$ \\
\hline & 54,61 & 146,9 & 0,75 & 6,72 & $<1$ \\
\hline & 861,7 & 101,5 & 0,66 & 6,74 & $<1$ \\
\hline & 298,3 & 112,1 & 0,65 & 6,81 & $<1$ \\
\hline & 633,1 & 103,4 & 0,64 & 6,43 & 340 \\
\hline & 401,3 & 142,9 & 0,52 & 6,60 & $<1$ \\
\hline & 26,78 & 154,5 & 1,24 & 6,92 & $<1$ \\
\hline & 95,85 & 123,1 & 0,74 & 7,00 & 4 \\
\hline & 23,05 & 178,3 & 1,15 & 6,00 & $<1$ \\
\hline
\end{tabular}


TABELA 23 - Resultados da fase III do ponto B.

\begin{tabular}{|c|c|c|c|c|c|}
\hline & $\begin{array}{c}\text { СОТ } \\
\left(\mu \mathrm{g} \mathrm{L}^{-1}\right)\end{array}$ & $\begin{array}{c}\text { Cl } \\
\left(\mu \mathrm{g} \mathrm{L}^{-1}\right)\end{array}$ & $\begin{array}{l}\text { Condutividade } \\
\qquad\left(\mu \mathrm{S} \mathrm{cm}^{-1}\right)\end{array}$ & pH & $\begin{array}{c}\text { Contagem de aeróbios } \\
\text { totais } \\
(\mathrm{UFC} \mathrm{mL})\end{array}$ \\
\hline \multirow{38}{*}{$\begin{array}{l}\equiv \\
\Phi \\
\mathscr{D} \\
\mathscr{L}\end{array}$} & $<\mathrm{LD}$ & 190,5 & 0,64 & 6,76 & $<1$ \\
\hline & 226,6 & 101,4 & 0,58 & 5,97 & 4 \\
\hline & 240,1 & 131,0 & 0,72 & 6,35 & 1 \\
\hline & 685,8 & 137,3 & 0,84 & 6,40 & $<1$ \\
\hline & 115,2 & 129,2 & 0,68 & 6,63 & $<1$ \\
\hline & 94,74 & 128,9 & 0,79 & 6,98 & $<1$ \\
\hline & 8,13 & 150,8 & 0,82 & 7,18 & $<1$ \\
\hline & 105,3 & 134,1 & 0,97 & 6,17 & $<1$ \\
\hline & 32,34 & 129,4 & 1,09 & 6,47 & $<1$ \\
\hline & 176,9 & 111,4 & 0,63 & 5,94 & $<1$ \\
\hline & 52,51 & 122,6 & 0,64 & 6,33 & 87 \\
\hline & 40,44 & 115,3 & 0,65 & 6,04 & $<1$ \\
\hline & 57,36 & 141,5 & 0,75 & 6,65 & 11 \\
\hline & 224,3 & 116,2 & 0,68 & 6,22 & $<1$ \\
\hline & 335,3 & 154,7 & 0,73 & 6,17 & 90 \\
\hline & 209,6 & 128,7 & 0,64 & 6,06 & 30 \\
\hline & 132,1 & 144,7 & 0,73 & 6,24 & 940 \\
\hline & 125,4 & 162,2 & 0,93 & 6,82 & 93 \\
\hline & 105,9 & 189,6 & 0,85 & 6,47 & 76 \\
\hline & 91,97 & 131,2 & 0,69 & 6,53 & $<1$ \\
\hline & 28,31 & 116,1 & 0,65 & 6,00 & 56 \\
\hline & 168,2 & 132,9 & 0,95 & 5,82 & 14 \\
\hline & 237,7 & 343,2 & 0,78 & 6,35 & 20 \\
\hline & 61,98 & 131,0 & 0,73 & 5,77 & 26 \\
\hline & 44,08 & 155,7 & 0,86 & 5,76 & 20 \\
\hline & 161,9 & 177,5 & 0,72 & 5,72 & 36 \\
\hline & 43,75 & 158,8 & 1,08 & 5,71 & 54 \\
\hline & 19,36 & 212,0 & 0,71 & 5,87 & $<1$ \\
\hline & 201,1 & 156,9 & 0,83 & 6,06 & $<1$ \\
\hline & 104,2 & 137,2 & 0,76 & 5,84 & $>6.500$ \\
\hline & 8,51 & 173,1 & 0,85 & 5,68 & 23 \\
\hline & 223,7 & 158,3 & 0,68 & 6,18 & 27 \\
\hline & 122,50 & 145,4 & 0,84 & 6,06 & 60 \\
\hline & 121,2 & 215,0 & 3,63 & 7,63 & $<1$ \\
\hline & 196,5 & 162,0 & 0,71 & 6,23 & 11 \\
\hline & 148,3 & 154,2 & 0,75 & 5,87 & 44 \\
\hline & 185,3 & 141,0 & 0,77 & 6,27 & 1 \\
\hline & 49,02 & 130,9 & 0,70 & 6,73 & $<1$ \\
\hline
\end{tabular}


TABELA 23 - Continuação.

\begin{tabular}{|c|c|c|c|c|c|}
\hline & $\begin{array}{c}\text { COT } \\
\left(\mu \mathrm{g} \mathrm{L}^{-1}\right)\end{array}$ & $\begin{array}{c}\text { Cl } \\
\left(\mu \mathrm{g} \mathrm{L}^{-1}\right)\end{array}$ & $\begin{array}{l}\text { Condutividade } \\
\qquad\left(\mu \mathrm{S} \mathrm{cm}^{-1}\right)\end{array}$ & $\mathrm{pH}$ & $\begin{array}{c}\text { Contagem de aeróbios } \\
\text { totais } \\
\left(\mathrm{UFC} \mathrm{mL} \mathrm{mL}^{-1}\right)\end{array}$ \\
\hline \multirow{10}{*}{ 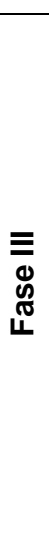 } & 84,02 & 125,8 & 0,67 & 5,84 & $<1$ \\
\hline & 46,57 & 140,7 & 0,72 & 6,15 & $<1$ \\
\hline & 135,4 & 123,2 & 0,62 & 5,66 & $<1$ \\
\hline & 198,8 & 140,7 & 0,69 & 6,35 & $<1$ \\
\hline & 74,90 & 140,1 & 0,81 & 6,26 & $<1$ \\
\hline & 71,47 & 157,5 & 0,79 & 6,94 & 1.400 \\
\hline & 167,8 & 148,7 & 0,82 & 6,28 & 13 \\
\hline & 141,8 & 111,0 & 0,62 & 6,03 & 11 \\
\hline & 72,29 & 228,8 & 0,66 & 6,38 & $<1$ \\
\hline & 143,9 & 225,4 & 0,67 & 6,51 & $<1$ \\
\hline
\end{tabular}

TABELA 24 - Resultados da fase IV do ponto B.

\begin{tabular}{|c|c|c|c|c|c|}
\hline & $\begin{array}{c}\text { COT } \\
\left(\mu \mathrm{g} \mathrm{L}^{-1}\right)\end{array}$ & $\begin{array}{c}\mathrm{Cl} \\
\left(\mu \mathrm{g} \mathrm{L}^{-1}\right)\end{array}$ & $\begin{array}{l}\text { Condutividade } \\
\qquad\left(\mu \mathrm{S} \mathrm{cm}^{-1}\right)\end{array}$ & pH & $\begin{array}{l}\text { Contagem de aeróbios totais } \\
\qquad\left(\mathrm{UFC} \mathrm{mL} \mathrm{mL}^{-1}\right)\end{array}$ \\
\hline \multirow{16}{*}{ 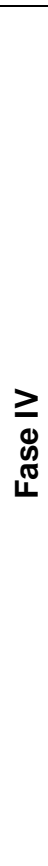 } & 37,59 & 164,3 & 0,76 & 6,05 & 39 \\
\hline & 193,8 & 128,9 & 0,77 & 6,31 & $<1$ \\
\hline & 145,2 & 114,8 & 1,07 & 6,0 & 150 \\
\hline & 225,0 & 132,7 & 0,83 & 6,0 & 49 \\
\hline & 395,6 & 149,4 & 0,79 & 5,5 & 15 \\
\hline & 59,3 & 148,2 & 0,79 & 6,01 & 4 \\
\hline & 862,2 & 267,1 & 0,87 & 5,90 & 26 \\
\hline & 148,4 & 132,1 & 0,77 & 6,70 & $<1$ \\
\hline & 911,2 & 181,9 & 0,89 & 6,24 & $<1$ \\
\hline & 52,47 & 169,1 & 0,91 & 6,80 & 14 \\
\hline & 70,12 & 109,0 & 0,59 & 6,14 & 24 \\
\hline & 88,01 & 180,8 & 0,88 & 6,76 & 310 \\
\hline & 114,8 & 140,6 & 0,69 & 6,34 & 33 \\
\hline & 40,81 & 211,1 & 0,74 & 6,02 & $<1$ \\
\hline & 73,3 & 144,4 & 0,98 & 6,17 & $<1$ \\
\hline & 163,3 & 215,9 & 0,97 & 6,72 & 6 \\
\hline
\end{tabular}




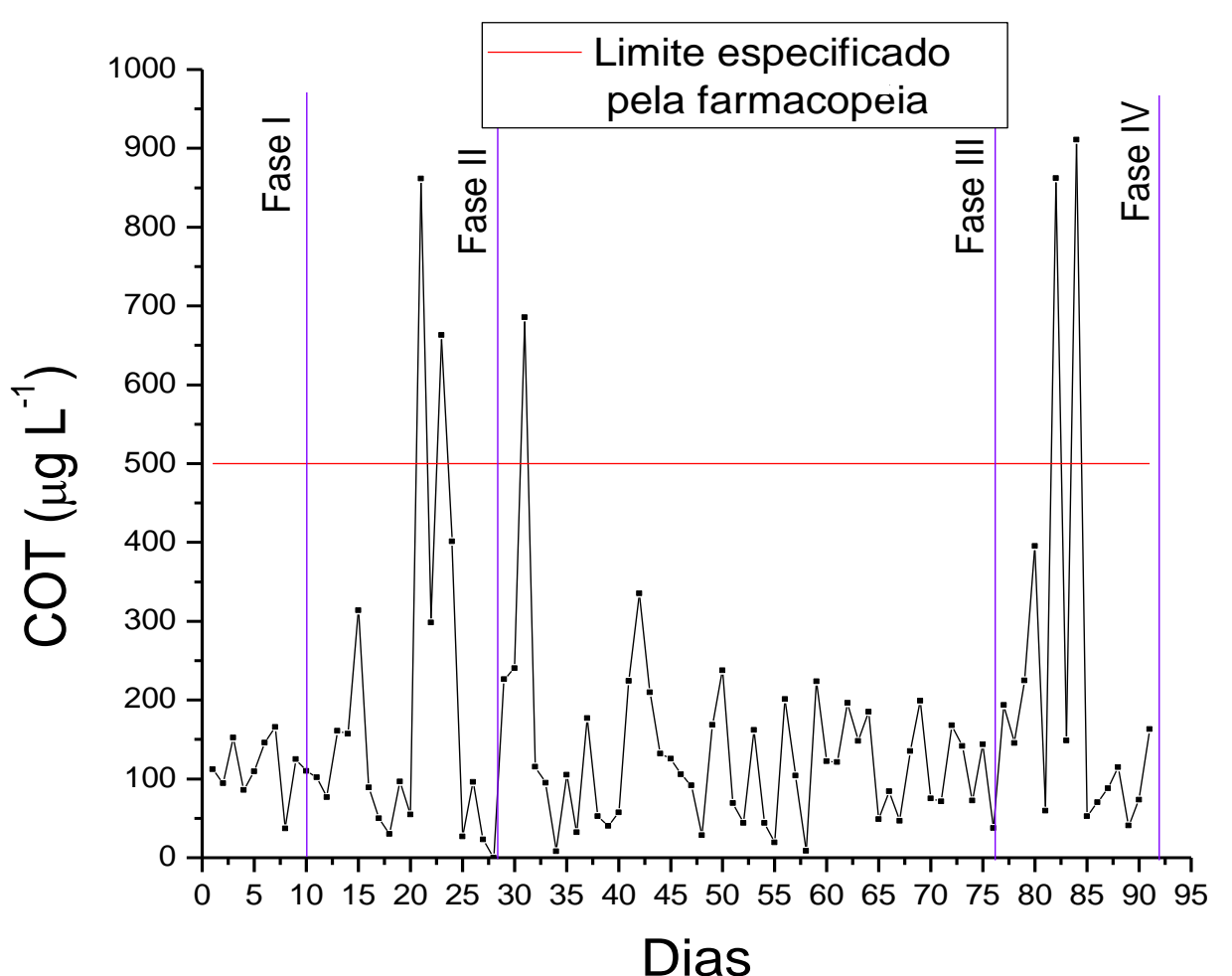

FIGURA 25 - Monitoramento de COT do ponto B.

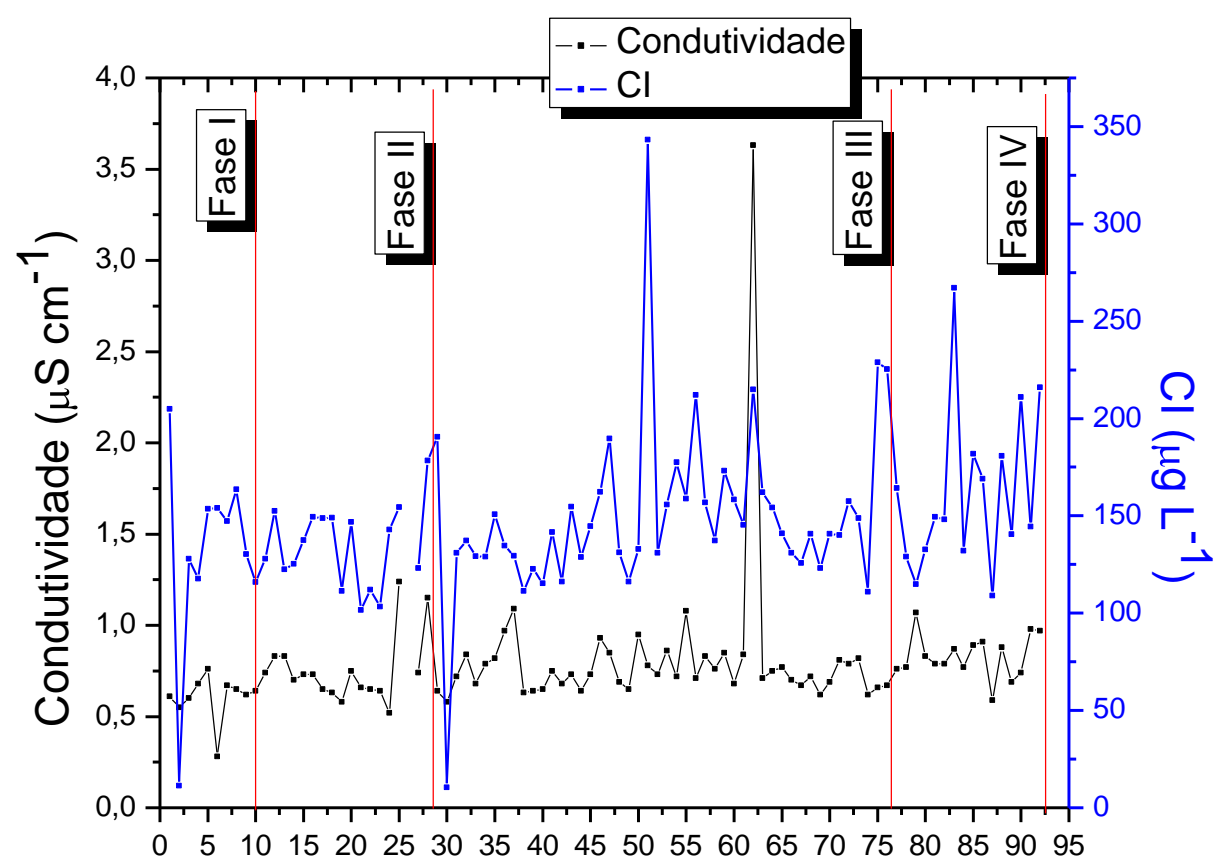

Dias

FIGURA 26 - Resultados de $\mathrm{Cl}$ e condutividade do ponto B. 
Durante a fase I, os resultados de COT para o ponto $B$ foram abaixo de $500 \mu \mathrm{g} \mathrm{L}^{-1}$, com valor médio de cerca de $150 \mu \mathrm{g} \mathrm{L}^{-1}$. Durante a fase II-III, o rompimento do encanamento da água potável que alimentava o equipamento causou contaminação com material orgânico ocasionando alguns desvios na concentração de COT, como mostrado na FIG. 25. O Cl e a condutividade não foram influenciados com o ocorrido (FIG. 26). Na FIG. 25 foram observados picos de $\mathrm{Cl}$ e de condutividade durante a fase III, que não foram relacionados entre si, sugerindo que a variação de condutividade foi devido a outros fatores.

Os resultados de contagem microbiológica durante as fases II-IV não foram relacionados à alteração no COT.

\subsubsection{Ponto C}

Os resultados das análises da água produzida pelo purificador denominado por ponto C (AP) estão apresentados nas TAB. 25, 26 e 27. Na FIG. 27 estão representados os resultados de COT enquanto que na FIG. 28 estão relacionados os resultados de $\mathrm{Cl}$ e condutividade. 
TABELA 25 - Resultados das fases I e II do ponto C.

\begin{tabular}{|c|c|c|c|c|c|}
\hline & $\begin{array}{c}\text { COT } \\
\left(\mu \mathrm{g} \mathrm{L}^{-1}\right)\end{array}$ & $\begin{array}{c}\text { Cl } \\
\left(\mu \mathrm{g} \mathrm{L}^{-1}\right)\end{array}$ & $\begin{array}{l}\text { Condutividade } \\
\qquad\left(\mu \mathrm{S} \mathrm{cm}^{-1}\right)\end{array}$ & pH & $\begin{array}{c}\text { Contagem de aeróbios } \\
\text { totais } \\
(\mathrm{UFC} \mathrm{mL})\end{array}$ \\
\hline \multirow{10}{*}{$\begin{array}{l}\bar{\Phi} \\
\text { ळ } \\
\text { L }\end{array}$} & 355,8 & 192,1 & 1,07 & 6,86 & $<1$ \\
\hline & 320,7 & 202,2 & 0,99 & 6,46 & $<1$ \\
\hline & 106,3 & 149,1 & 0,53 & 5,85 & $<1$ \\
\hline & 108,5 & 169,8 & 0,79 & 6,95 & 5 \\
\hline & 49,37 & 161,6 & 0,91 & 6,55 & 12 \\
\hline & $<$ LD & 172,7 & 0,97 & 6,79 & 66 \\
\hline & $<$ LD & 189,0 & 0,86 & 6,67 & 4 \\
\hline & 69,57 & 175,6 & 0,76 & 6,56 & 4 \\
\hline & 11,78 & 191,2 & 0,91 & 6,56 & 8 \\
\hline & 387,4 & 192,8 & 0,68 & 6,43 & 140 \\
\hline \multirow{17}{*}{ 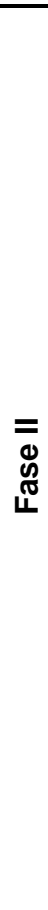 } & 151,7 & 199,1 & 0,81 & 6,66 & 10 \\
\hline & 431,7 & 148,9 & 0,80 & 6,24 & $<1$ \\
\hline & 265,6 & 171,7 & 1,22 & 6,40 & 15 \\
\hline & 258,4 & 217,9 & 1,10 & 6,85 & 10 \\
\hline & 140,8 & 182,6 & 0,67 & 6,80 & 1 \\
\hline & 207,9 & 168,9 & 0,80 & 6,23 & 8 \\
\hline & 48,02 & 183,6 & 0,88 & 6,22 & 12 \\
\hline & 359,5 & 131,2 & 0,67 & 6,88 & 22 \\
\hline & 14,21 & 170,9 & 1,24 & 6,97 & 9 \\
\hline & 17,83 & 179,1 & 0,99 & 6,79 & 8 \\
\hline & $-^{*}$ & $-*$ & $0,00^{*}$ & 6,92 & 2 \\
\hline & 172,1 & 168,9 & 0,83 & 6,96 & 6 \\
\hline & 43,03 & 201,1 & 1,07 & 6,89 & 9 \\
\hline & 78,22 & 168,3 & 0,98 & 6,38 & 3 \\
\hline & 138,3 & 159,7 & 1,16 & 6,61 & 6 \\
\hline & 112,2 & 281,3 & 1,05 & 6,26 & 8 \\
\hline & 126,1 & 185,4 & 0,86 & 6,23 & 3 \\
\hline
\end{tabular}


TABELA 26 - Resultados da fase III do ponto C.

\begin{tabular}{|c|c|c|c|c|c|}
\hline & $\begin{array}{c}\text { СОТ } \\
\left(\mu \mathrm{g} \mathrm{L}^{-1}\right)\end{array}$ & $\begin{array}{c}\text { Cl } \\
\left(\mu \mathrm{g} \mathrm{L}^{-1}\right)\end{array}$ & $\begin{array}{l}\text { Condutividade } \\
\qquad\left(\mu \mathrm{S} \mathrm{cm}^{-1}\right)\end{array}$ & pH & $\begin{array}{c}\text { Contagem de aeróbios } \\
\text { totais } \\
(\mathrm{UFC} \mathrm{mL})\end{array}$ \\
\hline \multirow{38}{*}{ 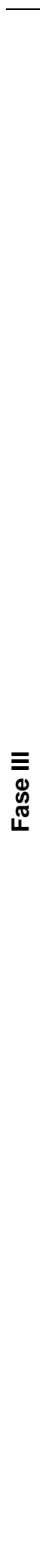 } & $<\mathrm{LD}$ & 305,1 & 0,83 & 6,96 & 2.800 \\
\hline & 78,50 & 199,8 & 0,80 & 6,51 & 7 \\
\hline & 48,0 & 170,3 & 0,84 & 6,89 & 1 \\
\hline & $<$ LD & 244,0 & 0,89 & 6,48 & L \\
\hline & 118,2 & 181,8 & 0,82 & 6,94 & 1 \\
\hline & 54,43 & 163,0 & 0,83 & 6,82 & $<1$ \\
\hline & 519,0 & 151,0 & 0,84 & 6,20 & 9 \\
\hline & 29,90 & 20,77 & 0,71 & 6,56 & 15 \\
\hline & 62,1 & 180,6 & 0,92 & 6,54 & 15 \\
\hline & 312,3 & 149,1 & 0,98 & 6,03 & $<1$ \\
\hline & 98,02 & 140,9 & 0,81 & 6,63 & $<1$ \\
\hline & 115,3 & 144,7 & 0,93 & 5,90 & $<1$ \\
\hline & 148,4 & 148,5 & 0,93 & 6,93 & $<1$ \\
\hline & 103,2 & 169,8 & 0,98 & 6,11 & $<1$ \\
\hline & 62,98 & 174,0 & 1,13 & 5,88 & $<1$ \\
\hline & 34,52 & 171,2 & 1,15 & 6,36 & $<1$ \\
\hline & 65,4 & 192,8 & 0,91 & 6,11 & 12 \\
\hline & 134,2 & 152,7 & 0,98 & 6,29 & $<1$ \\
\hline & 56,84 & 178,1 & 0,96 & 6,20 & 1 \\
\hline & 71,83 & 162,3 & 1,13 & 6,73 & $<1$ \\
\hline & 94,95 & 149,0 & 0,92 & 5,91 & $<1$ \\
\hline & 7.889 & 184,5 & 0,99 & 5,86 & 1 \\
\hline & 269,3 & 197,9 & 0,92 & 6,38 & 2 \\
\hline & 2.112 & 188,8 & 1,02 & 6,31 & 7 \\
\hline & 973,5 & 213,7 & 1,20 & 6,51 & 26 \\
\hline & 264,8 & 180,5 & 0,76 & 6,49 & 10 \\
\hline & 128,7 & 153,8 & 1,17 & 6,18 & $<1$ \\
\hline & 440,8 & 155,0 & 1,04 & 6,13 & $<1$ \\
\hline & 1493 & 141,8 & 0,96 & 6,16 & 4 \\
\hline & 172,4 & 157,9 & 0,92 & 6,68 & $<1$ \\
\hline & 121,3 & 161,0 & 0,98 & 6,31 & $<1$ \\
\hline & 151,6 & 198,3 & 1,06 & 6,57 & 5 \\
\hline & 15,40 & 176,0 & 0,87 & 6,77 & 1 \\
\hline & $<L D$ & 157,8 & 0,86 & 6,42 & $<1$ \\
\hline & 12,40 & 6,94 & 0,95 & 5,79 & 1 \\
\hline & 60,28 & 218,4 & 1,00 & 6,34 & $<1$ \\
\hline & 75,26 & 201,0 & 1,00 & 6,24 & 120 \\
\hline & 186,2 & 237,1 & 1,11 & 6,62 & 3 \\
\hline
\end{tabular}


TABELA 26 - Continuação.

\begin{tabular}{|c|c|c|c|c|c|}
\hline & $\begin{array}{c}\text { СОT } \\
\left(\mu \mathrm{g} \mathrm{L}^{-1}\right)\end{array}$ & $\begin{array}{c}C l \\
\left(\mu \mathrm{g} \mathrm{L}^{-1}\right)\end{array}$ & $\begin{array}{l}\text { Condutividade } \\
\qquad\left(\mu \mathrm{S} \mathrm{cm}^{-1}\right)\end{array}$ & pH & $\begin{array}{c}\text { Contagem de aeróbios } \\
\text { totais } \\
\left(\mathrm{UFC} \mathrm{mL} \mathrm{mL}^{-1}\right)\end{array}$ \\
\hline \multirow{11}{*}{ 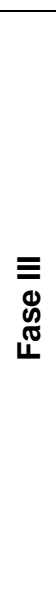 } & 148,3 & 277,5 & 1,14 & 6,89 & $<1$ \\
\hline & 169,7 & 259,5 & 1,14 & 6,64 & 1 \\
\hline & 453,6 & 157,8 & 0,66 & 6,74 & $<1$ \\
\hline & 105,2 & 171,0 & 1,15 & 5,91 & $<1$ \\
\hline & 35,42 & 171,9 & 0,94 & 6,96 & $<1$ \\
\hline & 77,66 & 189,6 & 1,05 & 6,31 & $<1$ \\
\hline & 67,00 & 169,2 & 0,94 & 6,72 & $<1$ \\
\hline & 180,5 & 289,7 & 1,16 & 6,73 & 3 \\
\hline & 212,7 & 184,9 & 1,08 & 6,98 & 19 \\
\hline & 181,6 & 182,5 & 0,74 & 6,60 & 30 \\
\hline & 338,7 & 163,8 & 1,00 & 6,4 & $<1$ \\
\hline
\end{tabular}

TABELA 27 - Resultados da fase IV do ponto C.

\begin{tabular}{|c|c|c|c|c|c|}
\hline & $\begin{array}{c}\text { COT } \\
\left(\mu \mathrm{g} \mathrm{L}^{-1}\right)\end{array}$ & $\begin{array}{c}\text { Cl } \\
\left(\mu \mathrm{g} \mathrm{L}^{-1}\right)\end{array}$ & $\begin{array}{l}\text { Condutividade } \\
\qquad\left(\mu \mathrm{S} \mathrm{cm}^{-1}\right)\end{array}$ & $\mathrm{pH}$ & $\begin{array}{l}\text { Contagem de aeróbios totais } \\
\qquad\left(\mathrm{UFC} \mathrm{mL}^{-1}\right)\end{array}$ \\
\hline \multirow{16}{*}{$\begin{array}{l}\geq \\
\mathbb{\Phi} \\
\mathbb{E} \\
\text { L }\end{array}$} & $<\mathrm{LD}$ & 175,3 & 0,91 & 6,97 & $>6.500$ \\
\hline & 156,4 & 153,8 & 1,03 & 6,99 & $<1$ \\
\hline & 143,9 & 235,0 & 1,26 & 5,53 & $<1$ \\
\hline & 177,1 & 189,0 & 0,88 & 6,67 & $<1$ \\
\hline & 285,3 & 178,5 & 1,16 & 6,76 & $<1$ \\
\hline & 1292 & 164,7 & 0,94 & 6,95 & 27 \\
\hline & 126,1 & 202,6 & 1,01 & 6,98 & $<1$ \\
\hline & 74,03 & 181,5 & 1,07 & 6,72 & 1 \\
\hline & 82,11 & 165,7 & 0,86 & 6,83 & $<1$ \\
\hline & 33,74 & 137,3 & 0,71 & 6,88 & $<1$ \\
\hline & 102,2 & 159,6 & 1,25 & 6,52 & 6 \\
\hline & 48,78 & 212,7 & 0,75 & 6,88 & 1 \\
\hline & 256,3 & 157,9 & 0,83 & 6,82 & $<1$ \\
\hline & 34,14 & 130,7 & 0,74 & 6,14 & $>6.500$ \\
\hline & 217,1 & 173,2 & 0,89 & 6,46 & $<1$ \\
\hline & 59,33 & 189,0 & 0,91 & 6,51 & $<1$ \\
\hline
\end{tabular}




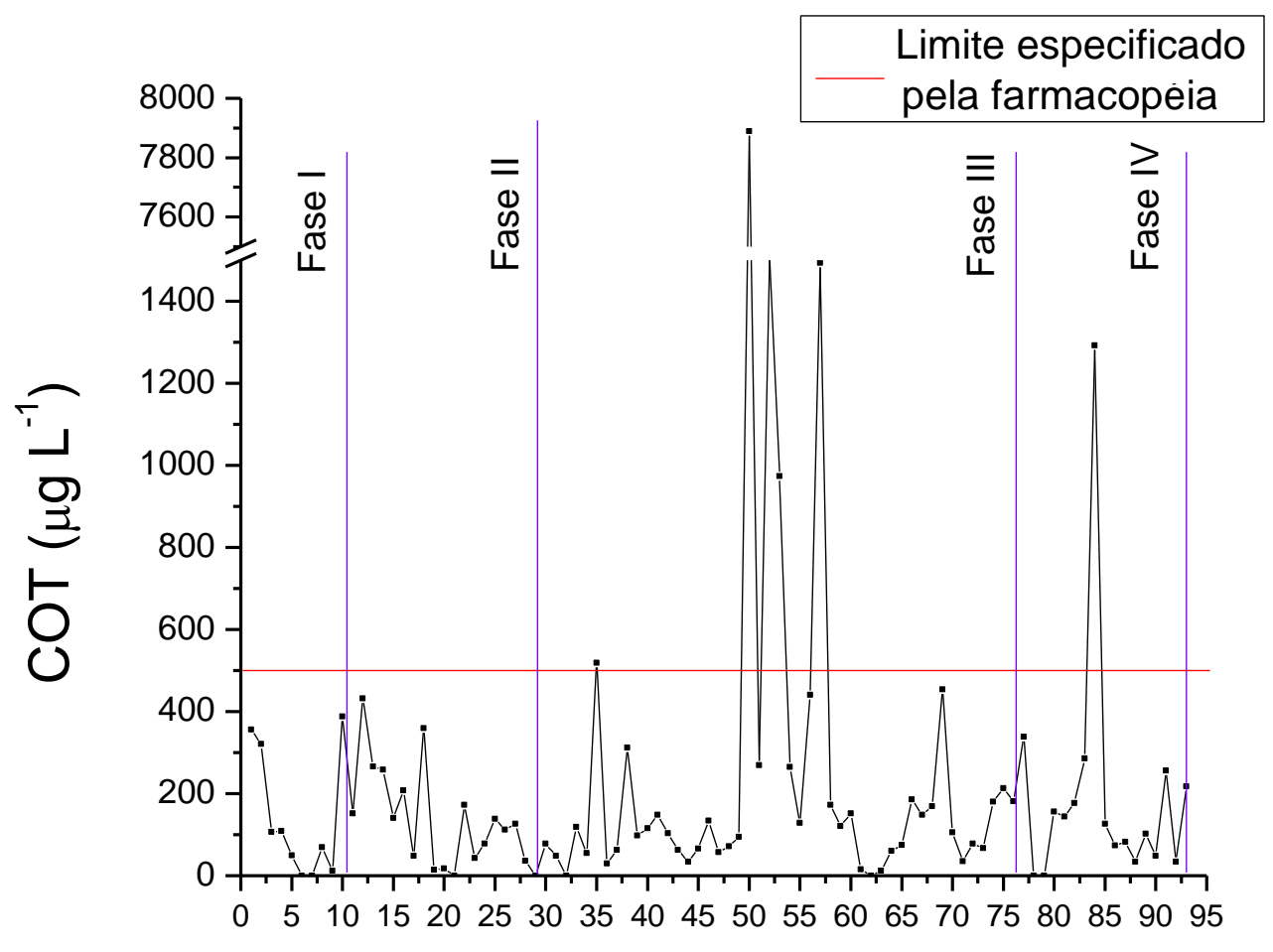

Dias

FIGURA 27 - Monitoramento de COT do ponto C.

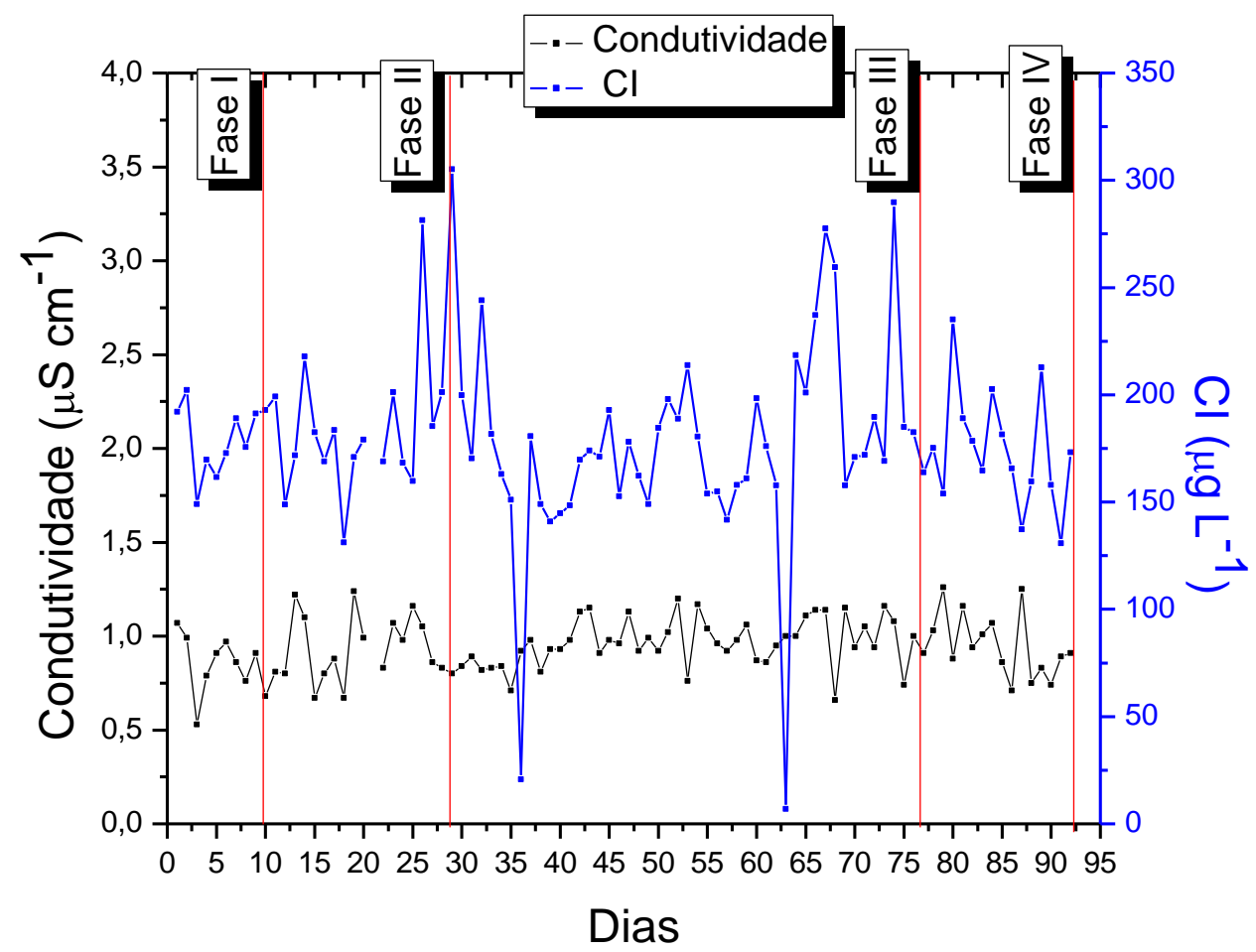

FIGURA 28 - Resultados de $\mathrm{Cl}$ e condutividade do ponto C. 
A água coletada do sistema identificado como ponto $\mathrm{C}$ apresentou resultados físico-químicos fora das especificações durante as fases III e IV, apresentando COT acima do especificado $\left(500 \mu \mathrm{g} \mathrm{L}^{-1}\right)$ em algumas coletas consecutivas indicando a necessidade de troca do filtro misto de pirofosfato de celulose e carvão ativo (FIG. 27). Durante o período monitorado, o valor médio de concentração de COT $\left(200 \mu \mathrm{g} \mathrm{L}^{-1}\right)$ foi maior que no ponto A (AP), o que pode ser atribuído à frequência de limpeza do reservatório.

As concentrações de $\mathrm{Cl}$ maiores que a média de $150 \mu \mathrm{g} \mathrm{L}^{-1}$ não refletiram em aumento de condutividade, indicando que $0 \mathrm{Cl}$ pode sofrer alterações sem afetar a condutividade (FIG. 28).

Os resultados das análises de contagem de aeróbios totais apresentaram-se fora do especificado em algumas ocasiões que não refletiram nos resultados de COT.

Segundo o esquema de coleta por 45 dias, com um programa diferenciado de manutenção e de limpeza do reservatório, os resultados estão apresentados na TAB. 28. 
TABELA 28 - Resultados do esquema de coletas de 45 dias do ponto C.

\begin{tabular}{|c|c|c|c|c|}
\hline & $\underset{\left(\mu \mathrm{g} \mathrm{L}^{-1}\right)}{\mathrm{COT}}$ & $\begin{array}{l}\text { Condutividade } \\
\left(\mu \mathrm{S} \mathrm{cm}^{-1}\right)\end{array}$ & $\mathrm{pH}$ & $\begin{array}{c}\text { Contagem de aeróbios } \\
\text { totais } \\
\text { (UFC } \mathrm{mL}^{-1} \text { ) }\end{array}$ \\
\hline \multirow{9}{*}{ 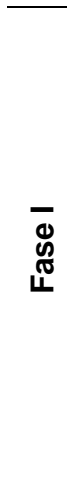 } & 30,56 & 0,62 & 6,31 & 6 \\
\hline & 19,79 & 0,69 & 6,63 & 16 \\
\hline & 34,65 & 0,74 & 6,17 & 6 \\
\hline & 190,5 & 0,63 & 6,64 & 2 \\
\hline & 207,2 & 0,58 & 6,53 & 10 \\
\hline & 85,92 & 0,69 & 6,52 & 10 \\
\hline & 481,0 & 0,64 & 6,78 & 6 \\
\hline & 17,15 & 0,90 & 6,91 & 6 \\
\hline & 121,1 & 0,59 & 6,52 & 6 \\
\hline \multirow{6}{*}{ 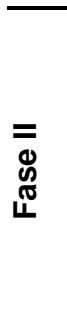 } & 137,8 & 0,68 & 6,25 & 3 \\
\hline & 20,34 & 0,68 & 6,42 & 5 \\
\hline & 182,7 & 0,81 & 6,24 & 15 \\
\hline & 59,72 & 0,95 & 6,81 & $<1$ \\
\hline & 44,39 & 0,67 & 6,52 & 12 \\
\hline & 201,6 & 0,81 & 6,49 & 25 \\
\hline \multirow{4}{*}{ 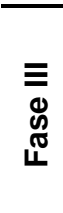 } & 102,6 & 0,69 & 6,63 & 16 \\
\hline & 29,29 & 0,81 & 6,29 & 17 \\
\hline & 99,44 & 0,77 & 6,98 & 13 \\
\hline & 131,7 & 0,61 & 6,81 & 7 \\
\hline
\end{tabular}

Os resultados dos parâmetros analisados na água produzida pelo sistema definido como ponto $\mathrm{C}$ atenderam aos limites estabelecidos pelas farmacopeias.

Comparando-se os resultados das análises da água produzida pelos pontos $A, B$ ou $C$, que possuem os mesmos sistemas de purificação, pode-se observar que quanto maior a frequência de limpeza do reservatório, menor a concentração de COT. Com uma frequência de limpeza do reservatório quinzenal os valores de COT da água foram de cerca de $200 \mu \mathrm{g} \mathrm{L}^{-1}$ e com uma frequência semestral e com esvaziamento diário os valores de COT são de cerca de $400 \mu \mathrm{g} \mathrm{L}^{-1}$

\subsubsection{Ponto D}

Os resultados das análises de desempenho do purificador para produção de API, definido como ponto D, estão representados nas TAB. 29, 30 e 
31. Os resultados do monitoramento de COT do ponto $D$ (API) estão representados na FIG. 29 e na FIG. $\mathbf{3 0}$ estão relacionados os resultados de $\mathbf{C l}$ e condutividade.

TABELA 29 - Resultados das fases I e II do ponto D.

\begin{tabular}{|c|c|c|c|c|c|c|}
\hline & $\begin{array}{c}\text { COT } \\
\left(\mu \mathrm{g} \mathrm{L}^{-1}\right)\end{array}$ & $\begin{array}{c}\text { Cl } \\
\left(\mu \mathrm{g} \mathrm{L}^{-1}\right)\end{array}$ & $\begin{array}{l}\text { Condutividade } \\
\qquad\left(\mu \mathrm{S} \mathrm{cm}^{-1}\right)\end{array}$ & $\mathrm{pH}$ & $\begin{array}{l}\text { Contagem de } \\
\text { aeróbios totais } \\
\left(\text { UFC } 100 \mathrm{~mL}^{-1} \text { ) }\right.\end{array}$ & $\begin{array}{c}\text { Endotoxina } \\
\text { Bacteriana } \\
\left(\mathrm{UE} \mathrm{mL^{-1 } )}\right.\end{array}$ \\
\hline \multirow{10}{*}{ 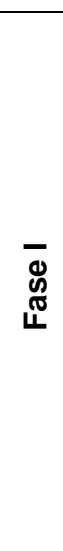 } & 117,9 & 128,3 & 1,20 & 6,82 & $<1$ & $<0,06$ \\
\hline & 64,02 & 141,1 & 0,68 & 6,57 & $<1$ & $<0,06$ \\
\hline & 67,82 & 123,3 & 0,70 & 6,32 & 1 & $<0,06$ \\
\hline & 51,92 & 114,2 & 0,54 & 7,00 & $<1$ & $<0,06$ \\
\hline & 77,09 & 110,7 & 0,69 & 5,80 & $<1$ & $<0,06$ \\
\hline & $<$ LD & 96,48 & 0,52 & 6,99 & $<1$ & $<0,06$ \\
\hline & $<$ LD & 165,7 & 0,61 & 7,00 & $<1$ & $<0,06$ \\
\hline & 154,3 & 114,9 & 0,86 & 6,89 & $<1$ & $<0,06$ \\
\hline & $<L D$ & 161,0 & 0,67 & 6,10 & 2 & $<0,06$ \\
\hline & 148,4 & 127,2 & 0,53 & 6,13 & 10 & $<0,06$ \\
\hline \multirow{17}{*}{$\begin{array}{l}\overline{\bar{\Phi}} \\
\mathscr{D} \\
\mathscr{L} \\
\mathscr{L}\end{array}$} & 36,96 & 97,1 & 0,51 & 6,50 & $<1$ & $<0,06$ \\
\hline & 105,4 & 120,6 & 0,81 & 6,67 & $<1$ & $<0,06$ \\
\hline & $<L D$ & 229,7 & 0,25 & 6,18 & $<1$ & $<0,06$ \\
\hline & 90,03 & 157,7 & 0,71 & 6,94 & $<1$ & $<0,06$ \\
\hline & 51,69 & 107,3 & 0,00 & 6,63 & $<1$ & $<0,06$ \\
\hline & 262,8 & 107,9 & 0,49 & 6,48 & $<1$ & $<0,06$ \\
\hline & $<L D$ & 153,7 & 0,63 & 6,20 & 11 & $<0,06$ \\
\hline & $<L D$ & 100,7 & 0,49 & 6,28 & $<1$ & $<0,06$ \\
\hline & 7,434 & 125,9 & 1,04 & 7,00 & $<1$ & $<0,06$ \\
\hline & 2,16 & 127,9 & 0,28 & 6,85 & $<1$ & $<0,06$ \\
\hline & $-*$ & $-^{*}$ & 2,40 & 6,44 & $<1$ & $<0,06$ \\
\hline & 43,84 & 109,2 & 0,53 & 6,39 & $<1$ & $<0,06$ \\
\hline & 19,06 & 136,2 & 0,85 & 6,63 & $<1$ & $<0,06$ \\
\hline & $<L D$ & 122,4 & 0,57 & 6,48 & $<1$ & $<0,06$ \\
\hline & 35,58 & 100,6 & 0,76 & 6,41 & 5 & $<0,06$ \\
\hline & 3,52 & 158,4 & 0,79 & 6,52 & 14 & $<0,06$ \\
\hline & 307,7 & 141,7 & 0,80 & 6,31 & $<1$ & $<0,06$ \\
\hline
\end{tabular}

*Não realizado 
TABELA 30 - Resultados da fase III do ponto D.

\begin{tabular}{|c|c|c|c|c|c|c|}
\hline & $\begin{array}{c}\text { COT } \\
\left(\mu \mathrm{g} \mathrm{L}^{-1}\right)\end{array}$ & $\begin{array}{c}\text { Cl } \\
\left(\mu \mathrm{g} \mathrm{L}^{-1}\right)\end{array}$ & $\begin{array}{l}\text { Condutividade } \\
\qquad\left(\mu \mathrm{S} \mathrm{cm}^{-1}\right)\end{array}$ & $\mathrm{pH}$ & $\begin{array}{l}\text { Contagem de } \\
\text { aeróbios totais } \\
\left(\text { UFC } 100 \mathrm{~mL}^{-1} \text { ) }\right.\end{array}$ & $\begin{array}{c}\text { Endotoxina } \\
\text { Bacteriana } \\
\left(\mathrm{UE} \mathrm{mL} \mathrm{m}^{-1}\right)\end{array}$ \\
\hline \multirow{39}{*}{ 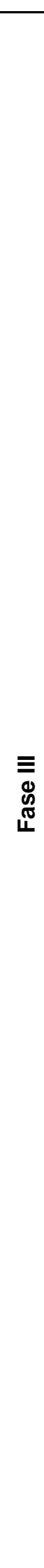 } & $<\mathrm{LD}$ & 312,8 & 0,58 & 6,69 & $<1$ & $<0,06$ \\
\hline & 37,0 & 119,7 & 0,53 & 6,53 & 5 & $<0,06$ \\
\hline & 13,1 & 111,7 & 0,54 & 6,97 & $<1$ & $<0,06$ \\
\hline & $<L D$ & 405,7 & 0,58 & 6,63 & $>200$ & $<0,06$ \\
\hline & 41,70 & 99,3 & 1,11 & 6,65 & $<1$ & $<0,06$ \\
\hline & 4,4 & 107,6 & 0,54 & 7,00 & $<1$ & $<0,06$ \\
\hline & 25,0 & 108,1 & 0,81 & 6,35 & $<1$ & $<0,06$ \\
\hline & 84,24 & 41,84 & 0,78 & 5,86 & $<1$ & $<0,06$ \\
\hline & 17,39 & 117,7 & 0,49 & 6,12 & $<1$ & $<0,06$ \\
\hline & 135,6 & 82,39 & 0,52 & 6,82 & $<1$ & $<0,06$ \\
\hline & 40,94 & 99,72 & 0,46 & 6,23 & $<1$ & $<0,06$ \\
\hline & 93,09 & 77,29 & 0,59 & 6,46 & $<1$ & $<0,06$ \\
\hline & 74,19 & 91,21 & 0,55 & 6,19 & $<1$ & $<0,06$ \\
\hline & 40,62 & 111,8 & 0,57 & 6,20 & $<1$ & $<0,06$ \\
\hline & 77,78 & 118,6 & 0,52 & 6,62 & $<1$ & $<0,06$ \\
\hline & 7,75 & 111,7 & 0,97 & 6,40 & $<1$ & $<0,06$ \\
\hline & 32,61 & 139,8 & 0,75 & 6,84 & $<1$ & $<0,06$ \\
\hline & 49,40 & 151,1 & 0,69 & 6,94 & $<1$ & $<0,06$ \\
\hline & 64,70 & 116,2 & 0,70 & 7,00 & 17 & $<0,06$ \\
\hline & 28,73 & 126,9 & 0,75 & 6,96 & $<1$ & $<0,06$ \\
\hline & 87,98 & 118,8 & 0,67 & 6,96 & $<1$ & $<0,06$ \\
\hline & 9843 & 119,9 & 0,70 & 6,93 & 3 & $<0,06$ \\
\hline & 184,50 & 147,3 & 0,85 & 6,66 & $<1$ & $<0,06$ \\
\hline & 369,8 & 103,8 & 0,68 & 6,03 & $<1$ & $<0,06$ \\
\hline & 354,0 & 162,0 & 0,69 & 6,42 & $<1$ & $<0,06$ \\
\hline & 32,67 & 118,5 & 0,56 & 6,51 & $<1$ & $>0,25$ \\
\hline & 141,6 & 120,8 & 0,54 & 6,47 & $<1$ & $<0,06$ \\
\hline & 456,9 & 126,0 & 0,52 & 6,15 & 1 & $<0,06$ \\
\hline & 88,14 & 85,0 & 0,92 & 6,68 & $>200$ & $<0,06$ \\
\hline & 92,76 & 97,18 & 0,75 & 6,56 & $<1$ & $>0,25$ \\
\hline & 38,62 & 128,3 & 0,48 & 6,94 & $<1$ & $<0,06$ \\
\hline & 31,78 & 96,36 & 0,49 & 6,89 & $<1$ & $<0,06$ \\
\hline & $<\mathrm{LD}$ & 112,3 & 0,58 & 6,69 & 2 & $<0,06$ \\
\hline & 114,4 & 126,6 & 0,72 & 6,42 & 4 & $<0,06$ \\
\hline & 10,8 & 304,8 & 0,74 & 6,28 & 1 & $<0,06$ \\
\hline & 68,57 & 154,9 & 0,77 & 6,25 & $<1$ & $<0,06$ \\
\hline & 21,72 & 145,3 & 0,57 & 6,63 & $<1$ & $<0,06$ \\
\hline & 55,67 & 131,9 & 0,70 & 6,27 & 1 & $<0,06$ \\
\hline & 71,58 & 172,6 & 0,83 & 6,50 & $<1$ & $<0,06$ \\
\hline
\end{tabular}


TABELA 30 - Continuação.

\begin{tabular}{|c|c|c|c|c|c|c|}
\hline & $\begin{array}{c}\text { COT } \\
\left(\mu \mathrm{g} \mathrm{L}^{-1}\right)\end{array}$ & $\begin{array}{c}\mathrm{Cl} \\
\left(\mu \mathrm{g} \mathrm{L}^{-1}\right)\end{array}$ & $\begin{array}{l}\text { Condutividade } \\
\qquad\left(\mu \mathrm{Scm}^{-1}\right)\end{array}$ & pH & $\begin{array}{l}\text { Contagem de } \\
\text { aeróbios totais } \\
\left(\text { UFC } 100 \mathrm{~mL}^{-1} \text { ) }\right.\end{array}$ & $\begin{array}{c}\text { Endotoxina } \\
\text { Bacteriana } \\
\left(\mathrm{UE} \mathrm{mL^{-1 } )}\right.\end{array}$ \\
\hline \multirow{9}{*}{ 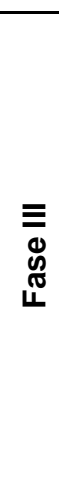 } & 84,00 & 165,09 & 0,68 & 6,32 & $<1$ & $<0,06$ \\
\hline & $<L D$ & 287,7 & 1,08 & 6,83 & 8 & $<0,06$ \\
\hline & 335,3 & 117,9 & 0,57 & 6,85 & $<1$ & $<0,06$ \\
\hline & 346,2 & 132,6 & 0,70 & 6,84 & 2 & $<0,06$ \\
\hline & 239,2 & 108,9 & 0,65 & 6,55 & $<1$ & $<0,06$ \\
\hline & 238,3 & 122,6 & 0,80 & 6,89 & 5 & $<0,06$ \\
\hline & 88,0 & 245,6 & 0,85 & 6,92 & $<1$ & $<0,06$ \\
\hline & 146,6 & 149,3 & 0,68 & 6,63 & $<1$ & $<0,06$ \\
\hline & 83,80 & 127,2 & 1,05 & 6,84 & 1 & $<0,06$ \\
\hline
\end{tabular}

TABELA 31 - Resultados da fase IV do ponto D.

\begin{tabular}{|c|c|c|c|c|c|c|}
\hline & $\begin{array}{c}\text { COT } \\
\left(\mu \mathrm{g} \mathrm{L}^{-1}\right)\end{array}$ & $\begin{array}{c}\text { Cl } \\
\left(\mu \mathrm{g} \mathrm{L}^{-1}\right)\end{array}$ & $\begin{array}{l}\text { Condutividade } \\
\qquad\left(\mu \mathrm{S} \mathrm{cm}^{-1}\right)\end{array}$ & $\mathrm{pH}$ & $\begin{array}{l}\text { Contagem de } \\
\text { aeróbios totais } \\
\left(\text { UFC } 100 \mathrm{~mL}^{-1}\right)\end{array}$ & $\begin{array}{c}\text { Endotoxina } \\
\text { Bacteriana } \\
\left(\mathrm{UE} \mathrm{mL} \mathrm{mL}^{-1}\right)\end{array}$ \\
\hline \multirow{15}{*}{$\begin{array}{l}\geq \\
\mathbb{8} \\
\mathbb{E} \\
\text { एँ }\end{array}$} & 270,6 & 100,7 & 0,50 & 6,94 & 10 & $<0,06$ \\
\hline & $<$ LD & 114,7 & 0,74 & 6,70 & $>200$ & $<0,06$ \\
\hline & 259,2 & 82,32 & 0,51 & 6,85 & 71 & $<0,06$ \\
\hline & 169,80 & 117,9 & 0,68 & 6,32 & $<1$ & $<0,06$ \\
\hline & 231,8 & 106,4 & 0,62 & 6,90 & $<1$ & $<0,06$ \\
\hline & 106,0 & 117,3 & 0,74 & 6,69 & $<1$ & $<0,06$ \\
\hline & 43,47 & 119,6 & 0,79 & 6,85 & $<1$ & $<0,06$ \\
\hline & 110,0 & 101,0 & 0,75 & 6,58 & $<1$ & $<0,06$ \\
\hline & 9,91 & 124,4 & 0,78 & 6,83 & $<1$ & $<0,06$ \\
\hline & 396,8 & 130,0 & 0,63 & 6,86 & $<1$ & $<0,06$ \\
\hline & 30,14 & 88,99 & 0,50 & 6,48 & $>200$ & $<0,06$ \\
\hline & 115,8 & 124,5 & 0,71 & 6,26 & $<1$ & $<0,06$ \\
\hline & 25,99 & 141,2 & 0,62 & 6,98 & $<1$ & $<0,06$ \\
\hline & 41,06 & 169,0 & 0,77 & 6,92 & $<1$ & $<0,06$ \\
\hline & 100,9 & 111,5 & 0,56 & 6,18 & $<1$ & $<0,06$ \\
\hline
\end{tabular}




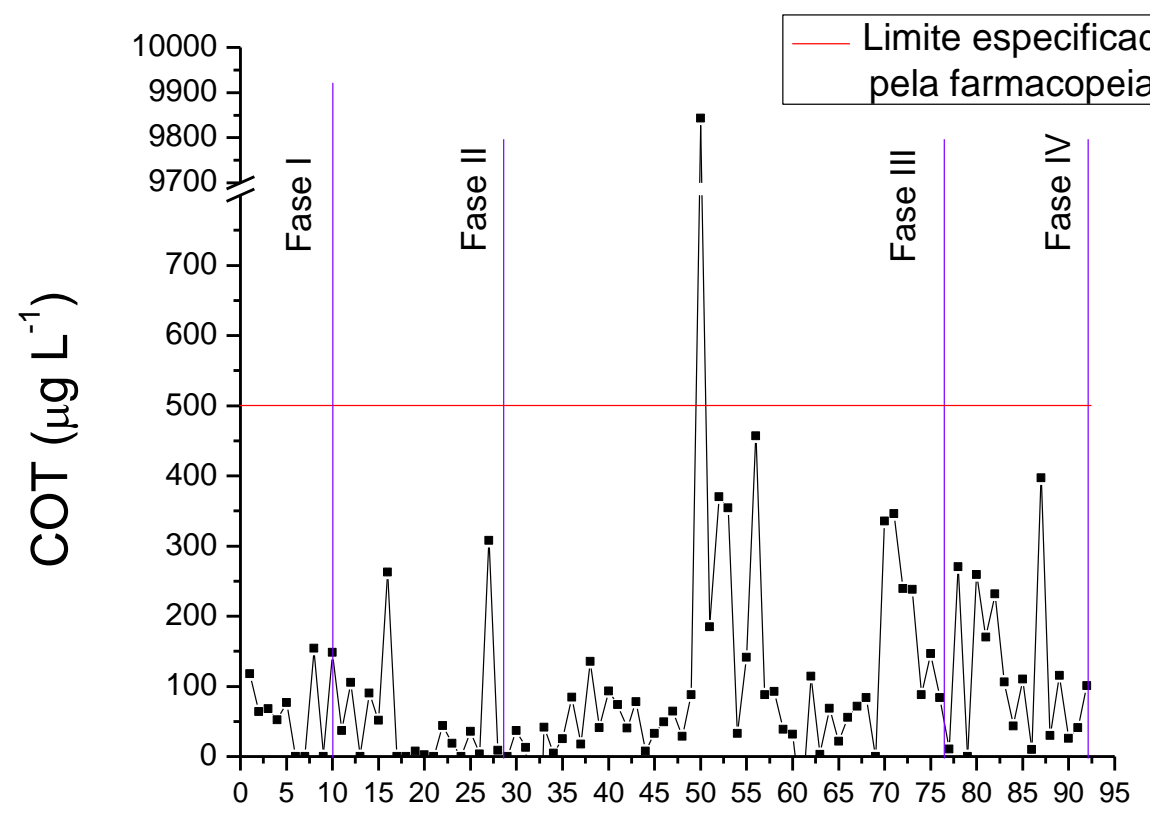

Dias

FIGURA 29 - Monitoramento de COT do ponto D.

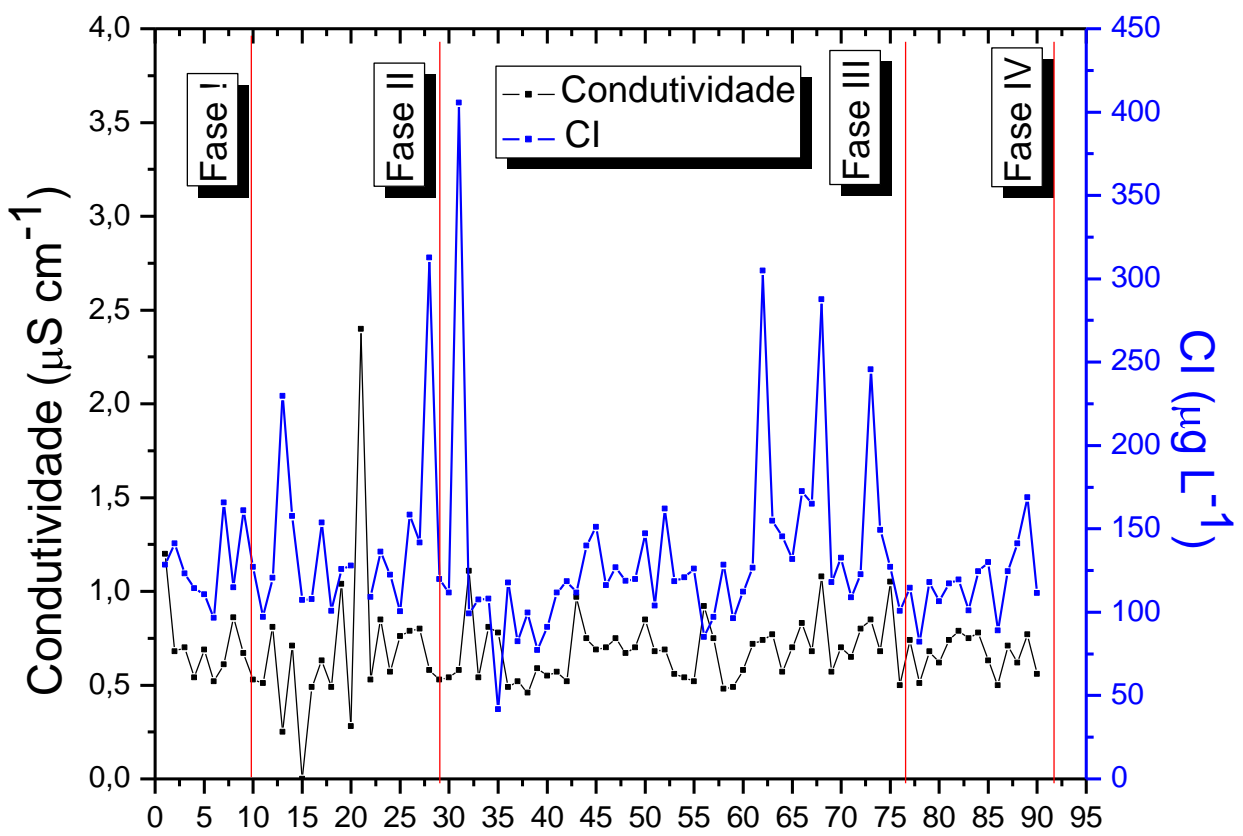

Dias

FIGURA 30 - Resultados de $\mathrm{Cl}$ e condutividade do ponto D. 
Durante toda a fase I, a água coletada no ponto $\mathrm{C}$ apresentou resultados que atenderam aos limites descritos nas farmacopeias. No entanto durante as fases II-IV foram encontrados desvios de COT, condutividade, contagem de aeróbios totais e endotoxina bacteriana.

De acordo com a FIG. 29, o teor de COT encontrado no ponto D apresentou tendência a manter-se abaixo de $100 \mu \mathrm{g} \mathrm{L}^{-1}$, no entanto devido à falha na manutenção do equipamento, houve aumento deste parâmetro durante as fases III e IV sendo encontrado concentração de COT de cerca de quase 20 vezes o limite de $500 \mu \mathrm{g} \mathrm{L}^{-1}$. Tal concentração foi reflexo da contaminação orgânica encontrada na AP proveniente do sistema do ponto C que alimentou o ponto $D$, que não foi removido pelo sistema de purificação. Isto indicou que a água admitida no sistema para produção de API deve atender aos requisitos de AP para que a purificação seja eficiente.

Na FIG. 30 observou-se que valores de Cl maiores que $150 \mu \mathrm{L} \mathrm{L}^{-1}$ não estavam relacionados à condutividade.

Apesar de obter desempenho físico-químico satisfatório, os resultados de contagem de aeróbios totais deste equipamento foram insatisfatórios. Foi estabelecido um programa de limpeza e manutenção adequado e foi feito um novo programa de coleta de água, com duração de 45 dias e os resultados estão apresentados na TAB. 32. 
TABELA 32 - Resultados do esquema de coletas de 45 dias do ponto D.

\begin{tabular}{|c|c|c|c|c|c|}
\hline & $\begin{array}{c}\text { COT } \\
\left(\mu \mathrm{g} \mathrm{L}^{-1}\right)\end{array}$ & $\begin{array}{l}\text { Condutividade } \\
\qquad\left(\mu \mathrm{S} \mathrm{cm}^{-1}\right)\end{array}$ & $\mathrm{pH}$ & $\begin{array}{l}\text { Contagem de } \\
\text { aeróbios totais } \\
\text { (UFC } 100 \mathrm{~mL}^{-1} \text { ) }\end{array}$ & $\begin{array}{c}\text { Endotoxina } \\
\text { Bacteriana } \\
\left(\mathrm{UE} \mathrm{mL} \mathrm{mL}^{-1}\right)\end{array}$ \\
\hline \multirow{9}{*}{ 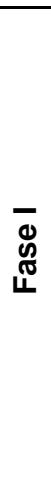 } & 35,89 & 0,51 & 6,51 & $<1$ & $<0,06$ \\
\hline & 52,13 & 0,57 & 6,65 & $<1$ & $<0,06$ \\
\hline & 0,1365 & 0,54 & 5,98 & $<1$ & $<0,06$ \\
\hline & 43,11 & 0,48 & 6,54 & $<1$ & $<0,06$ \\
\hline & 6,807 & 0,55 & 6,65 & $<1$ & $<0,06$ \\
\hline & 34,24 & 0,81 & 6,39 & $<1$ & $<0,06$ \\
\hline & 101,1 & 0,60 & 6,61 & $<1$ & $<0,06$ \\
\hline & 37,17 & 0,63 & 6,95 & $<1$ & $<0,06$ \\
\hline & 64,57 & 0,92 & 6,35 & $<1$ & $<0,06$ \\
\hline \multirow{6}{*}{ 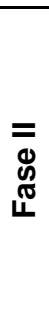 } & 319,0 & 0,63 & 6,27 & $<1$ & $<0,06$ \\
\hline & 52,47 & 0,53 & 6,33 & $<1$ & $<0,06$ \\
\hline & 105,4 & 0,53 & 6,52 & $<1$ & $<0,06$ \\
\hline & 138,7 & 0,73 & 6,53 & $<1$ & $<0,06$ \\
\hline & 41,64 & 0,69 & 6,29 & $<1$ & $<0,06$ \\
\hline & 313,7 & 0,56 & 6,31 & $<1$ & $<0,06$ \\
\hline \multirow{4}{*}{ 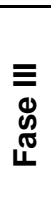 } & 21,32 & 0,48 & 6,52 & $<1$ & $<0,06$ \\
\hline & 86,27 & 0,66 & 6,26 & $<1$ & $<0,06$ \\
\hline & 56,13 & 0,53 & 6,51 & $<1$ & $<0,06$ \\
\hline & 93,26 & 0,64 & 6,16 & $<1$ & $<0,06$ \\
\hline
\end{tabular}

Todos os parâmetros analisados apresentaram resultados que atenderam aos limites estabelecidos pelas farmacopeias. Os resultados das TAB. 31 e 32 indicaram a importância do controle da qualidade da AP (ponto C) (FIG. 27) para a obtenção de API (ponto $D$ ) que atendam aos requisitos preconizados.

\subsubsection{Ponto E}

Os resultados das análises de $\mathrm{API}$ coletada no ponto $\mathrm{E}$ estão apresentados nas TAB. 33, 34 e 35. Os resultados do monitoramento de COT estão representados na FIG. 31 e os resultados de $\mathrm{Cl}$ e condutividade estão relacionados na FIG. 32 
TABELA 33 - Resultados das fases I e II do ponto E.

\begin{tabular}{|c|c|c|c|c|c|c|}
\hline & $\begin{array}{c}\text { COT } \\
\left(\mu \mathrm{g} \mathrm{L}^{-1}\right)\end{array}$ & $\begin{array}{c}C l \\
\left(\mu \mathrm{g} \mathrm{L}^{-1}\right)\end{array}$ & $\begin{array}{l}\text { Condutividade } \\
\qquad\left(\mu \mathrm{Scm}^{-1}\right)\end{array}$ & pH & $\begin{array}{l}\text { Contagem de } \\
\text { aeróbios totais } \\
\left(\text { UFC } 100 \mathrm{~mL}^{-1}\right)\end{array}$ & $\begin{array}{c}\text { Endotoxina } \\
\text { Bacteriana } \\
\left(\mathrm{UE} \mathrm{mL} \mathrm{mL}^{-1}\right)\end{array}$ \\
\hline \multirow{10}{*}{$\begin{array}{l}\bar{\Phi} \\
\mathscr{W} \\
\text { L }\end{array}$} & 252,7 & 100,8 & 0,15 & 6,99 & $<1$ & $<0,06$ \\
\hline & 88,11 & 71,44 & 0,28 & 6,80 & $<1$ & $<0,06$ \\
\hline & 194,8 & 88,28 & 0,65 & 6,64 & 3 & $<0,06$ \\
\hline & 8,79 & 103,6 & 0,57 & 6,00 & $<1$ & $<0,06$ \\
\hline & 92,21 & 84,42 & 0,48 & 6,84 & $<1$ & $<0,06$ \\
\hline & 64,14 & 63,7 & 0,40 & 6,85 & $<1$ & $<0,06$ \\
\hline & 28,73 & 81,8 & 0,47 & 7,07 & $<1$ & $<0,06$ \\
\hline & 113,7 & 136,0 & 0,79 & 6,87 & $<1$ & $<0,06$ \\
\hline & 62,71 & 95,72 & 0,43 & 7,12 & $<1$ & $<0,06$ \\
\hline & 81,42 & 67,71 & 0,39 & 6,99 & $<1$ & $<0,06$ \\
\hline \multirow{17}{*}{$\begin{array}{l}\overline{\bar{\Phi}} \\
\mathscr{D} \\
\mathscr{\Xi} \\
\mathscr{L}\end{array}$} & 220,3 & 101,5 & 0,72 & 6,87 & $<1$ & $<0,06$ \\
\hline & 348,3 & 99,2 & 0,92 & 6,56 & 16 & $<0,06$ \\
\hline & 131,5 & 74,9 & 0,75 & 6,09 & $<1$ & $<0,06$ \\
\hline & 267,2 & 63,5 & 0,42 & 6,30 & 1 & $<0,06$ \\
\hline & 56,15 & 123,8 & 0,56 & 6,81 & $<1$ & $<0,06$ \\
\hline & 102,3 & 89,3 & 0,48 & 6,22 & 65 & $<0,06$ \\
\hline & 37,10 & 169,6 & 0,75 & 6,69 & 35 & $<0,06$ \\
\hline & 59,85 & 110,9 & 0,56 & 6,24 & $<1$ & $<0,06$ \\
\hline & 32,34 & 126,8 & 0,41 & 6,83 & $>200$ & $<0,06$ \\
\hline & 76,14 & 101,8 & 0,68 & 6,52 & $<1$ & $<0,06$ \\
\hline & 57,35 & 120,7 & 0,82 & 6,71 & $<1$ & $<0,06$ \\
\hline & 115,3 & 69,6 & 0,46 & 6,99 & $<1$ & $<0,06$ \\
\hline & $<$ LD & 132,3 & 0,70 & 6,17 & 92 & $<0,06$ \\
\hline & 36,95 & 118,6 & 0,77 & 6,14 & $<1$ & $<0,06$ \\
\hline & 62,22 & 133,2 & 0,67 & 6,17 & $<1$ & $<0,06$ \\
\hline & 51,04 & 109,0 & 0,92 & 6,06 & 10 & $<0,06$ \\
\hline & 27,14 & 136,2 & 1,05 & 6,05 & $<1$ & $<0,06$ \\
\hline
\end{tabular}


TABELA 34 - Resultados da fase III do ponto E.

\begin{tabular}{|c|c|c|c|c|c|c|}
\hline & $\begin{array}{c}\text { COT } \\
\left(\mu \mathrm{g} \mathrm{L}^{-1}\right)\end{array}$ & $\begin{array}{c}\mathrm{Cl} \\
\left(\mu \mathrm{g} \mathrm{L}^{-1}\right)\end{array}$ & $\begin{array}{l}\text { Condutividade } \\
\qquad\left(\mu \mathrm{S} \mathrm{cm}^{-1}\right)\end{array}$ & $\mathrm{pH}$ & $\begin{array}{l}\text { Contagem de } \\
\text { aeróbios totais } \\
\left(\text { UFC } 100 \mathrm{~mL}^{-1} \text { ) }\right.\end{array}$ & $\begin{array}{c}\text { Endotoxina } \\
\text { Bacteriana } \\
\left(\mathrm{UE} \mathrm{mL} \mathrm{m}^{-1}\right)\end{array}$ \\
\hline \multirow{38}{*}{ 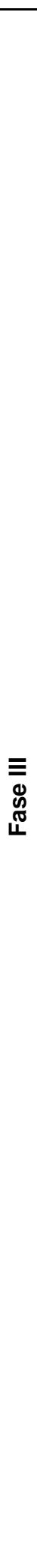 } & 41,29 & 128,4 & 0,70 & 6,57 & $<1$ & $<0,06$ \\
\hline & 103,3 & 216,9 & 0,45 & 6,24 & $<1$ & $<0,06$ \\
\hline & 396,2 & 222,8 & 0,77 & 6,53 & 1 & $<0,06$ \\
\hline & 66,88 & 128,6 & 0,84 & 6,23 & $<1$ & $<0,06$ \\
\hline & 32,28 & 106 & 0,48 & 6,22 & $<1$ & $<0,06$ \\
\hline & 77,51 & 123,9 & 0,76 & 6,77 & $<1$ & $<0,06$ \\
\hline & 146,2 & 70,5 & 0,57 & 6,70 & $<1$ & $<0,06$ \\
\hline & 140,7 & 154,3 & 0,76 & 6,08 & $<1$ & $<0,06$ \\
\hline & 31,39 & 101,7 & 1,08 & 6,61 & $<1$ & $<0,06$ \\
\hline & 62,98 & 119,1 & 0,71 & 5,87 & $<1$ & $<0,06$ \\
\hline & 57,14 & 214,4 & 0,44 & 6,39 & $<1$ & $<0,06$ \\
\hline & 51,87 & 89,78 & 0,58 & 6,02 & $<1$ & $<0,06$ \\
\hline & 116,2 & 122,4 & 0,71 & 6,84 & $<1$ & $<0,06$ \\
\hline & 192,9 & 92,2 & 0,55 & 6,01 & $<1$ & $<0,06$ \\
\hline & 149,7 & 82,8 & 0,51 & 6,35 & $<1$ & $<0,06$ \\
\hline & 146,9 & 80,3 & 0,58 & 6,40 & $<1$ & $<0,06$ \\
\hline & 1.100 & 80,69 & 0,43 & 6,51 & 1 & $<0,06$ \\
\hline & 260,5 & 106,1 & 0,66 & 6,84 & 3 & $<0,06$ \\
\hline & 87,49 & 134,3 & 0,70 & 6,30 & $<1$ & $<0,06$ \\
\hline & 102,6 & 110,6 & 0,75 & 6,47 & $<1$ & $<0,06$ \\
\hline & 17,09 & 155,5 & 0,80 & 6,52 & $<1$ & $<0,06$ \\
\hline & 4.649 & 113,4 & 0,62 & 6,12 & $<1$ & $<0,06$ \\
\hline & 114,6 & 117,8 & 0,60 & 5,90 & $<1$ & $<0,06$ \\
\hline & 81,99 & 92,34 & 0,61 & 5,92 & $<1$ & $<0,06$ \\
\hline & 146,1 & 212,6 & 0,70 & 5,78 & 5 & $<0,06$ \\
\hline & 27,86 & 270,9 & 0,60 & 6,00 & $<1$ & $<0,06$ \\
\hline & 32,84 & 272,8 & 0,72 & 5,89 & $<1$ & $<0,06$ \\
\hline & 70,58 & 124,4 & 0,85 & 6,16 & 20 & $<0,06$ \\
\hline & 524,1 & 217,5 & 0,84 & 6,03 & $<1$ & $<0,06$ \\
\hline & 133,9 & 211,2 & 0,54 & 6,16 & 37 & $<0,06$ \\
\hline & 15,33 & 105,8 & 0,63 & 6,07 & $<1$ & $<0,06$ \\
\hline & $<$ LD & 224,9 & 0,51 & 6,33 & $<1$ & $<0,06$ \\
\hline & 349,8 & 240,8 & 0,77 & 6,43 & $<1$ & $<0,06$ \\
\hline & 62,86 & 131,0 & 0,77 & 5,94 & 36 & $<0,06$ \\
\hline & 164,4 & 107,7 & 0,56 & 6,64 & $<1$ & $<0,06$ \\
\hline & 51,79 & 226 & 0,71 & 6,11 & $<1$ & $<0,06$ \\
\hline & 132,3 & 268,4 & 0,63 & 6,51 & 2 & $<0,06$ \\
\hline & 40,24 & 119,5 & 0,69 & 6,84 & $<1$ & $<0,06$ \\
\hline
\end{tabular}


TABELA 34 - Continuação.

\begin{tabular}{|c|c|c|c|c|c|c|}
\hline & $\begin{array}{c}\text { COT } \\
\left(\mu \mathrm{g} \mathrm{L}^{-1}\right)\end{array}$ & $\begin{array}{c}\text { Cl } \\
\left(\mu \mathrm{g} \mathrm{L}^{-1}\right)\end{array}$ & $\begin{array}{l}\text { Condutividade } \\
\qquad\left(\mu \mathrm{S} \mathrm{cm}^{-1}\right)\end{array}$ & pH & $\begin{array}{l}\text { Contagem de } \\
\text { aeróbios totais } \\
\left(\text { UFC } 100 \mathrm{~mL}^{-1} \text { ) }\right.\end{array}$ & $\begin{array}{c}\text { Endotoxina } \\
\text { Bacteriana } \\
\left(\mathrm{UE} \mathrm{mL} \mathrm{mL}^{-1}\right)\end{array}$ \\
\hline \multirow{10}{*}{ 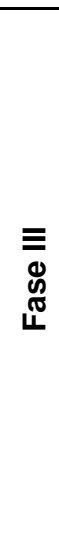 } & 278,5 & 227,4 & 0,75 & 6,57 & $<1$ & $<0,06$ \\
\hline & 37,34 & 124,1 & 0,80 & 6,08 & $<1$ & $<0,06$ \\
\hline & 239,8 & 93,7 & 0,26 & 6,63 & $<1$ & $<0,06$ \\
\hline & 222,5 & 87,8 & 0,59 & 6,69 & $<1$ & $<0,06$ \\
\hline & 209,9 & 122,9 & 0,73 & 6,51 & $<1$ & $<0,06$ \\
\hline & 64,14 & 111,6 & 0,32 & 6,83 & 12 & $<0,06$ \\
\hline & 62,78 & 99,54 & 0,61 & 6,72 & $<1$ & $<0,06$ \\
\hline & 271,3 & 82,7 & 0,71 & 5,74 & 8 & $<0,06$ \\
\hline & 113,9 & 100,6 & 0,73 & 6,52 & $<1$ & $<0,06$ \\
\hline & 197,4 & 104,5 & 0,59 & 6,84 & 1 & $<0,06$ \\
\hline
\end{tabular}

TABELA 35 - Resultados da fase IV do ponto E.

\begin{tabular}{|c|c|c|c|c|c|c|}
\hline & $\begin{array}{c}\text { COT } \\
\left(\mu \mathrm{g} \mathrm{L}^{-1}\right)\end{array}$ & $\begin{array}{c}\mathrm{Cl} \\
\left(\mu \mathrm{g} \mathrm{L}^{-1}\right)\end{array}$ & $\begin{array}{l}\text { Condutividade } \\
\qquad\left(\mu \mathrm{S} \mathrm{cm}^{-1}\right)\end{array}$ & $\mathrm{pH}$ & $\begin{array}{l}\text { Contagem de } \\
\text { aeróbios totais } \\
\left(\text { UFC } 100 \mathrm{~mL}^{-1} \text { ) }\right.\end{array}$ & $\begin{array}{c}\text { Endotoxina } \\
\text { Bacteriana } \\
\left(\mathrm{UE} \mathrm{mL} \mathrm{m}^{-1}\right)\end{array}$ \\
\hline \multirow{16}{*}{$\begin{array}{l}\geq \\
\mathbb{\Phi} \\
\mathscr{L} \\
\mathscr{L}\end{array}$} & 118,4 & 98,7 & 0,68 & 6,02 & 10 & $<0,06$ \\
\hline & 86,98 & 93,7 & 0,59 & 6,81 & $<1$ & $<0,06$ \\
\hline & 242,4 & 83,46 & 0,72 & 5,5 & $<1$ & $<0,06$ \\
\hline & 37,32 & 97,5 & 0,74 & 5,5 & 33 & $<0,06$ \\
\hline & 165,5 & 89,33 & 0,70 & 5,0 & $<1$ & $<0,06$ \\
\hline & 89,28 & 104,7 & 0,68 & 6,03 & 2 & $<0,06$ \\
\hline & 95,08 & 212,8 & 0,61 & 6,06 & $<1$ & $<0,06$ \\
\hline & 167,4 & 124,4 & 0,60 & 6,67 & $<1$ & $<0,06$ \\
\hline & 137,0 & 93,28 & 0,69 & 6,22 & $<1$ & $<0,06$ \\
\hline & $<\mathrm{LD}$ & 131,7 & 0,92 & 6,75 & 1 & $<0,06$ \\
\hline & 13,83 & 160,1 & 0,63 & 6,37 & $<1$ & $<0,06$ \\
\hline & 130,1 & 208,2 & 0,97 & 6,91 & $<1$ & $<0,06$ \\
\hline & 30,83 & 127,6 & 0,67 & 6,55 & 10 & $<0,06$ \\
\hline & 46,51 & 210,1 & 0,56 & 6,62 & $<1$ & $<0,06$ \\
\hline & 150,4 & 125,3 & 0,83 & 6,48 & $<1$ & $<0,06$ \\
\hline & 233,1 & 330,1 & 1,44 & 6,34 & 9 & $<0,06$ \\
\hline
\end{tabular}




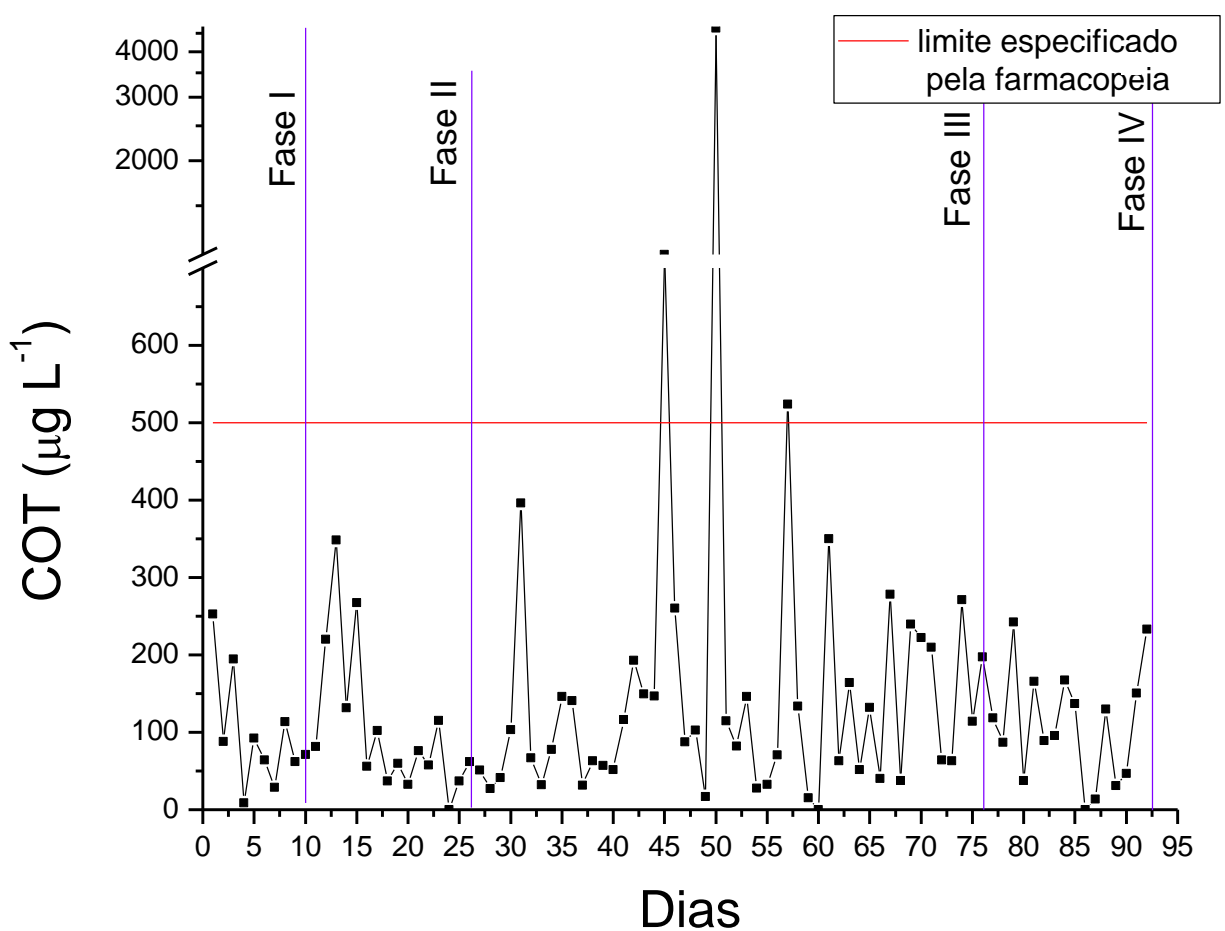

FIGURA 31 - Monitoramento de COT do ponto E.

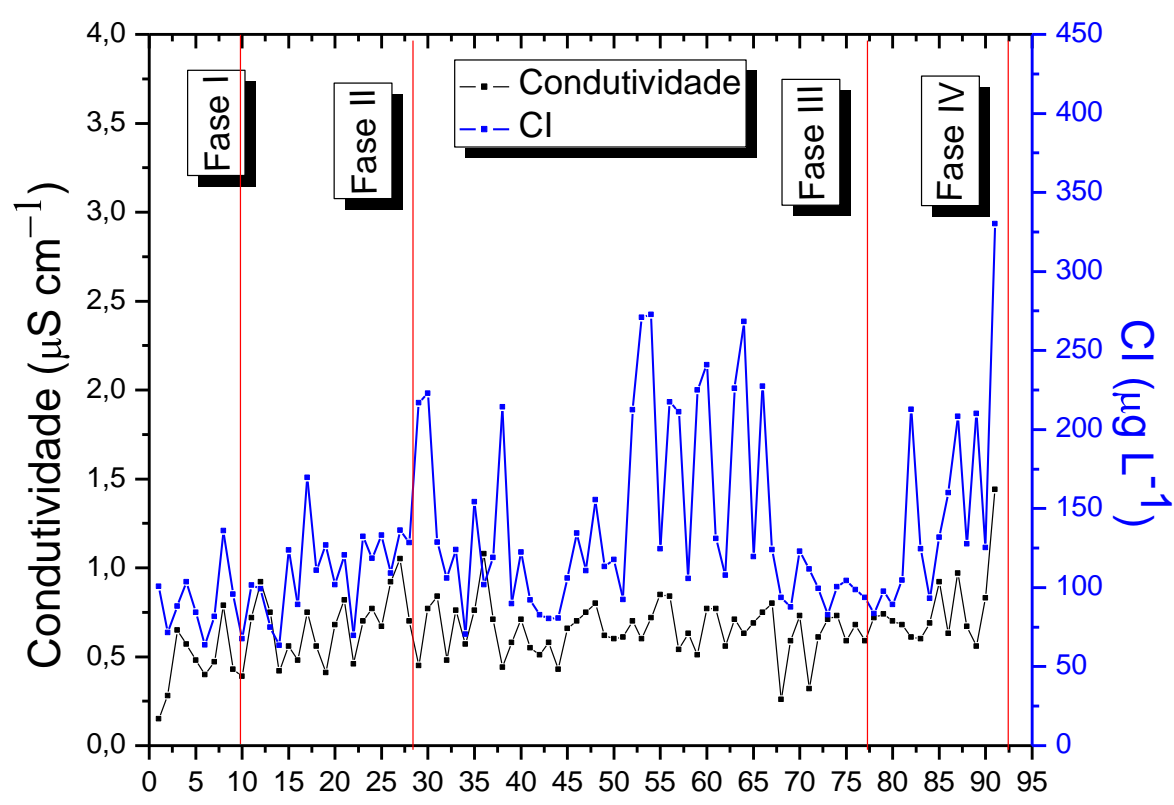

Dias

FIGURA 32 - Resultados de $\mathrm{Cl}$ e condutividade do ponto $\mathrm{E}$. 
Durante o período de monitoramento do ponto $E$ foram encontrados desvios de COT, $\mathrm{pH}$ e contagem de aeróbios totais, evidenciando a necessidade de adequação do sistema de purificação e armazenamento (FIG. 31). Na fase III, o aumento de $\mathrm{Cl}$ (FIG. 32) acarretou em aumento no COT (FIG. 31). O aumento no $\mathrm{Cl}$ não alterou o perfil da condutividade, indicando que substâncias não iônicas estão contribuindo para composição deste parâmetro.

\subsubsection{Ponto F}

Os resultados das análises de API produzida pelo ponto E coletada no sistema de distribuição após o reservatório de armazenagem (ponto $\mathrm{F}$ ) estão apresentados nas TAB. 36, 37 e 38. Na FIG. 33 estão relacionados os resultados do monitoramento de COT e na FIG. 34 estão representados os resultados de CI e condutividade. 
TABELA 36 - Resultados das fases I e II do ponto F.

\begin{tabular}{|c|c|c|c|c|c|c|}
\hline & $\begin{array}{c}\text { COT } \\
\left(\mu \mathrm{g} \mathrm{L}^{-1}\right)\end{array}$ & $\begin{array}{c}\text { Cl } \\
\left(\mu \mathrm{g} \mathrm{L}^{-1}\right)\end{array}$ & $\begin{array}{l}\text { Condutividade } \\
\qquad\left(\mu \mathrm{S} \mathrm{cm}^{-1}\right)\end{array}$ & $\mathrm{pH}$ & $\begin{array}{l}\text { Contagem de } \\
\text { aeróbios totais } \\
\left(\text { UFC } 100 \mathrm{~mL}^{-1} \text { ) }\right.\end{array}$ & $\begin{array}{c}\text { Endotoxina } \\
\text { Bacteriana } \\
\left(\mathrm{UE} \mathrm{mL} \mathrm{L}^{-1}\right)\end{array}$ \\
\hline \multirow{10}{*}{$\begin{array}{l}\bar{\Phi} \\
\mathscr{\mathscr { E }} \\
\mathscr{L}\end{array}$} & 49,32 & 233,8 & 0,62 & 6,69 & 2 & $<0,06$ \\
\hline & 184,1 & 132,8 & 0,64 & 6,70 & 65 & $<0,06$ \\
\hline & 162,6 & 123,3 & 0,45 & 6,62 & 15 & $<0,06$ \\
\hline & 38,16 & 149,0 & 0,69 & 7,34 & $<1$ & $<0,06$ \\
\hline & 118,9 & 148,2 & 0,79 & 6,72 & 80 & $<0,06$ \\
\hline & 112,6 & 148,5 & 0,79 & 6,63 & $<1$ & $<0,06$ \\
\hline & 60,74 & 169,9 & 0,85 & 6,96 & $>200$ & $<0,06$ \\
\hline & 35,87 & 187,6 & 0,89 & 6,05 & $<1$ & $<0,06$ \\
\hline & 116,0 & 135,1 & 0,73 & 6,28 & 10 & $<0,06$ \\
\hline & 70,33 & 129,7 & 0,73 & 6,78 & 30 & $<0,06$ \\
\hline \multirow{17}{*}{ 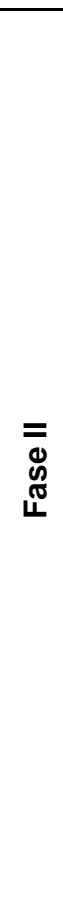 } & 48,86 & 97,1 & 0,71 & 6,33 & $>200$ & $<0,06$ \\
\hline & 321,4 & 156,8 & 0,92 & 6,75 & $>200$ & $<0,06$ \\
\hline & 117,1 & 126,2 & 1,05 & 6,73 & 15 & $<0,06$ \\
\hline & 216,6 & 151,6 & 0,89 & 6,39 & 8 & $<0,06$ \\
\hline & 663,0 & 3421 & 67,5 & 6,95 & $>200$ & $>0,25$ \\
\hline & 642,5 & 3474 & 66,4 & 7,63 & 1 & $>0,25$ \\
\hline & 780,0 & 2367 & 43,8 & 7,71 & $>200$ & $>0,25$ \\
\hline & 875,3 & 3487 & 68,9 & 8,71 & $<1$ & $>0,25$ \\
\hline & 716,0 & 3248 & 65,3 & 8,12 & $>200$ & $>0,25$ \\
\hline & 55,42 & 191,3 & 0,85 & 6,90 & $<1$ & $<0,06$ \\
\hline & 174,6 & 147,7 & 0,77 & 6,93 & $<1$ & $<0,06$ \\
\hline & 120,6 & 116,0 & 0,62 & 7,50 & $>200$ & $<0,06$ \\
\hline & 124,8 & 97,22 & 0,62 & 6,72 & $>200$ & $<0,06$ \\
\hline & 45,37 & 158,3 & 0,78 & 5,78 & 12 & $<0,06$ \\
\hline & 70,3 & 186,1 & 0,79 & 5,82 & 95 & $<0,06$ \\
\hline & 81,64 & 177,6 & 1,02 & 6,74 & 2 & $<0,06$ \\
\hline & 14,45 & 167,1 & 1,13 & 5,96 & 8 & $<0,06$ \\
\hline
\end{tabular}


TABELA 37 - Resultados da fase III do ponto F.

\begin{tabular}{|c|c|c|c|c|c|c|}
\hline & $\begin{array}{c}\text { COT } \\
\left(\mu \mathrm{g} \mathrm{L}^{-1}\right)\end{array}$ & $\begin{array}{c}\text { Cl } \\
\left(\mu \mathrm{g} \mathrm{L}^{-1}\right)\end{array}$ & $\begin{array}{l}\text { Condutividade } \\
\qquad\left(\mu \mathrm{S} \mathrm{cm}^{-1}\right)\end{array}$ & $\mathrm{pH}$ & $\begin{array}{l}\text { Contagem de } \\
\text { aeróbios totais } \\
\left(\text { UFC } 100 \mathrm{~mL}^{-1} \text { ) }\right.\end{array}$ & $\begin{array}{c}\text { Endotoxina } \\
\text { Bacteriana } \\
\left(\mathrm{UE} \mathrm{mL} \mathrm{mL}^{-1}\right)\end{array}$ \\
\hline \multirow{39}{*}{ 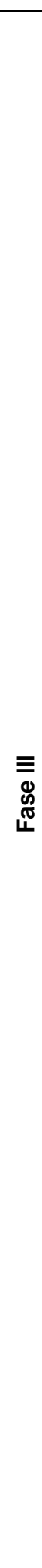 } & 15,51 & 186,1 & 0,74 & 6,28 & 63 & $<0,06$ \\
\hline & 133,4 & 165,0 & 0,77 & 6,65 & 51 & $<0,06$ \\
\hline & 480,1 & 237,0 & 1,07 & 6,56 & $<1$ & $>0,25$ \\
\hline & 142,6 & 161,0 & 0,93 & 6,34 & $<1$ & $<0,06$ \\
\hline & 122,4 & 164,5 & 0,79 & 6,33 & 65 & $>0,25$ \\
\hline & 75,89 & 145,4 & 0,83 & 6,56 & $<1$ & $<0,06$ \\
\hline & 143,5 & 120,8 & 0,86 & 6,84 & 14 & $<0,06$ \\
\hline & 98,58 & 180,8 & 0,97 & 6,19 & 15 & $<0,06$ \\
\hline & 71,25 & 226,2 & 2,05 & 6,29 & 37 & $>0,25$ \\
\hline & 100,1 & 193,6 & 1,06 & 7,57 & 5 & $>0,25$ \\
\hline & 17,22 & 195,8 & 0,59 & 6,50 & 20 & $<0,06$ \\
\hline & 85,76 & 144,5 & 0,74 & 6,98 & $<1$ & $<0,06$ \\
\hline & 59,29 & 157,0 & 0,67 & 6,38 & $<1$ & $<0,06$ \\
\hline & 56,31 & 220,7 & 1,19 & 7,16 & $<1$ & $<0,06$ \\
\hline & 53,85 & 233,3 & 0,66 & 6,45 & $<1$ & $<0,06$ \\
\hline & 128,7 & 153,5 & 0,67 & 6,12 & 24 & $<0,06$ \\
\hline & 2.522 & 1.574 & 31,1 & 7,63 & 170 & $>0,25$ \\
\hline & 1.919 & 1.315 & 1,24 & 7,20 & $>200$ & $>0,25$ \\
\hline & 133,5 & 229,0 & 0,70 & 6,77 & 6 & $<0,06$ \\
\hline & 42,49 & 157,5 & 0,65 & 6,57 & $<1$ & $<0,06$ \\
\hline & 63,05 & 157,9 & 0,78 & 6,57 & 12 & $<0,06$ \\
\hline & 491,9 & 160,9 & 0,88 & 6,62 & 35 & $<0,06$ \\
\hline & 1.008 & 167,5 & 1,61 & 5,83 & $>200$ & $<0,06$ \\
\hline & 81,00 & 127,2 & 0,79 & 6,75 & 59 & $<0,06$ \\
\hline & 419,0 & 162,6 & 0,83 & 6,39 & 10 & $<0,06$ \\
\hline & 171,7 & 178,0 & 0,60 & 6,34 & 82 & $>0,25$ \\
\hline & 26,91 & 122,7 & 1,02 & 5,89 & 40 & $<0,06$ \\
\hline & 105,9 & 177,4 & 1,09 & 6,49 & $>200$ & $<0,06$ \\
\hline & 196,9 & 205,7 & 0,86 & 5,99 & 1 & $<0,06$ \\
\hline & 36,06 & 141,8 & 0,82 & 6,40 & 57 & $>0,25$ \\
\hline & $<$ LD & 237,3 & 0,82 & 6,12 & $<1$ & $<0,06$ \\
\hline & $<\mathrm{LD}$ & 249,3 & 0,69 & 6,83 & $<1$ & $<0,06$ \\
\hline & 122,4 & 273,8 & 1,50 & 7,03 & 13 & $<0,06$ \\
\hline & 62,5 & 173,5 & 0,88 & 6,51 & 4 & $<0,06$ \\
\hline & 42,87 & 225,7 & 1,24 & 7,38 & $<1$ & $>0,25$ \\
\hline & 113,6 & 208,2 & 0,75 & 6,59 & 20 & $<0,06$ \\
\hline & 131,6 & 166,2 & 0,63 & 6,51 & $<1$ & $<0,06$ \\
\hline & 47,31 & 196,2 & 0,69 & 6,84 & $<1$ & $<0,06$ \\
\hline & 145,8 & 181,3 & 0,80 & 6,96 & $<1$ & $<0,06$ \\
\hline
\end{tabular}


TABELA 37- Continuação.

\begin{tabular}{|c|c|c|c|c|c|c|}
\hline & $\begin{array}{c}\text { COT } \\
\left(\mu \mathrm{g} \mathrm{L}^{-1}\right)\end{array}$ & $\begin{array}{c}C l \\
\left(\mu \mathrm{g} \mathrm{L}^{-1}\right)\end{array}$ & $\begin{array}{l}\text { Condutividade } \\
\qquad\left(\mu \mathrm{S} \mathrm{cm}^{-1}\right)\end{array}$ & pH & $\begin{array}{l}\text { Contagem de } \\
\text { aeróbios totais } \\
\left(\text { UFC } 100 \mathrm{~mL}^{-1} \text { ) }\right.\end{array}$ & $\begin{array}{c}\text { Endotoxina } \\
\text { Bacteriana } \\
\left(\mathrm{UE} \mathrm{mL^{-1 } )}\right.\end{array}$ \\
\hline \multirow{9}{*}{$\begin{array}{l}\equiv \\
\Phi \\
\mathscr{D} \\
\mathscr{L} \\
\mathscr{L}\end{array}$} & 46,16 & 181,6 & 0,77 & 6,04 & $>200$ & $<0,06$ \\
\hline & 40,42 & 262,6 & 0,60 & 6,32 & $<1$ & $<0,06$ \\
\hline & 79,39 & 161,2 & 0,78 & 6,79 & $<1$ & $<0,06$ \\
\hline & 136,8 & 181,9 & 0,79 & 6,76 & 22 & $<0,06$ \\
\hline & 59,92 & 195,8 & 0,77 & 6,99 & 54 & $<0,06$ \\
\hline & 82,94 & 130,3 & 0,71 & 6,87 & $<1$ & $<0,06$ \\
\hline & 44,48 & 270,1 & 0,77 & 6,69 & $<1$ & $<0,06$ \\
\hline & 54,12 & 151,2 & 0,73 & 6,81 & 12 & $<0,06$ \\
\hline & 50,41 & 156,7 & 0,82 & 6,89 & 1 & $<0,06$ \\
\hline
\end{tabular}

TABELA 38 - Resultados da fase IV do ponto F.

\begin{tabular}{|c|c|c|c|c|c|c|}
\hline & $\begin{array}{c}\text { COT } \\
\left(\mu \mathrm{g} \mathrm{L}^{-1}\right)\end{array}$ & $\begin{array}{c}\text { Cl } \\
\left(\mu \mathrm{g} \mathrm{L}^{-1}\right)\end{array}$ & $\begin{array}{l}\text { Condutividade } \\
\qquad\left(\mu \mathrm{S} \mathrm{cm}^{-1}\right)\end{array}$ & pH & $\begin{array}{l}\text { Contagem de } \\
\text { aeróbios totais } \\
\text { (UFC } 100 \mathrm{~mL}^{-1} \text { ) }\end{array}$ & $\begin{array}{c}\text { Endotoxina } \\
\text { Bacteriana } \\
\left(\mathrm{UE} \mathrm{mL} \mathrm{m}^{-1}\right)\end{array}$ \\
\hline \multirow{16}{*}{ 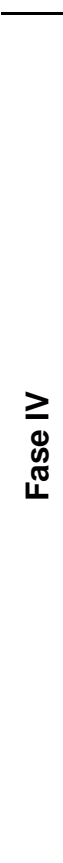 } & 82,53 & 115,7 & 0,74 & 6,17 & 11 & $<0,06$ \\
\hline & 84,14 & 154,2 & 0,99 & 6,85 & $<1$ & $<0,06$ \\
\hline & 110,2 & 122,0 & 0,74 & 5,5 & $<1$ & $<0,06$ \\
\hline & 23,32 & 152,5 & 1,24 & 5,5 & 3 & $<0,06$ \\
\hline & 40,19 & 175,7 & 0,84 & 5,0 & 15 & $<0,06$ \\
\hline & 17,35 & 282,9 & 0,87 & 6,38 & 1 & $<0,06$ \\
\hline & 142,3 & 164,9 & 0,71 & 6,56 & 18 & $<0,06$ \\
\hline & 58,8 & 140,6 & 0,92 & 6,84 & 4 & $<0,06$ \\
\hline & 62,7 & 149,0 & 0,73 & 6,19 & 1 & $<0,06$ \\
\hline & 237,5 & 296,2 & 22,0 & 9,95 & 5 & $<0,06$ \\
\hline & 52,22 & 155,4 & 0,75 & 6,79 & 1 & $<0,06$ \\
\hline & 272,4 & 181,8 & 1,05 & 6,77 & 15 & $<0,06$ \\
\hline & 68,47 & 148,9 & 0,90 & 6,54 & 46 & $<0,06$ \\
\hline & 59,9 & 233,9 & 0,89 & 6,76 & 3 & $<0,06$ \\
\hline & 78,1 & 140,8 & 1,15 & 6,17 & 85 & $<0,06$ \\
\hline & 132,5 & 192,8 & 1,38 & 6,42 & 3 & $<0,06$ \\
\hline
\end{tabular}




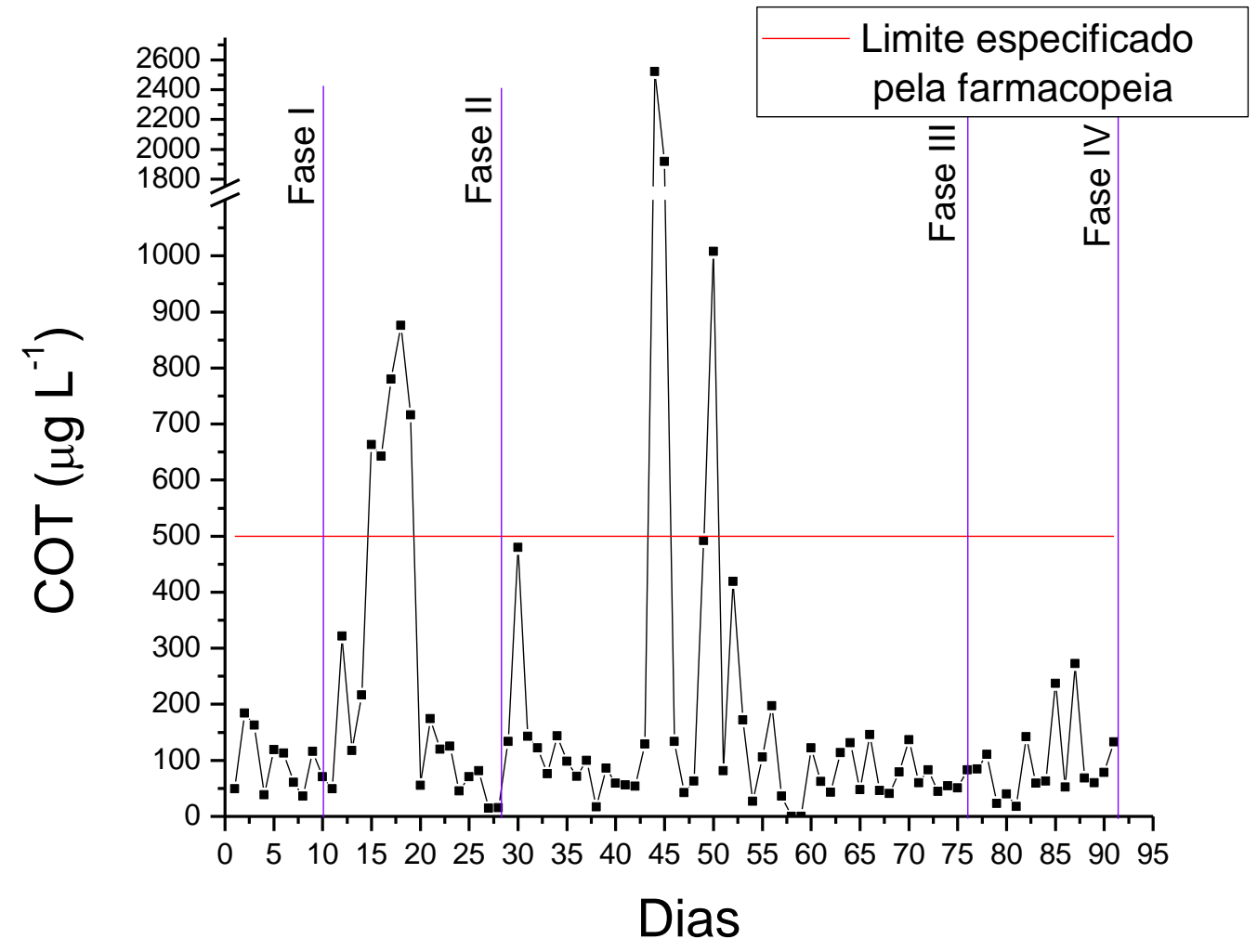

FIGURA 33 - Monitoramento de COT do ponto F.

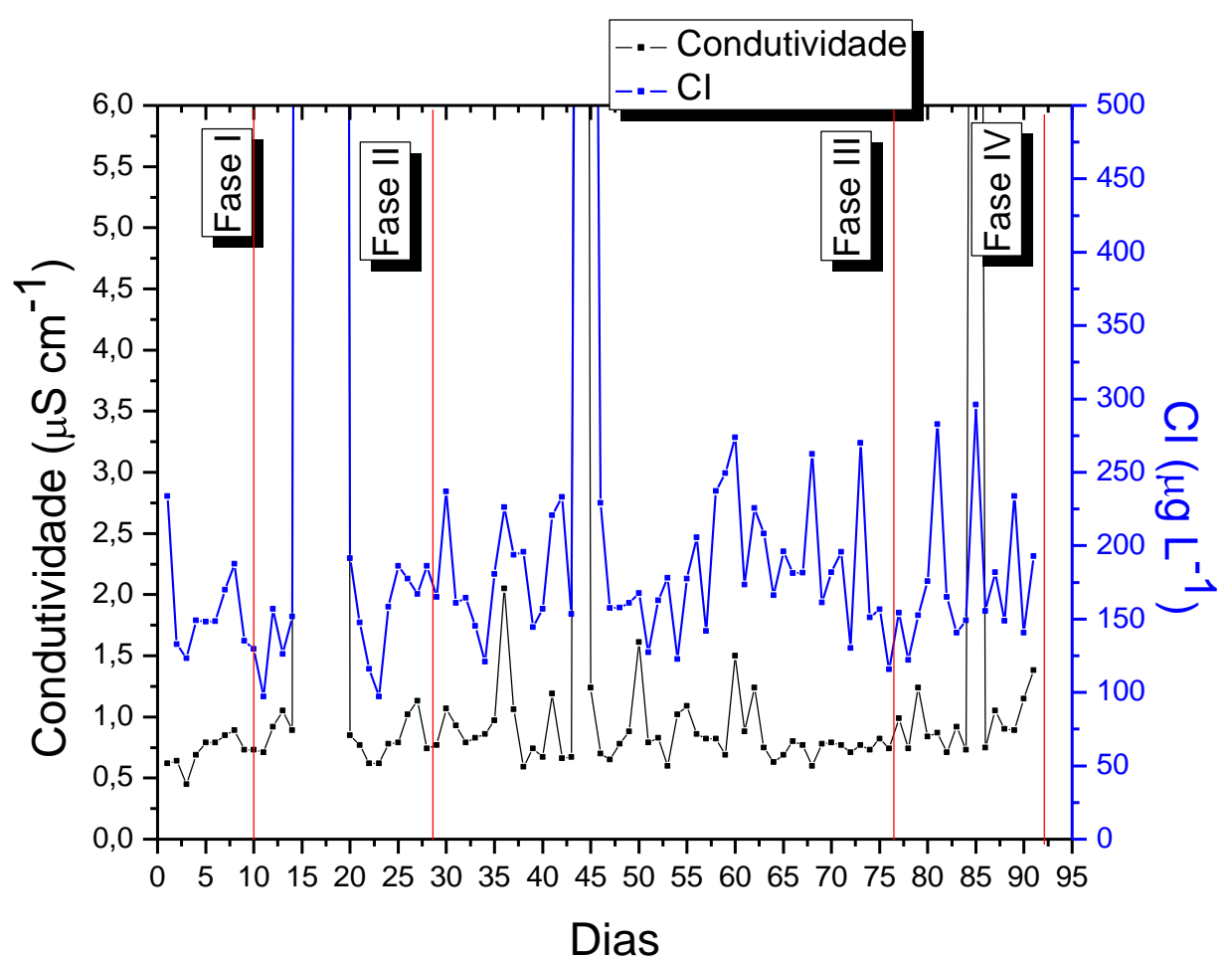

FIGURA 34 - Resultados de Cl e condutividade do ponto F. 
Durante todo o período de monitoramento, o ponto $\mathrm{F}$ apresentou desvios de COT, condutividade, $\mathrm{pH}$, contagem de aeróbios totais e endotoxina bacteriana durante as fases I-IV. O aumento de resultados de contagem de aeróbios totais fora do especificado comparado ao ponto $E$ evidenciou a inadequação do sistema de estocagem e distribuição na manutenção da qualidade da água produzida pelo ponto E. O material e o desenho da tubulação do sistema de distribuição (FIG. 35) pode contribuir para a formação de biofilme e resultar em aumento de COT. Entretanto, na fase III, mesmo os maiores valores de COT observados para ambos os pontos (E e F) não puderam ser relacionados à contaminação microbiana.

Os desvios de COT na fase III do ponto $\mathrm{F}$ puderam ser relacionados ao ponto E (FIG. 33 e 31, respectivamente) e indicaram a importância manutenção da qualidade da API (ponto E) pelo sistema de estocagem e distribuição (ponto F).

Na FIG. 34 os desvios de COT do ponto $\mathrm{F}$ foram relacionados $\mathrm{com} \mathrm{Cl}$, condutividade (FIG. 34) e pH (TAB 36-38).

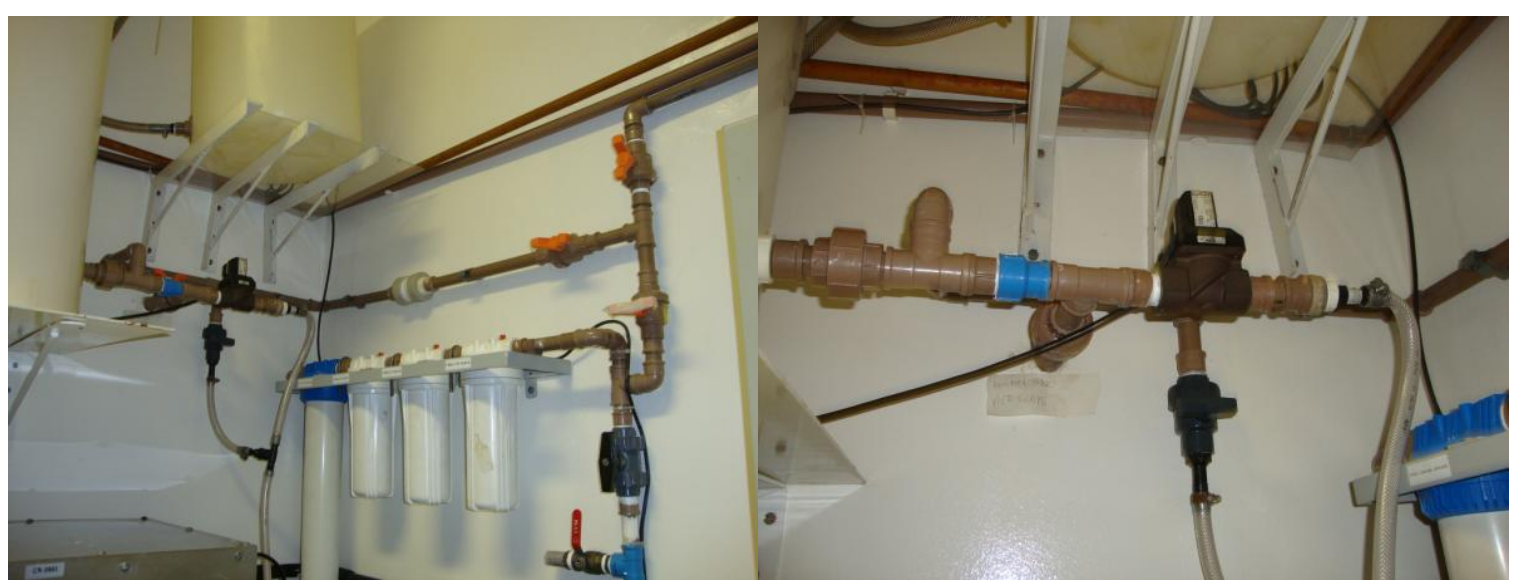

FIGURA 35 - Tubulação do sistema de distribuição do ponto F.

\subsection{Análise de qualidade de água para injeção adquirida de fornecedores externos}

Foram feitos os ensaios em amostras de API adquiridas de fornecedores externos e do ponto $D$ coletado no dia em que as amostras foram analisadas e os resultados estão representados na TAB. 39. 
TABELA 39 - Resultados das análises de qualidade de API de fornecedores externos e ponto $D$.

\begin{tabular}{|c|c|c|c|c|c|}
\hline $\begin{array}{c}\text { Marca } \\
\text { (Volume da } \\
\text { embalagem) }\end{array}$ & $\begin{array}{c}\text { COT } \\
\left(\mu \mathrm{g} \cdot \mathrm{L}^{-1}\right)\end{array}$ & $\begin{array}{l}\text { Condutividade } \\
\qquad\left(\mu \mathrm{S} . \mathrm{cm}^{-1}\right)\end{array}$ & pH & $\begin{array}{c}\text { Contagem de } \\
\text { aeróbios totais } \\
\text { (UFC/100 mL) }\end{array}$ & $\begin{array}{c}\text { Endotoxina } \\
\text { bacteriana } \\
\left(\text { UE. } \mathrm{mL}^{-1}\right)\end{array}$ \\
\hline $\begin{array}{c}\mathrm{G} \\
(1.000 \mathrm{~mL})\end{array}$ & 7119 & 6,40 & 6,04 & $<1$ & $<0,25$ \\
\hline $\begin{array}{c}\mathrm{H} \\
(250 \mathrm{~mL})\end{array}$ & 1537 & 1,67 & 6,84 & $<1$ & $<0,25$ \\
\hline $\begin{array}{c}\text { I } \\
(10 \mathrm{~mL})\end{array}$ & 439 & 4,88 & 6,79 & 6 & $<0,25$ \\
\hline $\begin{array}{c}\mathrm{J} 1 \\
(10 \mathrm{~mL})\end{array}$ & 620 & 1,38 & 6,64 & $<1$ & $<0,25$ \\
\hline $\begin{array}{c}\mathrm{J} 2 \\
(20 \mathrm{~mL})\end{array}$ & 904 & 1,35 & 6,46 & $<1$ & $<0,25$ \\
\hline $\begin{array}{c}\mathrm{K} 1 \\
(500 \mathrm{~mL})\end{array}$ & 1388 & 1,69 & 6,77 & $<1$ & $<0,25$ \\
\hline $\begin{array}{c}\mathrm{K} 2 \\
(500 \mathrm{~mL})\end{array}$ & 912 & 1,73 & 6,38 & $<1$ & $<0,25$ \\
\hline $\begin{array}{c}\mathrm{L} \\
(1.000 \mathrm{~mL})\end{array}$ & 802 & 1,26 & 6,96 & $<1$ & $<0,25$ \\
\hline Ponto D & 232 & 0,62 & 6,90 & $<1$ & $<0,25$ \\
\hline
\end{tabular}

Das API analisadas, somente a água I apresentou COT abaixo de $500 \mu \mathrm{g} \mathrm{L}^{-1}$, com condutividade acima do especificado para API, porém dentro das especificações de API embalada $\left(<5,0 \mu \mathrm{S} . \mathrm{cm}^{-1}\right)$ (8). Estes valores elevados de COT podem ser atribuídos a interação com a embalagem e a utilização de especificações diferentes daquelas empregadas neste trabalho, que se referem a água produzida no momento do uso. Em comparação, a API produzida pelo Ponto D apresentou melhor qualidade com valor bastante reduzido de COT e condutividade. 


\section{CONCLUSÃO}

Os ensaios de validação do método para determinação de COT em AP e API foram realizados de modo a atender às exigências preconizadas pela norma RE 899 de 29 de maio de 2003 da ANVISA e outras, que dispõem sobre validação de métodos analíticos, e os resultados atenderam às especificações para considerar a metodologia validada.

As análises realizadas na qualificação de desempenho mostraram que purificadores destinados ao uso em laboratórios podem ser utilizados para produção de AP e API a serem empregados em produção, controle de qualidade e pesquisa de radiofármacos em uma radiofarmácia industrial, com atendimento aos requisitos definidos pelas farmacopeias, desde que sejam observados os procedimentos de manutenção e limpeza adequados do sistema purificador e de armazenamento, de maneira a obter o teor de COT abaixo de $200 \mathrm{~g} \mathrm{~L}^{-1}$ para AP e abaixo de $100 \mu \mathrm{g} \mathrm{L}^{-1}$ para API. As APIs adquiridas de fornecedores externos atenderam ao requisito de esterilidade, mas apresentaram resultados de COT acima de $500 \mu \mathrm{g} \mathrm{L}^{-1}$.

A determinação de COT pode ser utilizada como indicador de qualidade e eficácia dos sistemas de purificação, estando correlacionada a desvios nos processos de purificação, necessidade de troca de pré-filtros, manutenção no sistema de osmose reversa/ deionização e necessidade de limpeza de reservatório de armazenamento da água produzida. A concentração de COT não pode ser relacionada à contaminação microbiana.

O trabalho desenvolvido mostrou a importância do monitoramento do teor de COT na água produzida por purificadores laboratoriais indicando necessidade de manutenções ou intervenções que garantam a qualidade da água. Indica também a necessidade da possibilidade de uso de cartas de controle para monitorar a qualidade de AP e API. 


\section{REFERÊNCIAS BIBLIOGRÁFICAS}

1. EATON, A.D.; CLESCERI, L.S.; RICE, E.W.; GRENNBERG, A.E. Standard Methods for the Examination of Water \& Wastewater. 21. ed., Maryland: Port City Press, 2005.

2. DABBAH, R. USP pharmaceutical waters, part 3: general information chapters. BioProcess Int., v. 5, n. 5, p.18-23, 2006.

3. CLEMENTINO, M.R.A.; NETO, P.J.R.; ALENCAR, J.R.B. Carbono orgânico total: metodologia analítica e aplicações para indústria farmacêutica. $\boldsymbol{R e v}$. Bras. Farm., v. 89, n.1, p. 74-80, 2008.

4. CLEMENTINO, M.R.A. Determinação do teor de TOC: metodologia analitica e aplicações na indústria farmacêutica. 2006. Dissertação (Mestrado) - Universidade Federal de Pernambuco, Recife, PE.

5. DIAS, F.N.; GODOY, I.; LOPES, B.V.; PENNA T.C.V. Avaliação de sistema de purificação de água alternativo à osmose reversa. Relatório de pesquisa FCF-USP, 2010.

6. DA SILVA, A.S.; SEVERO, A.A.L.; DUTRA, R.C.C.; DE LIRA, R.G.P.; CLEMENTINO, M.R.S.; CARVALHO, A.L.M. Revalidação de um sistema de tratamento de água: ações estratégicas da garantia de qualidade em uma indústria farmacêutica. Rev. Bras. Farm., v. 89, n. 2, 2008.

7. CASTIGLIA, S.G.; SILVA, C.P.G.; PEREIRA, N.S.; ARAYA, G.; MENDOZA, M.; FREIRE, D.E; VERDERA, S. Manual de protocolos de calidad de radiofarmacos - produccíon y control de radiofármacos, ARCAL XV, 1999.

8. UNITED STATES PHARMACOPOEIA USP-NF 35. Rockville: United States Pharmacopeia Convention, 2012.

9. NETO, M.B.; ROSSITO, S. Validação de sistemas de água purificada (PW e WFI) Rev. Controle da Contaminação, v. 103, p. 96-99, 2007.

10.FARQUHARSON, G.J. Validação do sistema de água para injetáveis, uma estratégia para controle da contaminação, SBCC, v. 2, p. 30-34, 2001. 
11.RIGOLIN, C.R.A. Sistemas de tratamento de água para uso farmacêutico, Fármacos \& Medicamentos, v. 26, p. 40-56, 2004.

12. CLARK, K. How to develop and validate a total organic carbon method for cleaning applications. PDA J. Pharm. Sci. Technol., v. 55, n. 5, p. 290294, 2001.

13.RIBEIRO, F.AL.; FERREIRA, M.M.C.; MORANO, S.C.; SILVA, L.R.; SCHNEIDER, R.P. Planilha de validação: uma ferramenta para estimar figuras de mérito na validação de métodos analíticos. Quim. Nova, v. 31, n. 1, p. 164-171, 2008.

14. [ANVISA] Agência Nacional de Vigilância Sanitária do Ministério da Saúde; Resolução específica (RE) n. 899 de 29 de maio de 2003. Disponível na Internet < http://www.anvisa.gov.br/legis/resol/2003/re/899 03re.htm > Acesso em: 02 de maio de 2012.

15.FONSECA, J.C.L.; SILVA, M.R.A.; BAUTITZ, I.R.; NOGUEIRA, R.F.P.; MARCHI, M.R.R. Avaliação da confiabilidade analítica das determinações de carbono orgânico total (COT). Ecletica Química, v. 31, n. 3, p. 47-52, 2006.

16.LEITE, F. Validação em análise química. 5. ed., São Paulo: Átomo, 2008.

17.SAHA, G.B. Fundamentals of Nuclear Pharmacy. 5. ed., New York: Springer, 2004.

18.OMUNWANNE, A.; PATEL, M.; SADEK, S. The Handbook of

Radiopharmaceuticals. 1. ed., London: Chapman \& Hall Medical, 1995.

19.OLIVEIRA, R.S. Radiofarmácia. 1. ed., São Paulo: Atheneu, 2010.

20.[ANVISA] Agência Nacional de Vigilância Sanitária do Ministério da Saúde; Resolução da Diretoria Colegiada (RDC) n. 17, de 16 de abril de 2010. Disponível na Internet <http://www. http://bvsms.saude.gov.br/bvs/saudelegis/anvisa/2010/res0017 1604201 $\underline{0 . h t m l}>$. Acesso em: 10 jan 2012.

21. [ANVISA] Agência Nacional de Vigilância Sanitária do Ministério da Saúde; Resolução da Diretoria Colegiada (RDC) n. 63, de 18 de dezembro de 2009. Disponível na Internet <http://www.anvisa.gov.br>. Acesso em: 10 jan 2012. 
22.FALLAIS, C.J.; SIVEWRIGHT, S.; OGLE, J.R. The radiopharmaceutical industry and European Union regulations. Eur. J. Nucl. Med., v. 24, p. 77-79, 1997.

23.VERDERA, E.S.; CASTIGLIA, S.G.; BARBOZA, M.F. Control de calidad de radiofarmacos. ASOCIACIÓN LATINOAMERICANA DE SOCIEDADES DE BIOLOGÍA Y MEDICINA NUCLEAR, 2011.

24.OLIVEIRA, R.S.; BENEVIDES, C.A.; HWANG, S.F.; SALVI, R.P.C.; FREITAS, I.M.A.T.R. Radiofarmácia e radiofármacos no Brasil: aspectos sanitários e fabris para a construção de uma linha de produção de radiofármacos PET. Bras. J. of Pharm. Sci., v. 44, n. 2., p. 181-184, 2008.

25.[ANVISA] Agência Nacional de Vigilância Sanitária do Ministério da Saúde; Resolução da Diretoria Colegiada (RDC) n. 306, de 7 de dezembro de 2004. Disponível na Internet <http://bvsms.saude.gov.br/bvs/saudelegis/anvisa/2004/res0306 $07 \quad 12 \quad 20$ 04.html >. Acesso em: 27 de maio de 2012.

26. [CNEN] Comissão Nacional de Energia Nuclear; Norma CNEN-NN-3.05, de abril de 1996. Disponível na Internet $<$ http://www.cnen.gov.br/seguranca/normas/mostra-norma.asp?op=305 $>$. Acesso em: 27 de maio de 2012.

27.BISUTTI, I.; HILKE, I.; RAESSLER, M. Determination of total organic carbon - an overview of current methods. Trends in Analytical Chemistry, v. 23, n. 10-11, p. 716-726, 2004.

28.FARMACOPEIA BRASILEIRA. 5. ed., v. 1, p. 391, 2011.

29.ALENCAR, J.R.B.; PINTO, P.M.D.V.; NETO, P.P.V.; OLIVEIRA, A.T.C.; MEDEIROS, F.P.M.; RAMOS, S.V.V.; NETO, P.J.R. Estratégia para validação do sistema de tratamento de água de uma indústria farmacêutica Rev. Bras. Farm., v. 85, n. 3, p. 85-88, 2004.

30.COUTO, R.M. TOC Analysis in pharmaceutical industry, SBCC, v. 19, p. 24-25, 2005.

31.PINTO, T.J.A.; KANEKO, T.M.; PINTO, A.F. Controle biológico de qualidade de produtos farmacêuticos correlatos e cosméticos. 3. ed., São Paulo: Atheneu, 2010. 
32.[ANVISA] Agência Nacional de Vigilância Sanitária do Ministério da Saúde; Portaria no 2.914, de 12 de dezembro de 2011. Disponível na internet $<$ http://bvsms.saude.gov.br/bvs/saudelegis/gm/2011/prt2914 12122011. $\underline{\mathrm{html}}$. . Acesso em maio de 2012.

33.SHIMADZU. Examining the role of TOC analyzers in the pharmaceutical laboratory. Columbia, USA, 2010.

34.EUROPEAN PHARMACOPOEIA. 6. ed., Strasbourg, Council of Europe, v. $1,2011$.

35. KOHLMANN, F.J. What is pH, and how is it measured: a technical handbook for industry. Hach Company, 2003.

36. FUKUMORI N.T.O. Determinação de endotoxina bacteriana (pirogênio em rádiofármacos pelo método de fromação de gel. Validação. 2008. Dissertação (Mestrado) - Universidade de São Paulo, São Paulo, SP.

37.SCHUMACHER, B.A. Methods for determination of Total Organic Carbon (TOC) in soils and sediments. Las Vegas: US. Enviromental Protection Agency, 2002.

38.GARCIA, J.C.S.; ECHARRUGA R.S.; SÁNCHEZ, M.; ALBARRAN, R.B.; HERNÁNDES, L.; ALFONSO, M.R.; LASA, A.M.; DE LA FUENTE, L.N. Biopharmaceutical facility cleaning validation using the total organic carbon test case studies show TOC is effective for cleaning validation. BioPharm Int,. v. 23, n. 6, p. 36-43, 2010.

39. Anatel Corporation. Total organic carbon analysis for cleaning validation in pharmaceutical manufacturing. Application note 12.99.2, Colorado, USA, 1999.

40.MATTEWS, R.W.; ABDULLAH, M.; LOW, G.K.C. Photocatalytic oxidation for total organic carbon analysis. Anal. Chim. Acta, v. 233, p. 171-179, 1990.

41.WALLACE, B.; PURCELL, M.; FURLONG, J. Total organic carbon analysis as a precursor to disinfection by products in potable water: oxidation technique considerations. J. Environ. Monit., v. 4, p. 35-42, 2002.

42.PEYTON, G.R. The free radical chemistry of persulfate-based total organic carbon analysis. Marine Chem., v. 41, p. 91-103, 1993. 
43. EURACHEM/CITAC. Guia EURACHEM/CITAC determinando a incerteza na medição analítica, 2. ed., 2002.

44.RIBANI, M.; BOTTOLI, C.B.G.; COLLINS, C.H.; JARDIM, I.C.S.F.; MELO L.F.C. Validação em métodos cromatográficos e eletroforéticos. Quim. Nova, v. 27, n. 5, p. 771-780, 2004.

45.BERNARDES, A.C.M.; DE SOUZA, S.V.C. Análise comparativa do guia para validação de métodos analíticos proposto pela ANVISA (RE n899 de 2003) com o documento orientativo do INMETRO e o protocolo internacional harmonizado pela AOAC internacional ISO e IUPAC. Analytica, v. 51, p. 66-77, 2011.

46. ICH. ICH Harmonized Tripartite Guideline: Validation of Analytical Procedures: Text and Methodology Q2 (R1), 2005.

47.FREIRE, M.T.A.; BOTTOLI, C.B.G.; REYES, S.F.F. Contaminantes voláteis provenientes de embalagens plásticas: desenvolvimento e validação de métodos analíticos. Quim. Nova, v. 31, n. 6, p. 1522-1532, 2008.

48.GIL, E.S. Controle físico-químico de qualidade de medicamentos. 2. ed, São Paulo: Pharmabooks, 2007.

49.BLIESNER, D.M. Validating cromatographic methods. New Jersey: Wiley Interscience, 2006.

50.HUBER, L. Validation and qualification in analytical laboratories. 2. ed., New York: Informa Healthcare, 2007.

51.ALMEIDA, E.V. Desenvolvimento e validação de metodologia para radiofármacos de tecnécio-99m empregando cromatografia líquida de alta eficiência (CLAE). 2009. Dissertação (Mestrado) - Universidade de São Paulo, São Paulo, SP.

52. [INMETRO]. Orientação sobre validação de métodos analíticos DOQ-CGCRE-008. Revisão 03, 2010.

53.MILLER, J.C.; MILLER J.N. Estadística para química analítica. 2. ed, Wilmington: Addison-Wesley Iberoamericana, 1993.

54.DE BARROS,C.B. Validação de métodos analíticos. Biologico, v. 64, n. 2, p. 175-177, 2002. 